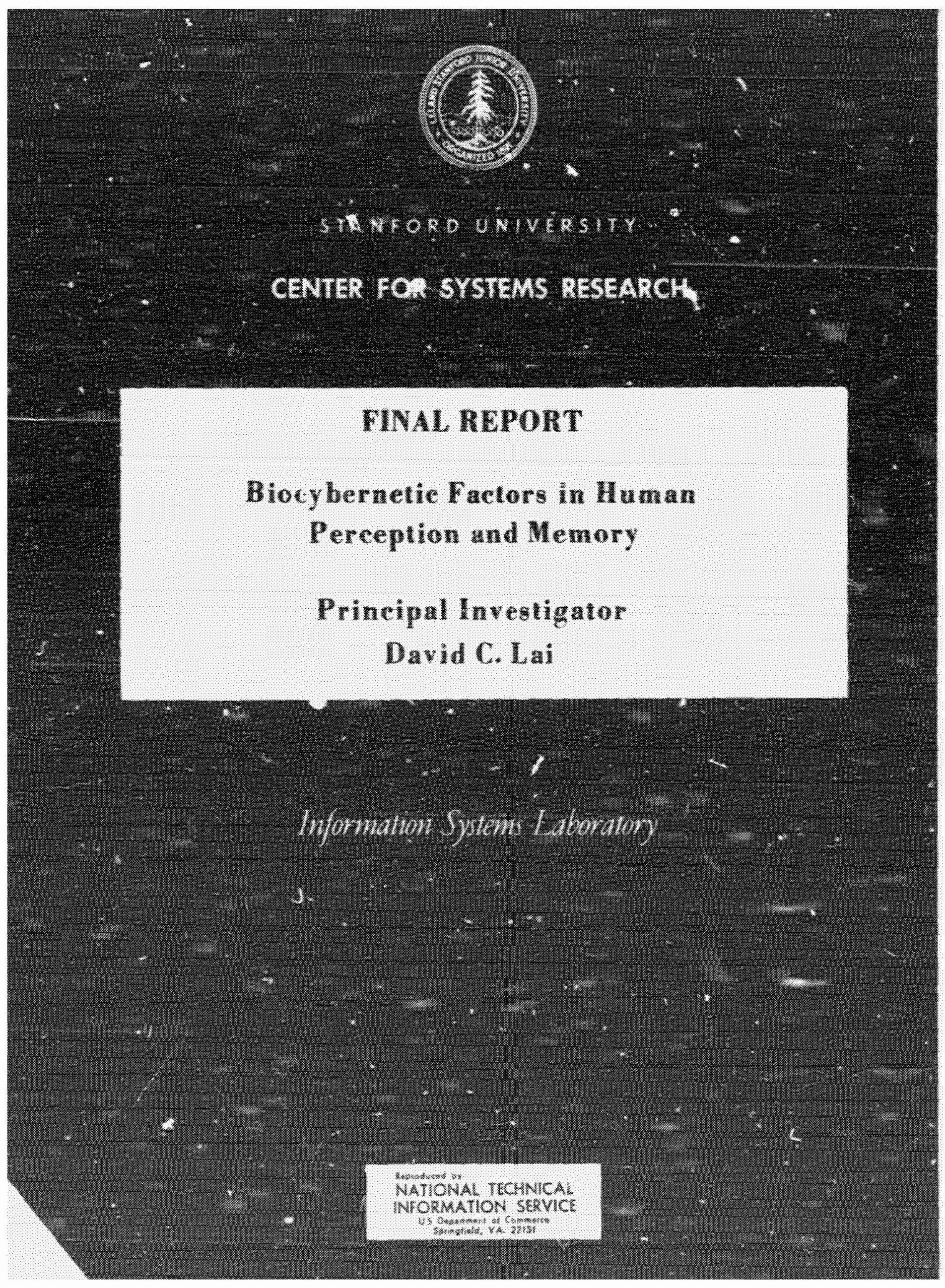


The views and conclusions contained in this document are those of the authors and should not be interpreted as necessarily representing the official policies, either expressed or implied, of the Advanced R. iearch Projects Agency or the $U$. S. Govermment.

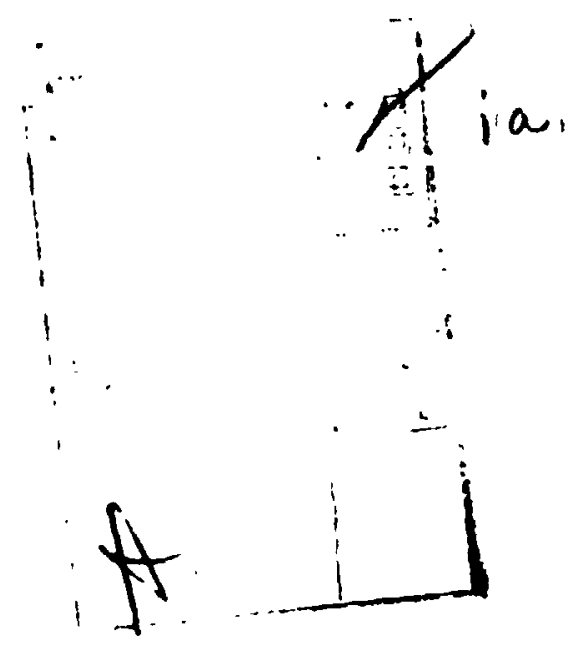


FINAL REPORT

for the Advanced Research Projects Agency

of the Department of Defense

BIOCYBBRNETIC FACTORS IN HULAN PERCEPTION AND MENORY

PRINCIPAL INVESTIGATOR:

Dr. David C. Lai

Contract No. DAKC 15-72-C-0232

ARPA Order No. 2190

September 1975

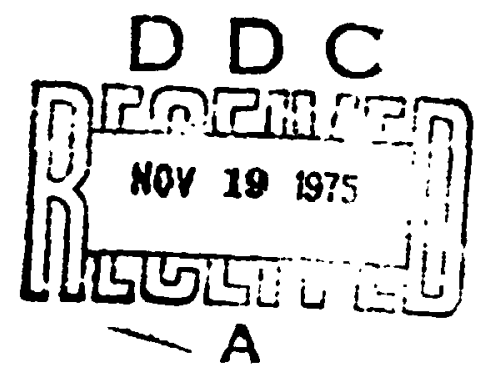

Technica1 Report No. 6741-5

Department of Electrical Engineering

Stanford Electronics Laboratories

Stanford University Stanford, California 94305 
FOREWORD

Th1s is the final report of our research on biocybernetic factore in human perception and mewory which was begun in 1972 at stanford University and - as supported partially* or fully by the Advanced Research Projects Agency of the Department of Defense under cortract DAaC15-72c-0232, which is now terminating. This report presents a brief sumary of the objectives and a description of the accoeplishments of the project.

Since its inception, this project has been the resuit of the collaborative efforts of many individuals. Most of the staff nembers contributed to the writing of this report.

*Partial support for tilis project was provided from :972-1973 by NASA/Ames Research Center under Grant NGR 05-020-575. 
PRESENT PROFESSIONAL PERSONNEL

Dr. D. C. Lal, Visiting Professor of Electrical Engineering, Principal Investigator

Dr. T. Kailath, Professor of Electrical Engineering and Director of Information Systems Laboratory, Co-Principal Investigator

Dr. J. E. Anliker, Consultant

Mr. A. Huang (Y.S.E.E.), Scientific Programer

Mr. L. D. Stricklar, (B.S.E.E.C.S.), Scientific Programmer

Ur. J. R. Nickolls (M.S.E.E.), Graduate Student Research Assistant

Mr. A. Shah (M.S.E.E. and M.S. Stat.), Graduate Student Research Assistant 


\title{
Blocybernetic Factors in Human Perception and Memory
}

\author{
SUMUHRY \\ The objective of this research project is to develop biocybernetic \\ techniques for use in the inalysis and developsent of skills required \\ for the enhancement of concrete images $\cdots$ the "eidetic" type. The scan \\ patterns of the eye during inspection ol scenes are treated as indicators \\ of the brain's strategy for the intake of visual information. We \\ attempt to determine the features that differentiate visual scan patterns \\ associated with superior imagery fron scan patterns associated with \\ inferior imagery, and simultaneously, to differentiate the EEG features \\ correlated with superior Imagery from those correlated with jaferior \\ imagery. For this purpose, we have designed a closely-coupled man-machine \\ system to generate image enhancement and to train the individual to \\ exert greater voluntary control over his own imagery. The models for \\ FEG signals and saccadic eye movement in the man-machine system have \\ been completed. These models are used for monitoring and prediction of \\ EEG signals and eye positions. At this moment, all parts but the feedback \\ path of tine man-machine system have been implemented. We shall describe \\ in this report the details of these models and discuss their usefulness. \\ We have assumed that the strategy of an individual with superior \\ visual memory is to fixate his eyes at the optimal locations of the \\ visual scere at the optimal time instants in relation to EEG. Through \\ the EEG model, we have concluded that the EEG signals play the role \\ of timing mechanisms for visual information acquisition and processing. \\ By using our chararterization of scar patterns, we are able to show that
}




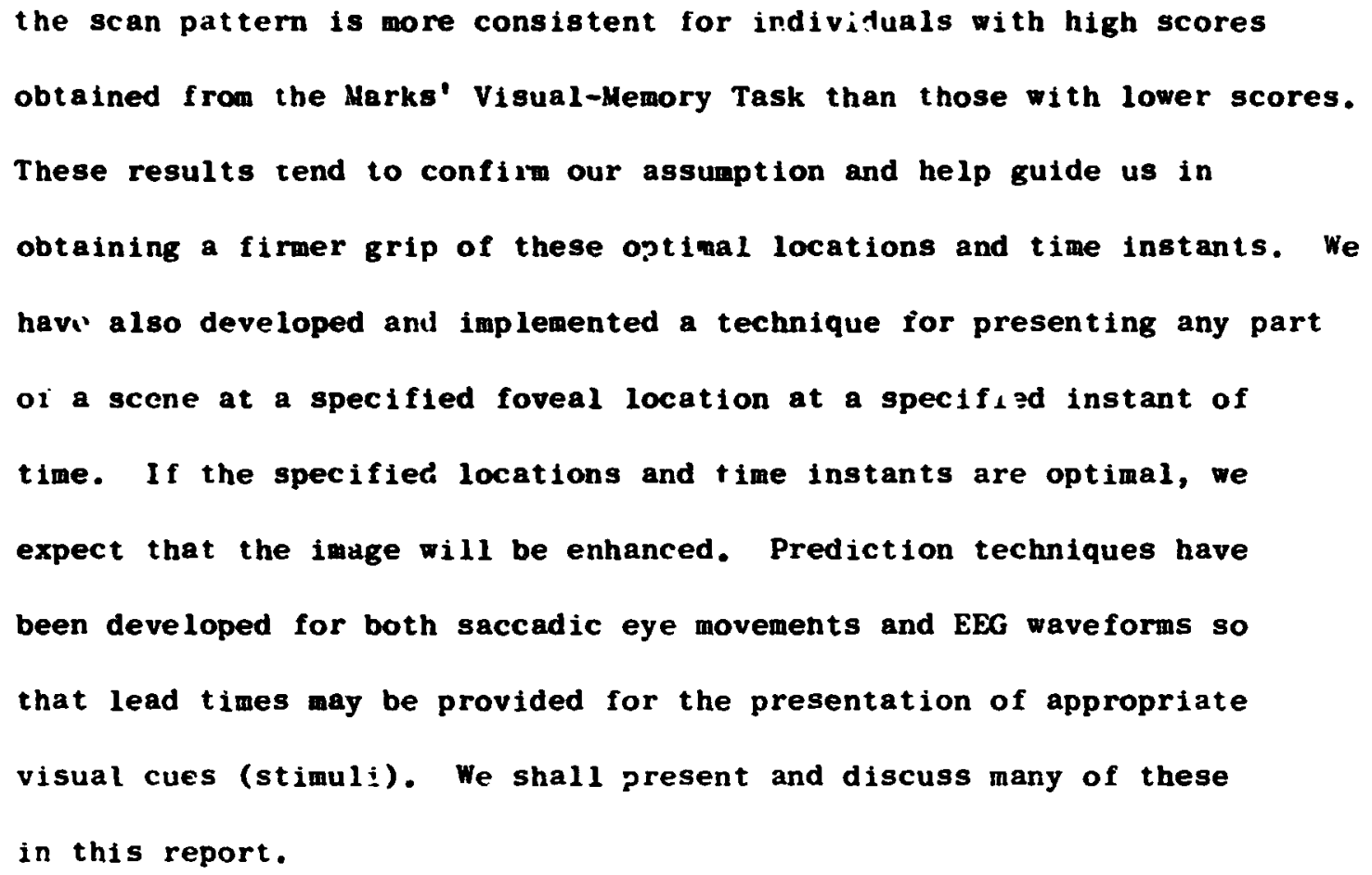


TABLE OF CONTENTS

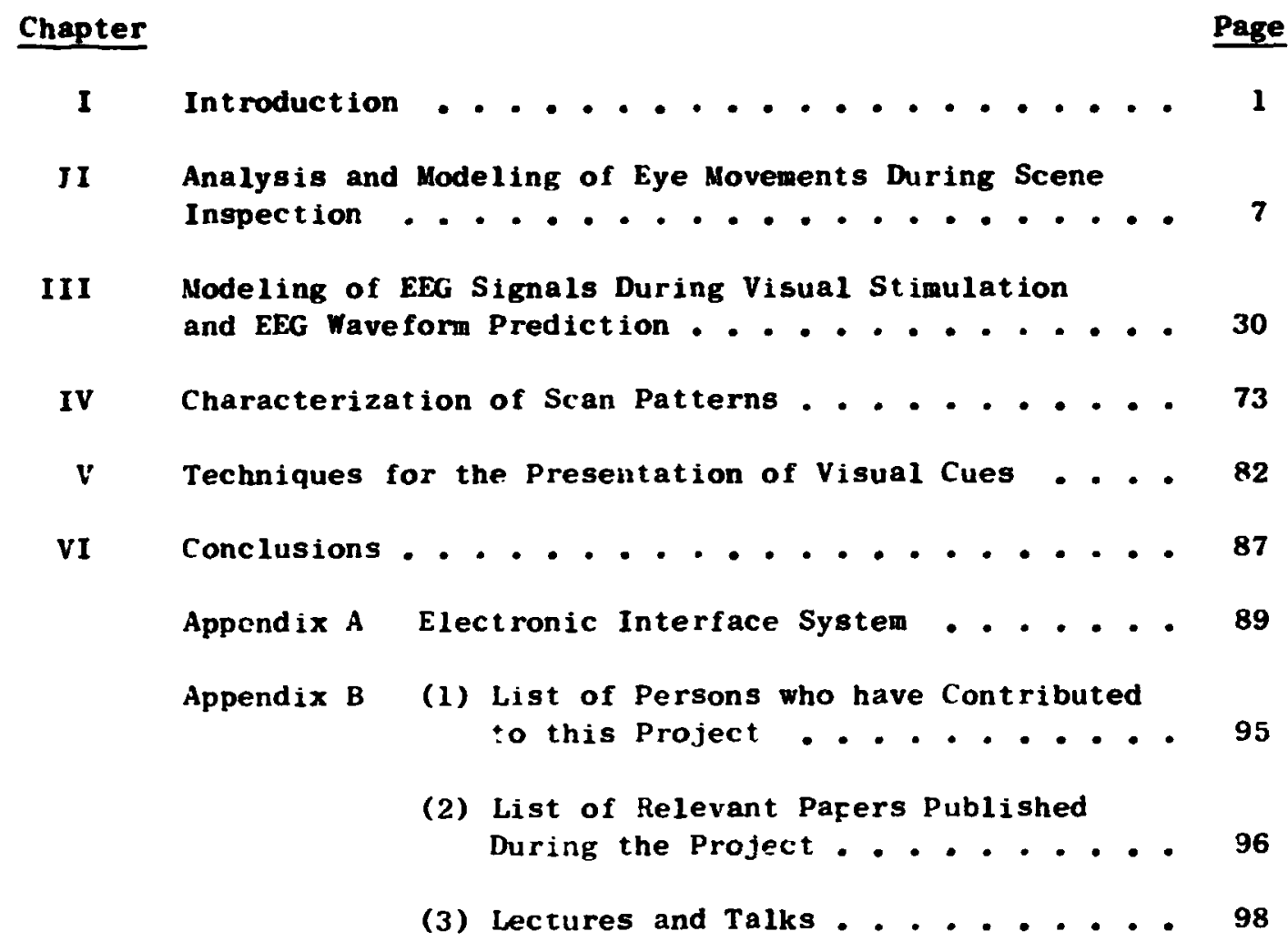




\section{LIST OF FIGURES}

\section{Figure Number}

1 Block diagram of the closely-coupled man-machine system for monitoring and training of visual memory skills ........................ 2

2 Raw eye movements for a 20-second scan . . . . . . . 10

3 Fixation sequence for the scan in Figure 2 . . . . 11

4 Stimulus overlaid by the fixation sequence in

Figure 3...................... 12

5 Typical position and velocity plots of a $15^{\circ}$ saccade.$~ 15$

6 Av :aged plots from 25 saccades of $10^{\circ}$ amplitude ... 16

7 A model characterizing dynamic properties of saccadic eye movement . . . . . . . . . . . . . . . 18 Model response ...... . . . . . . . . . . 21

$9 \quad$ Actual and model simulated saccade positjon . . . . 22

10 Actual and model simulated saccade position . . . . 23

11 Actual and model simulated saccade position ..... 25

12 Actual and model sinulated sacsade position and velocity with two-pulse input ............. 26

13 Actual and model simulated saccade position and velocity with three-pilse input ............. 27

14 Phase and amplitude perturbations ........... 33

15 Simulated EEG perturbations resulting from iiash at phases 0 and $\pi / 2$ radians ............ 37

Simulated EEG perturbations resulting from flash at phases of $\pi$ and $3 \pi / 2$ radians . . . . . . . . . 38

17 Simulated EEG spectra for flash frequencies from .5 $\mathrm{Hz}$ to $12.5 \mathrm{~Hz}$. . . . . . . . . . . . . 39

18 Simulated EEG spect.ra for flash frequencies from 13 $\mathrm{Hz}$ to $25 \mathrm{~Hz}$.................... 40 
19 Simulated thl spectra tor sine frequincies trum

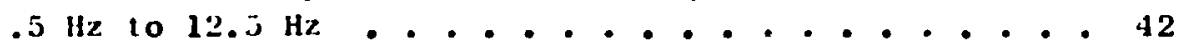

20 Simulated kEG spectra for sine frequencies from $13 \mathrm{~Hz}$ to $25 \mathrm{~Hz}$.................. 43

21 E.G spectrat trom subject L. H. for flash trequencies $.5 \mathrm{~Hz}$ to $1 \% .5 \mathrm{~Hz}$. . . . . . . . . . . . . . . . 16

22 H.tG spectra trom subject L. M. for f lash frequencies $13 \mathrm{~Hz} 1025 \mathrm{~Hz}$................. 47

23 F.G spectra trom s.t.ject . M. tor flash trequencies $.5 \mathrm{~Hz}$ to $12.5 \mathrm{~Hz}$. . . . . . . . . . . . . . 48

24 EKG spectra from subjzct 5 . N. tor 1 lash f requencies $13 \mathrm{~Hz}$ to $25 \mathrm{~Hz}$. . . . . . . . . . . . . 49

$25 \quad t . f($ spretra from subject $k$. $s$. for sine frequencies $.5 \mathrm{~Hz}$ to $12.5 \mathrm{~Hz}$. . . . . . . . . . . . . . 50

26 EEG spect ra trom subject $R$. $S$. for sine frequencies $13 \mathrm{~Hz}$ to $25 \mathrm{~Hz}$.................. ol

27 Actual and simulated EEG spectra in the absence of stimulation..................... 52

28 Actual and simulated EKG spectrá during llash stimulaticn of $10.5 \mathrm{~Hz}$. . . . . . . . . . . 53

29 Ictual and similated EHG spectra during flash stimulation of $21.5 \mathrm{~Hz}$. . . . . . . . . . . 54

30 Actual and simulated EEG spectra during flash stimulation of $5.5 \mathrm{~Hz}$. . . . . . . . . . . 55

31 Actual and simulated EEG spectra during flash

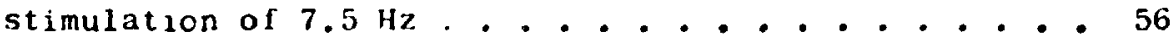

32 Autocorrelograms: solid curve from a typical EEG alpha waveform and dots 1 rom an autoregressive process $t$ it ted to the data . . . . . . . . . . . . . . . 59

33 A flowchart for the realization of the rediction scheme ..................... 68

34 Actual and predicted waveform for lead time of 24 msec ...................... 69

35 Actual and predicted wavelorm for lead time of 48 $\mathrm{msec}$. . . . . . . . . . . . . . . . 69 
36 Actual and pradicted waveform for lead time of

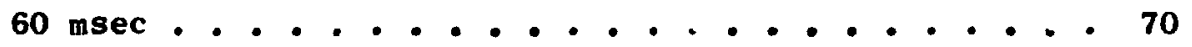

37 Actual and predicter waveform for lead time of

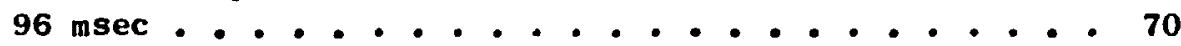

38 Actual and predicted wavefo:m for lead time of

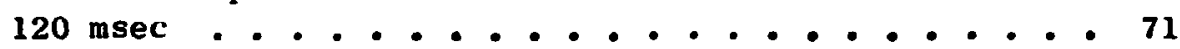

39 Prediction error variance vs. lead time ....... 71

40 Computer derived scan:ath superimposed on sketch of origin?l scene . . . . . . . . . . . . . . 74

41 Sequence of foveal fixations ............ 75

42 Scan of still life scene ............. 79

43 Most probable trarsitions between cluster centers . . 80

44 Fovea-only visual tield display ........... 84

45 Peripheral visual field display ........... 84

A.1 View of subject in the he id positioner with eyetracker electronics................ 90

A.2 View of eye-t1acker optics and subject ........ 90

A.3 Requested fixation points............. 93

A.4 Responses to requested fixation points ........ 94 


\section{Imrmovertion}

The project he bon elned at tive developmat and une of biocjber-

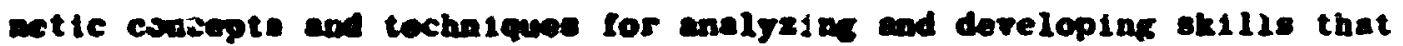
are sobential for the enmun. onent of co crote inges of the "eidetic" type. Je have coscentrated on the probles of achieving biocgbernetic expansion of vicual wury by using a cloeely-coupled an-machipe system wheh perfore real-tine nonttorins, analyais, and feedbeck of spatial and tecporal cued that cerve an keys to hman wenory encoding exd recal1. There to strons evidence that th_se cues are heavily depended on in menory escoding and retrieval by buan nemous systens. The closelycoupled aun-machine system is ueed lor the measurement and prediction of huan memonic performance to deternine the apatial and temporai cues as well as for the control and enhancenent of anemonic skills. Such a man-nachine systex for visual wemory tracking and training has been designed and is depicted in figure 1. This system is capable of felivering optimal sequences of sensory stimulation conditionaliy related to eye position and brain stat 3 , and thus to explore systenatically their relation to visual nemory retrieval.

It is seer. fron the man-machine system that we emphasize the realtine monitoring and prediction of central nervous activities through the EDG gipnals and through the tracking of eye mopenent and eye fixations. Employing these real-time techniques, we have attempted to determine the tedporal and spatial cues for human bemory enioding and recali by monitoring of brain states and eye positions. Again, tnrough this cluselycoupled man-machine system, we utilize this information to arrange the desired colncidences between various brain states, eye positions, and 
Eye-noverspt manurewent

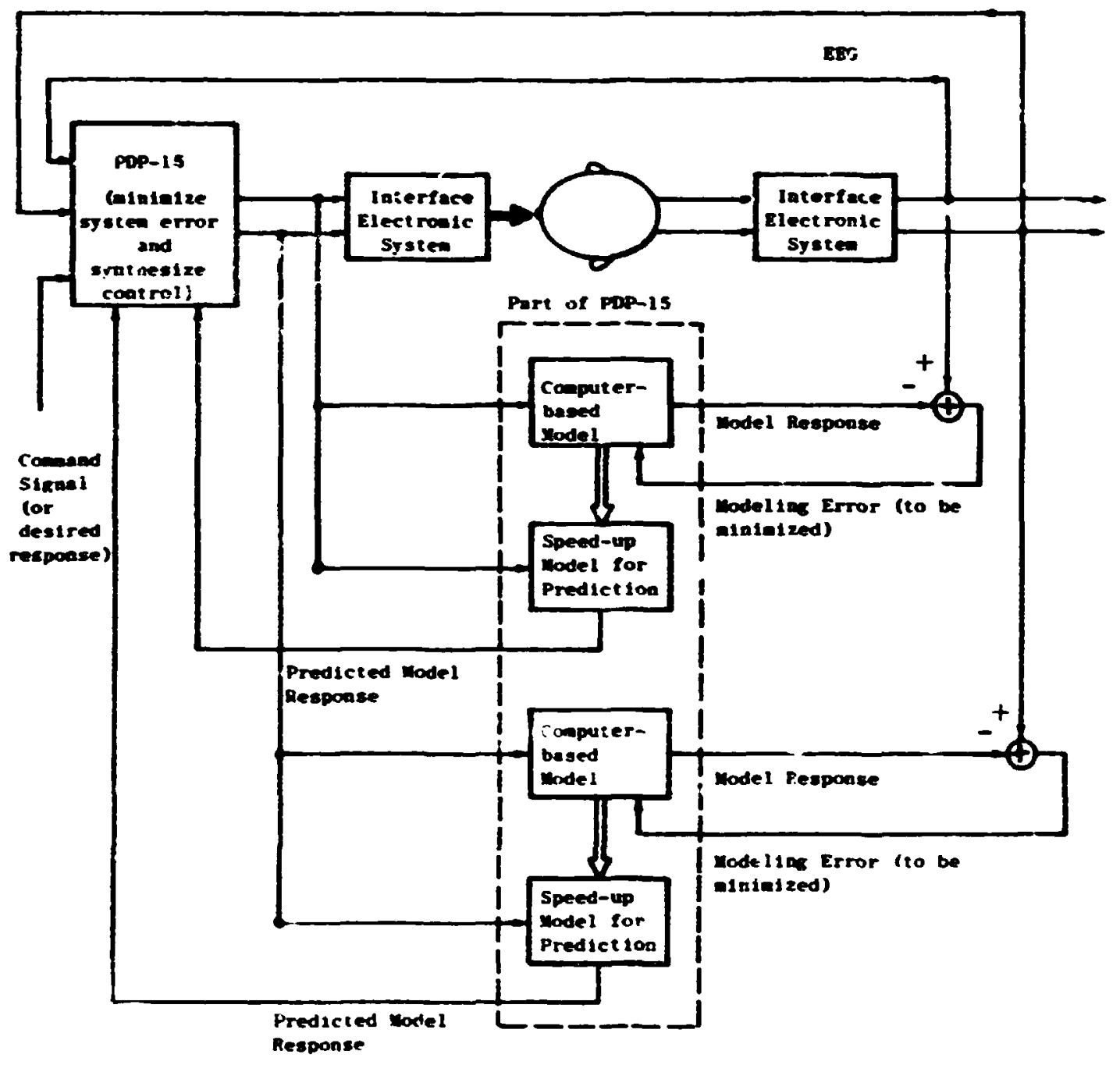

Figure 1 Block diagran of the closely-coupled man-machine system for monitoring and training of visual memory skills

the delivary of visual stinulation. The vasual stimuli have been presented on projection screen or ossilloscope displays for binocular or monocular viewing. The eye movement was measured wit' the Bionetrics' Eye Movement Monitor, Type SC; it is now measured with the Stanford Research Ins:itute's (SRI) Cornsweet Eye Tracker. The brain states have been monitored through the EEG signrls. It is expected that 
greeter control of Inage porsistence and image dissipation can be obtained by combining these real-tine monttoring and prediction techniques with a leedhsck schene to ciose tine conirol loop as depicted In the block diagren of the nan-machine gystan. In other words, we strive to use the computer system to supplewent and strengthen those deficiencies in human nenory that ordinarils rosult in inage dissipation bised on the assumption that a superior ecen pattern of visual inspecticn that results in 9 superior mesory 18 more consistent and also less proiable of natural occurrence than a visual inspection strategs that 18 less consistent. To sumarize, we attempt to steer the subjert toward improved encodiug and decoding strategies for nemory ty using the techniques which have been devsloped and inplemented on this man-machine system.

The closely-coupled man-machine systea utilizes computer-based models in the systen configuration to predict the kind of ftimuli which should be used in order to produce the desired future rusponscs. The EDG 8 ignals and the eye-movement measurement are shown as the resporses which art -losely controlled since the computer-based nodels are designed to aimic the actual physiological processes in regard to their stimulusresponse relaticas. To be more specific, since the visual cues (stinuli) wust be presented at \& ppropriate locations in the visual field at the right instants of time, monitoring and prediction on real-time basis of both eje movement and EBG gigmals are essential. These models have been developed for the purpose of monitoring and prediction. We heve completed the work on the computer-based models which w111 be described in detall in the following sections. These models have also been 
implemented on the PDP-15. All of the man-machine system, except the interface electronic devices, can be realized on the PDP-15 computer. At the close of this project, we have Implamented all but the feedback path of the man-machine sjstem.

In order to determine the visual cues which serve as leys to both memory eacoding an Jecoding, we have to characterize the scan patterns of observers during the inspection of scenes. With this quantitative characterization, we vill then be able to differentiate quantitatively a superior scan pattera of visual inspection that results in a superior memory from an inferior one. This quantitative description is intended for use in :ne determination of those vital visual cues. We have developed and implemented a statistical method for the characterization of visual scan patterns. Our experimental results have Established that observers with good visual memory, as scored by Marks' Yisual-Hemory Task, have a more consistent eye scan pattern in quantitative terms ihan those with poor visual memory. The characterization of the visual scan pattern and the related eye-movement measurement techniques will be discussed in Section Iy.

Last, but not least, we will present a technique for the presentation of the visual cues (stimuli) at appropriate locations in the visual field at the right moments. Since our ultimate goal of this project is the visual memory enhancement through biocybernetic techniques, once the visual cues are determined, they can then be presented to the observer or trainee using our technique. In other words, this computer-implemented technique will enable us to deliver visual stimulation to coincide with the desired brain atates ard eye positions since it controls, in real-time 
the eonocular fleld of view of an observer inspecting outline dranings of visual scenes on a graphical CIr diaplay. The detalls will be discuesed In Sectien $v$.

In Section VI, we shell sumarise our accomplishents and make concluding remarks. Some of these accomplishments have been published or presented in international scientific conferences. The list of publications relevant to this research project is included in Appendix B.

In sumary, we hava designed a closely-coupled man-archine systen for the purpose of developing and use of biocybernetic techniques for anslyzing and developing skills that are essential for the enhancenent of concrete images of the "eidetic" type. This man-achine system has been implemented except the feedback path. In this system, we have developed models for EEG signals during visual stioulation and for eye movement during inspection of stationary scenes, respectively. These models are then uged for the purpose of monitoring and prediction of various brain states and eye positions so that the desired coincidences between various brain states, eye positions, and the delivery of visual sideulation can be arranged. This arrangement of the desired coincidences can se cariled out by a technique we developed and inplemented. The electronic Interface systems in the man-machine system serve a very important role in data acquisition and monitoring of the brain states and eye positions. These electronic interface systems consist of EEG recording machines with Grass preamplifiers, eye-rovement measuring instrument, SRI Eye Tracker) and related interfacing hardware and software. We shall cover some of the unique features of the interface 
systems in Appendix A. This report will conclude with Appendix B which includes: (1) a list of the names of those who have contributed to this project; (2) a list of all relevant papers that have been or are to be published; and (3) a list of lectures and talks given. 


\section{ANALYSIS AND MODBHING OF BYB WOVRERTIS DURIIG SCERE INSPECTIOA}

In the closely-coupled man-machine systea depicted in Figure 1 , we have twe boxes, each labeled as computer-based model; one is for eye movement and the other is for BDo signals. These computer-based models are used for monitoring and prediction of eye positions and various brain states, respectively. The monitoring of the eye positions is nscessary for the determination of the spatial cues that serve as keys to visual memory encoding and retrieval and the prediction of eye position is essential for the presentation of these cues at the desired locations of the visual field. In this section, we shall discuss the development of such a model for eye movenents during inspection of two-dimensional scenes.

\section{An Algorithm for Automatic Identification of Fixations and Sacc ades}

Eye movements during inspection of tru-dimensional stationary scenes consist mainly of two cuaponents: fixations and saccades. The first step in our analysis of eye movements is to senarate the data into these two components. We need to determine the beginning and end points of the fixations and saccades. This helps us to determine the sequence of fixations during a volitional scan of a two-dimensional scene. The separation of saccades from fixations is useful for the modeifig to be described later. In the past, the delineation of fixations and saccades and the scoring of the fixation sequences has been done by hand. We have developed an algorithm which does this automatically and can thus reduce large amounts of 10 eye-movement data to a sequence 
of fixation points very quickly. With modifications, the algorith can perform in real time. In addition, it gives us an objective method of data analysis as opposed to the earlier methods.

The detection of saccade onget is essentially a problem of signal detection. We can consider the movements during fixation as noise and the saccade as the signal. At any instant, we compute the quantities

$$
R_{x}=\left|x_{F}-\sum_{i=1}^{k} w_{i} x_{i}\right|, R_{y}=\left|y_{F}-\sum_{i=1}^{k} w_{i} y_{i}\right|
$$

where $\left(x_{i}, y_{1}\right)$ are sampled values of the horizontal and vertical components of the raw data; $\left(X_{F}, Y_{F}\right)$ is the location of the fixation; and $\left[\omega_{i}\right]$ is a weighting function of length $k$. The algorithm indicates the onset of a saccade at $t=0$ if either $R_{x}>T$ or $R_{y}>T$, where $T$ is a preset threshz:iv value: otherwise, the weighting window $\left\{\omega_{i}\right\}$ is moved forward. The threshold $T$ is a parameter of the algorithm which depends on the noise level in the measurement, the size of the smallest saccade that has to be detected, the amount of delay (k) allowed before detection, etc. This approach is essentially equivalent to using a matched filter since the weights $\left\{\omega_{i}\right\}$ are determined using the saccade model to be described later. Based on this model, we can determine the error probabilities for different size saccades and set $T$ accordingly.

We use a sightly different approach to determine fixations since the end of a saccade is usually much slower than its onset. Naw we compute

$$
n=\#\left\{j:\left|x_{j}-\sum_{i=1}^{\ell} g_{i} x_{i}\right|<T_{s} \wedge\left|y_{j}-\sum_{i=1}^{\ell} g_{i} y_{i}\right|<T_{s}, 1 \leq j \leq \ell\right\}
$$

where $\left(g_{i}\right\}$ is an empirically determined weighting function and $T_{8}$ is a threshold value depending on the notse variance. In effect, we are 
computin: the number of points in a sample window of length $l$ which falls within a square of size $T_{s}$ around the window weighted mean $\left(\sum g_{i} x_{1}, \sum g_{1} y_{1}\right)$. The algorithm moves to the fixation state if $n$ exceeds a preset value $n_{s}(<\ell)$; otherwise, the sauple window is moved forward. In practice, a simple averaging function is found to be adequate for $\left(\mathrm{g}_{\mathbf{i}}\right)$

We have written a program to implement this algorithm. The program reads raw eye-data from the magtape and uses the algorithm to determine the fixation points. These are plotted and numbered. The program also outputs the starting and ending times and the standard deviations of each of the fixations. An example is shown in Figures 2, 3, and 4 . Figure 2 shows the raw eye-movement data. Figure 3 shows the sequence of fixation points obtained from this algorithm, and Figure 4 shows the fixation points superimposed on the actual stimulus used. It is clear that a considerable data reduction has been achieved and the result is easier to understanc and analyze. Other advantages of this algcrithm include easy adaptation to different noise levels andior measuring instruments by changing some parameters, and a quantitative estimation of error probabilities. In fact, the algorithm has been used quite successfully during the course of this project cn data obtained from both the biometrics unit and the SRI eye tracker by simply changing the thresholds.

\section{Modeling of Saccadic Eye Movement}

The rext step in the analysis of eye movements is the investigation of saccadic movement. We need to be able to monitor and predict the 


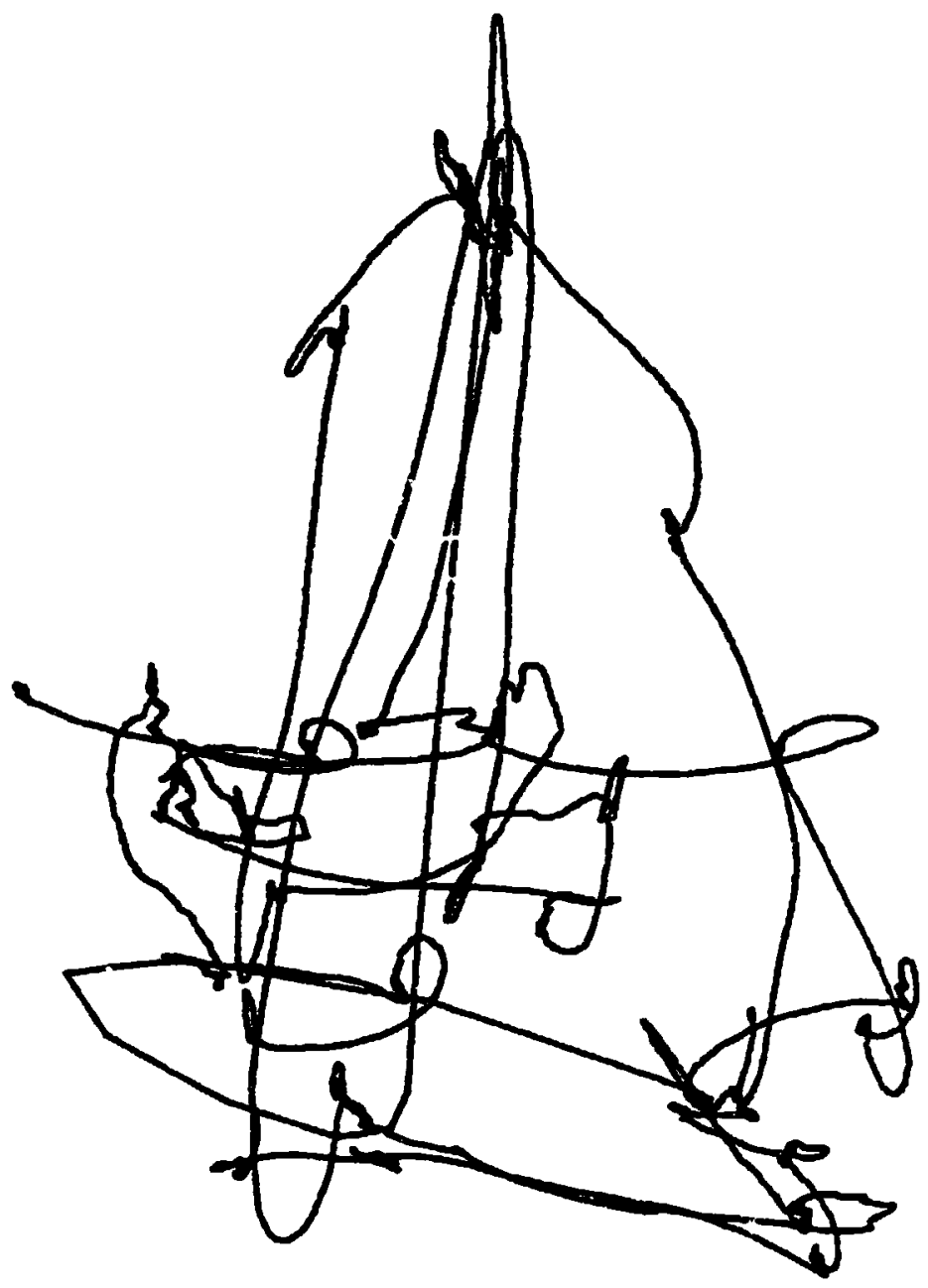

Figure 2 Raw eye movements for a 20 -second scan. Scale $=2.5 \mathrm{deg} /$ inch

10 


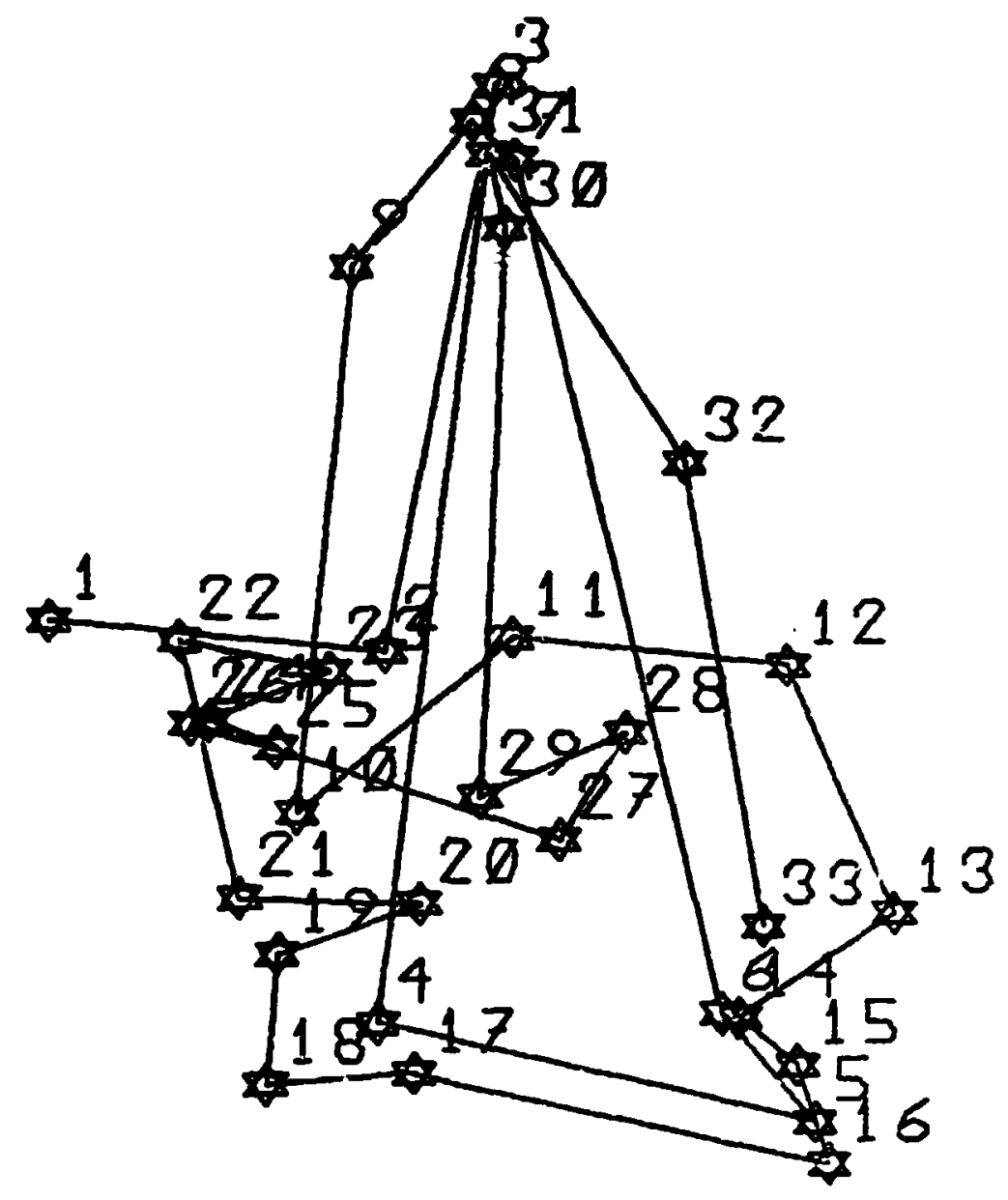

Figure 3 fixation sequence for the scan in rigure 2 


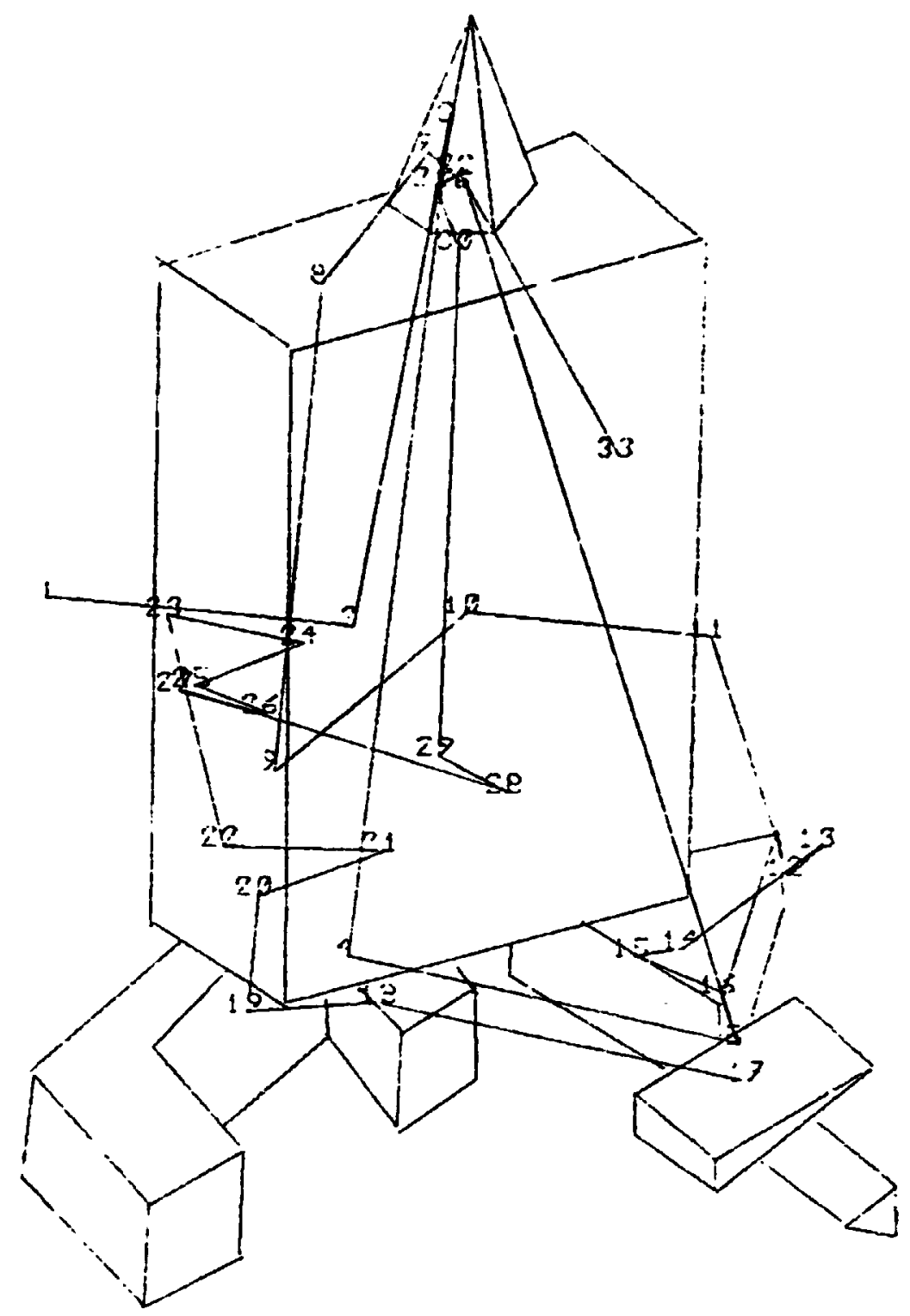

Figure 4 Stimulus overlaid by the fixation sequence in Figure 3 
saccade duration and length in order to present visual cues (stimuli) at the appropriate locations in the visual field at the desired moments. Thus, the detailed dynamics of the saccadic movement are of interest to us. Hence, our approach is first to develop an appropliate model which embodies the a/namic characteristics of the saccadic system. This model is ther utilizad for monitoring and prediction of the saccadic revent. The human saccadic eye-movement control system has been of great interest to researchers in neurophysiology and bioengineering. The general shapes of the position, velocity, and acceleration curves of the eye movement have been reported extensively. We have attempted to fit the nodel responses tc empirical data by classical least-squares techniques. This enables us to estimate certain parameters of the model. These parameters which will be used for predicting the final eye pcsitions have only been determined by indirect means in the reyorted models. We have also made important modifications to the model so that its output will accurately characterize the cbserved responses. We shall describe and discuss the model modifications, the parameter estimates, the curvefitting results, and the use in mitoring and prediction. For the present, we are concerned with horizontal eye movements only. For this purpose, an experiment for the study of rowizontal saccades has been designed and used. A row of LEDs equil ${ }^{2}$ tantly located, only one of which is 11 ghted at any given time, is used as stimulus. We will refer to the leftmost position as the rest position and the $0^{\text {ther }}$ six as the target positions. The target signal is supplied by a digital computer. The subject is instructed to follow the light spot, which repeatedly jumps from the rest position to one of the target 
positions and back. The successive target positions are chosen from a table of :andom permutations tc ryord anticipation by the subjects. An incerval of at least 1 second is provided between each position change. Eye movements are recorded and stored as cescribed eısewhere in this report.

Using the algorithm described above: we first mark the starting points of the saccades. Then the saccise position and velocity are plotted and equal length saccades are averaged with each sanple lined up at the start. As an exrmple, we show pnsition and velocity plots of a typical saccade in Figure 5 and the averaged plots from 25 saccades of one subject in Figure 6 . The saccades observed agree with thnse reported by other researchers in all aspects such as duration, overshoot, response delay, etc.

In order to monitor and predict the sacradic eye movements, we intend to fit the model output to the saccade position data by estimating the model parameters from the dita. The endpoint of the saccade can then be predicted from the model output by using these parameters. Let the corizontal position $y$ at time $t_{i}$ after she onset of the saccade be

$$
x_{1}=\theta\left(a_{1}, a_{2}, \ldots, a_{k} ; t_{i}\right)+n_{i}
$$

wherr $a_{1}, a_{2}, \ldots, a_{k}$ are the model parameters and $n_{i}$ is the noise term which represeits the errors introduced by the instrument, the data collection errors, the inherent random nat' re of the biological system, etc. We shall use the least-squares estimation to cietermine $a_{1}, a_{2}, \ldots$ 

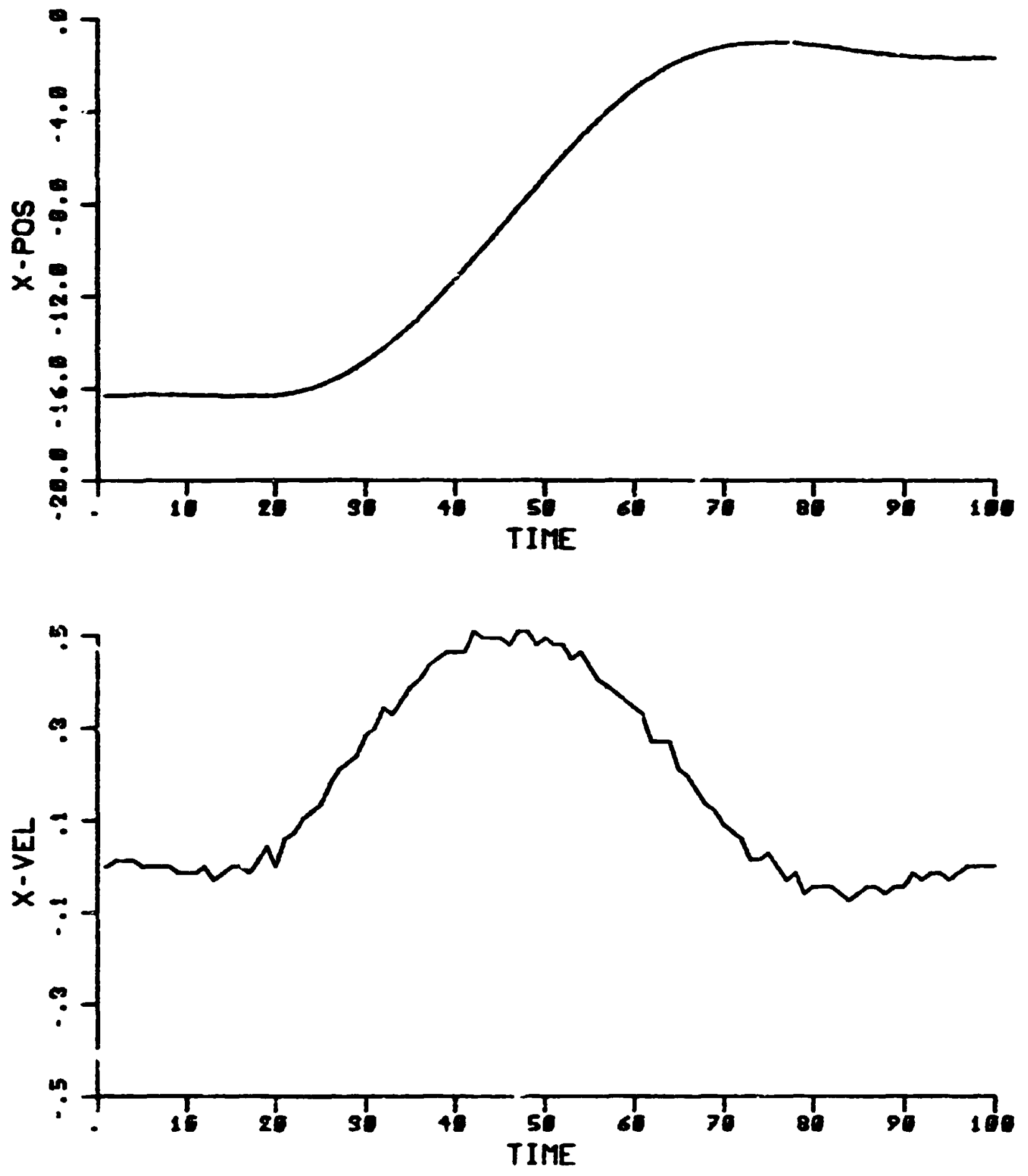

rigure 5 Typiral position and velocity plots of a $15^{\circ}$. ccade 

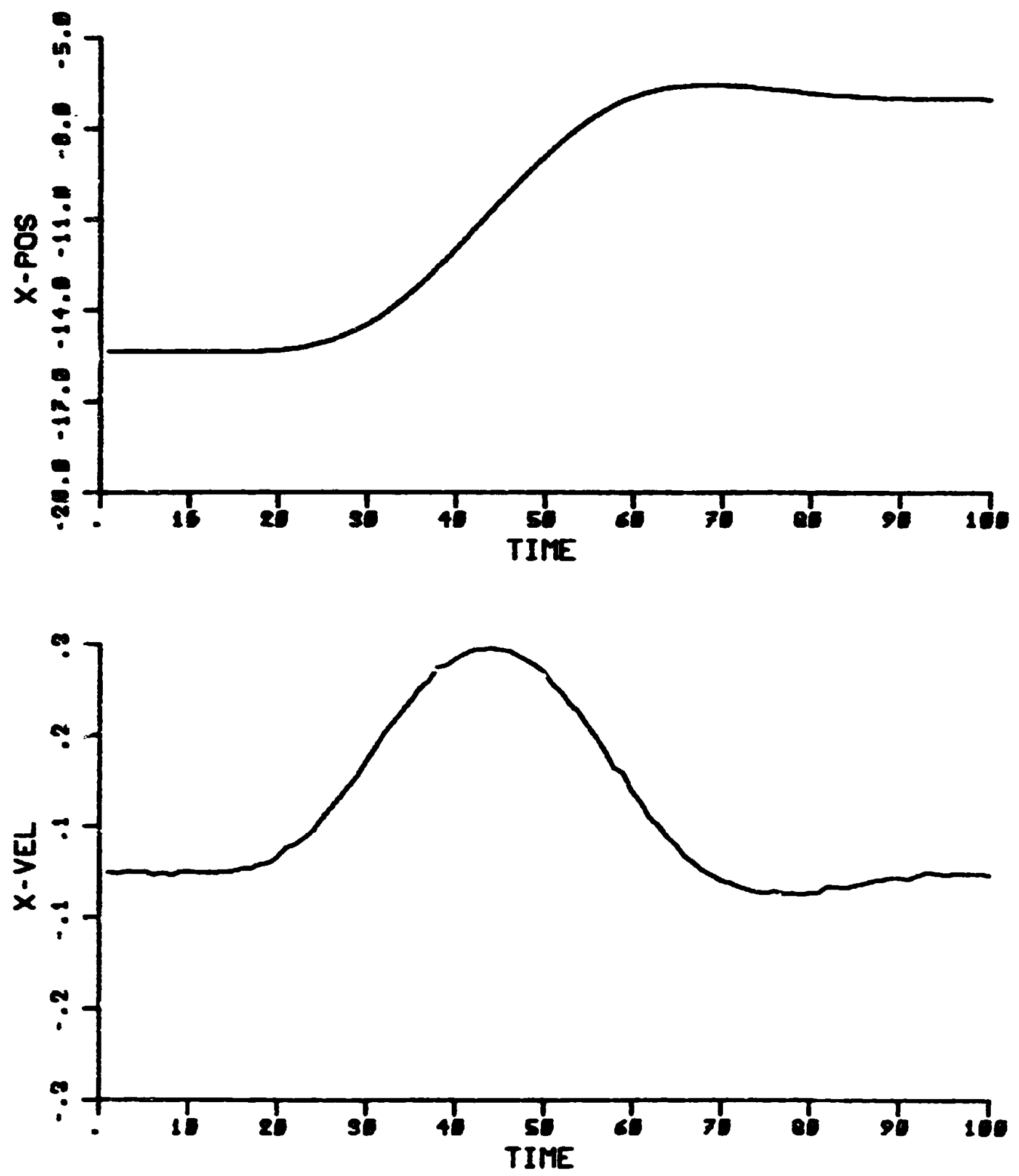

Figure 6 Averaged plots from

25 saccades of $10^{\circ}$ amplitude 
$a_{k}$. They are determined by minimizing the mean-square error

$$
S=\sum_{i=1}^{n}\left|x_{i}-\theta\left(a_{1}, a_{2}, \ldots a_{k} ; t_{i}\right)\right|^{2}
$$

where $n$ is the number of samples observed; i.e., by sol-arg t:e set of equations

$$
\begin{gathered}
\frac{\partial s}{\partial \mathbf{a}_{1}}=0 \\
\frac{\partial \mathbf{s}}{\partial \mathbf{a}_{2}}=\mathbf{0} \\
\vdots \\
\frac{\partial \dot{s}}{\partial \mathbf{a}_{\mathbf{k}}}=\mathbf{0} .
\end{gathered}
$$

In the case when $e$ is a linear function of the parameters $a_{1}, a_{2}, \ldots, a_{k}$, Eq. (2) is reduced to a set of linear equations which can be solved to obtain the parameter estimates. If $\theta$ is noalinear, then an iterative process has to be applied in order to solve for $a_{1}, a_{2}, \ldots a_{k}$. If we assume the noise $n_{i}$ to be white Gaussian, the least squares estimiles are known to be identical to the maximum likelihood estimates which are unbiased, consistent, and asymptotically efficient. With the above assumption, we can also estimate the variar is of $t r$ parameters and use $x^{2}$-test and $t$-test for goodness of fit. This gives us a quantitative measure of the goodness of our model.

The functional form for $\theta$ is determined by the particular model used. It undoubtedly relates to che dynamics of the eye-movement system. We have chosen to use Robinson's model for its simplicity. This model is block diagramed in figure 7 . 


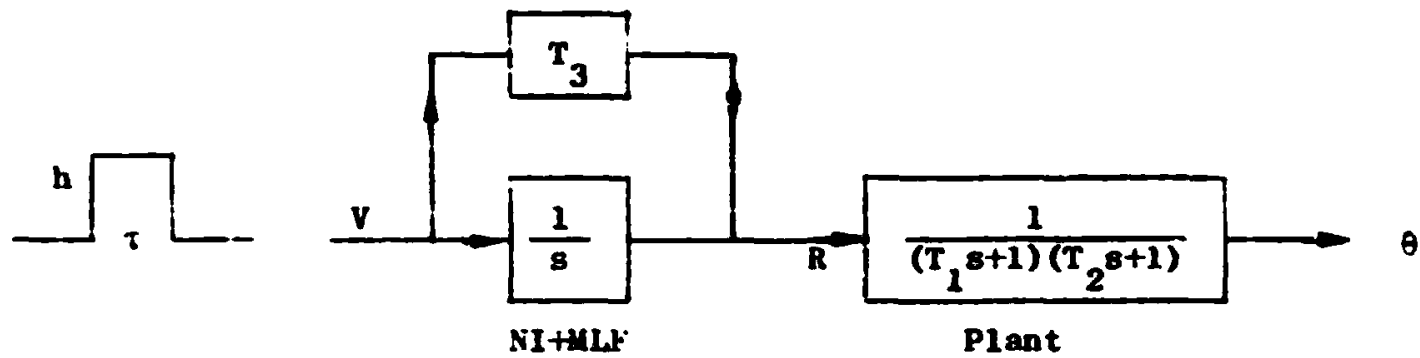

Figure 7 A model characte izing

dynamic properties of saccadic

eye morement

Here we have shown the dynamic part of the model only; the contmller part is left out. The input to the system is a pulse of height $h$ and width $\tau$. This frodiced a saccade of amplitude equal to the area under the pulse; i.e., ht. NI is the neural integrator and uLF the medial lungitudinal fasciculus which is a feed forward path in parallel with the integrator and provides a lead network to coapensate for the plant lag. R represents the oculomotoneuron firing rate. For a pulse input, we see that $R$ is a pulse step as desired. The plant is a secondorder uver-damped system with time constants $T_{1}$ and $T_{2} \cdot$ Robinson chose the MLF gain $T_{3}=T_{1}$. However, he suggested that in order to produce the observed overshoots and undershoots $T_{3}>T_{1}$ and $T_{3}<T_{1}$, respectively, should be used. For our purpose, we have decided to retain $T_{3}$ as a separate parameter. The output $\theta$ is the eye position. The complete transfer function is then

$$
\frac{\theta}{V}=\frac{T_{3} \varepsilon+1}{s} \frac{1}{\left(T_{1} s+1\right)\left(T_{2}{ }^{s+1}\right)}
$$

For the assumed pulse input, the output $\theta(t)$ becomes 


$$
\begin{aligned}
& \theta(t)=h \mid t+\left(T_{3}-T_{2}-T_{1}\right)+\frac{\left(T_{1}-T_{3}\right)}{T_{1}-T_{2}} T_{1} e^{-t / T_{1}}+ \\
& \left.\frac{\left(T_{2}-T_{3}\right)}{T_{2}-T_{1}} T_{2} e^{-t / T_{2}}\right), t \leq \tau \\
& =h\left(\tau+\frac{\left(T_{1}-T_{3}\right)}{T_{1}-T_{2}}-T_{1}\left(e^{-t / T_{1}}-e^{-(t-\tau) / T_{1}}\right)+\right. \\
& \left.\frac{\left(T_{2}-T_{3}\right)}{2^{-T_{1}}} T_{2}\left(e^{-t / t_{2}}-e^{-(t-\tau) / T_{2}}\right)\right], t>\tau
\end{aligned}
$$

The porition and velocity curves given by the above for $h=.5 \mathrm{dog} / \mathrm{hs}$ and $\tau=20$ as correspondjug to a $10^{\prime}$ saccade are show in Figure 8 . The values of the other parameters used are $T_{1}=150 \mathrm{~ms}$ and $T_{2}=7 \mathrm{~ms}$. (These values are suggested by Robinson.) Curves are shown for $T_{3}=190 \mathrm{~ms}$, $150 \mathrm{~ms}$, and $110 \mathrm{~ms}$. Note the overshoot and undershoot for $T_{3}>T_{1}$, and $T_{3}<T_{1}$, respectively.

Note that there are four unknown parameters, $h, T_{1}, T_{2}$, and $T_{3} \cdot$ For estimation, we have to solve Eq. (2) for $k=4$. However, fron the theoretical evaluation of the parameter variances, we found that the estimate of $T_{1}$ will have a very large variance. Thus, the estimate w111 not be very meaningful and hence, a fixed value of $T_{1}=150 \mathrm{~ms}$ will be used. As will be seen later, this does no: affect the results significantly. We have also found that, for reasons of numerical calculation, it is better to estimate $T_{j} / T_{1}$ th. $T_{3}$ itself. Thus, three parameters $a_{1}=h, a_{2}=r_{2}$, and $a_{3}=T_{3} / T_{1}$ were estimated by using the data from $t_{0}$ to $t_{0}+\tau$, where $t_{0}$ is the time of the onset of the saccade and $\tau$ is the input pulse width which is estimated from 
the saccade velocity by noting that the velocity reaches a maximum at $t_{0}+$ as shown in Figure 8. The estinated paraneters are then substituted into Eq. (3) to obtain the conplete saccade curve and the prediction of the finul position is made simply by extrapolation.

Typical results 1 rom the paraneter estimation and prediction schemes are shown in Figures 9 and 10 . The wodel output anches the actual data quite closely. The goodness of fit has been tested using the $x^{2}$-test on the sum of the squares of the residuals, $s$, and the $t-t e s t$ on the individual residuals at significance level $P=.05$. N.ste that the estimates of $T_{2}$ are $10.9 \mathrm{~ms}$ and $13.6 \mathrm{~ms}$ as opposed to the value suggested by Robinson. This regult is typical and the mean value of $I_{2}$ is about $13.0 \mathrm{~ms}$, although it varies between subjects. It is, however, significantly different from 7 as. $T_{3} / T_{1}>1$ is observed in most cases, although the difference is not significant as far as the final value prediction is concerned. The values of $h$ and depend on the saccade size which inplies that the size is controlled by both the amplitude and the width of the pulse. The exact relationship is being investigated.

In wost responses, an overshoot of the final position was observed. This overshoot is not produced by the model, as can be seen in Pigures 9 and 10. Even if we vary $T_{3}$, the overshoot could not be produced. This is because fo: $T_{3}>T_{1}$, the orershoot decays with a time constant $T_{1}$, whereas the actual overshoot decays much faster (at about the same rate as the initial rise). In addition, we could not fit the model response beyond $\tau$ to the cbserved data within the chose 1 significance level $P=.05$. This indicates that the model must be modified to 

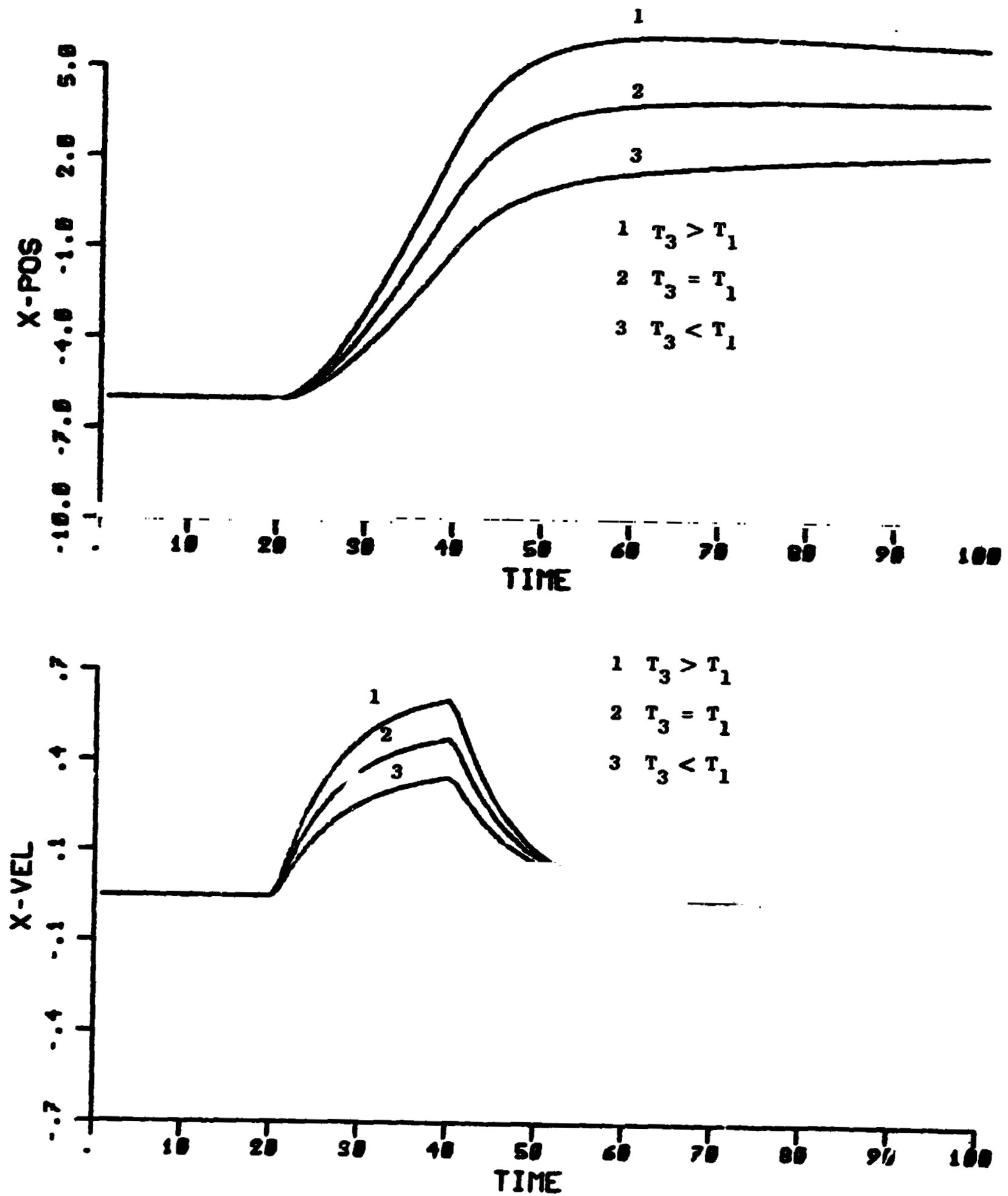

Figure 8 Model response for $T_{1}=15 \mathrm{hs}$,

$T_{2}=7 \mathrm{~ms}, T=20 \mathrm{~ms}, h=.5 \mathrm{deg} / \mathrm{ms}$,

$T_{3}=190,150,110 \mathrm{~ms}$ 


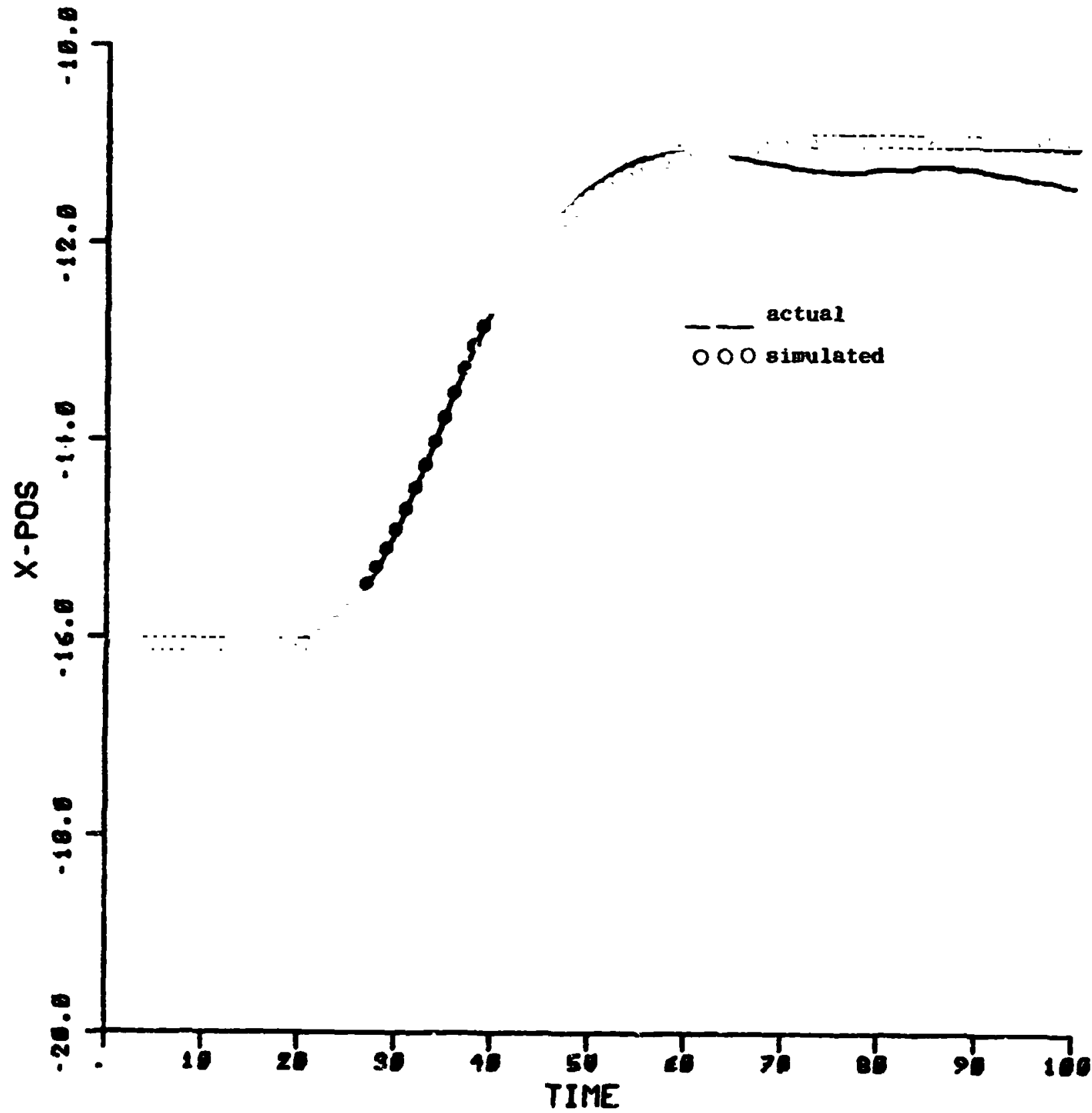

Figure 9 Actual and model simulated saccade position

$$
\begin{aligned}
& t_{0}=20 \mathrm{~ms}, T_{1}=150 \mathrm{~ms}, T_{2}=10.9 \mathrm{~ms}, \\
& T_{3}=160.5 \mathrm{~ms}, T=16 \mathrm{~ms}, h=.28 \mathrm{deg} / \mathrm{ms}
\end{aligned}
$$




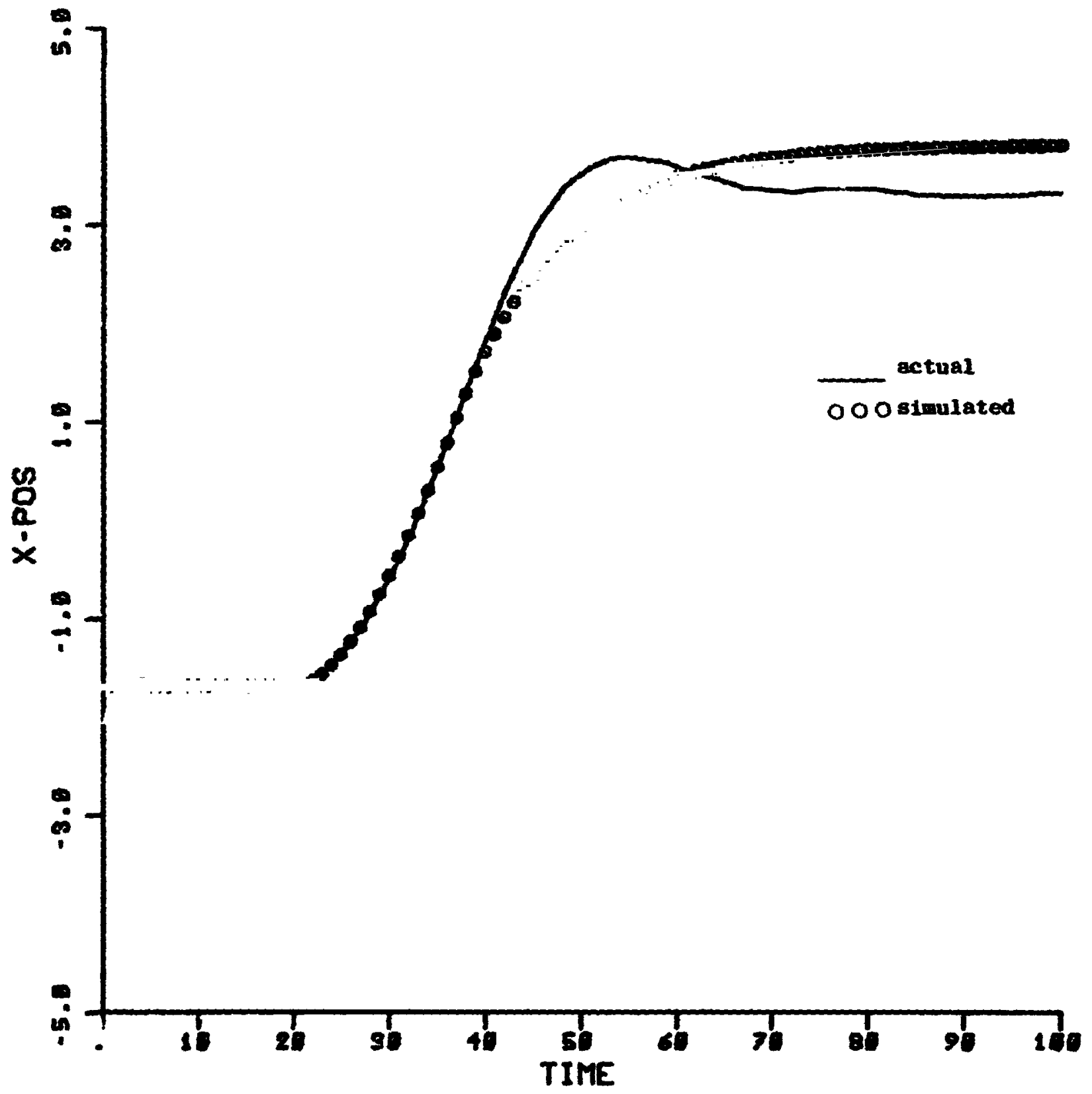

Figure 10 Actual and model Blmulated saccade position

$t_{0}=20 \mathrm{~ms}, T_{2}=150 \mathrm{~m}, T_{2}=13.6 \mathrm{~ms}$,

$T_{3}=168.2 \mathrm{~ms}, T=24 \mathrm{~ms}, \mathrm{~h}=.39 \mathrm{deg} / \mathrm{ms}$ 
produce the right response. The fact that the overshoot decays with a time constant of about $T_{2}$ and the input to the agonist and the antagonist muscles used by Clark and Stark suggests that the input to the model consists of a combination of pulses rather than a single pulse. A study of the velocity curve in Figure 6 also suggests that a positive pulse followed by a negative pulse can produce the desired output. Thus, our model input is changed to two pulses as shown below:

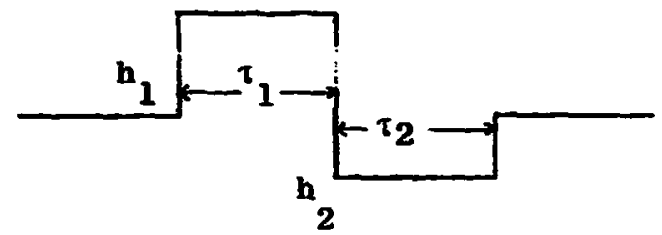

where the saccade amplitude $=h_{1} \tau_{1}+h_{2} \tau_{2}$. More generally, we can use $p$ pulses with saccade amplitude equal to

$$
\sum_{i=1}^{p} h_{i}{ }
$$

In practice, we found that no more than three pulses were ever necessary.

The results of this modification are seen in Figures 11 and 12. For all multi-pulse input fits, $T_{3}=T_{1}=150 \mathrm{~ms}$ was assumed. Figure 11 shows the results of estimation from a single pulse input. Figure 12 shows the same saccade with the model output from a two-nulse input keeping other parameters the same as before. The fit in the second case is clearly much better. Figure 12 also shows the fit of the velocity curves from the data and from the model. Thus, excellent fits are obtained to both the position and velocity curves with this model. Figure 13 shows a much more dramatic result where a three-puise input to the model 18 used. The Justification for using such an input can be clearly seen from the velocity curve which first rises to a maximum 


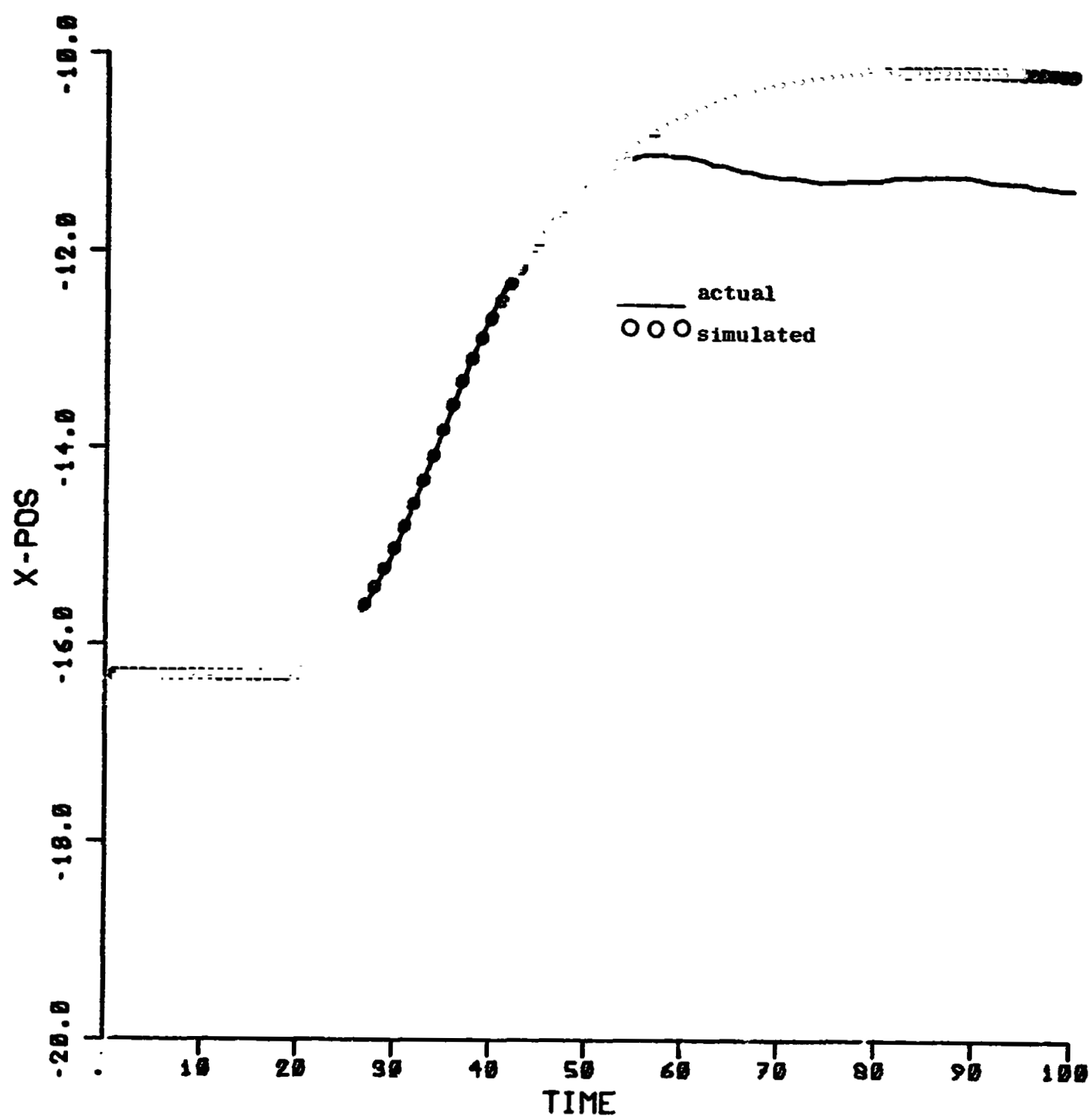

Figure 11 Actual and model simulated saccade position

$$
\begin{aligned}
& t_{0}=20 \mathrm{~ms}, T_{1}=150.0 \mathrm{~ms}, T_{2}=13.1 \mathrm{~ms}, \\
& T_{3}=150.0 \mathrm{~ms}, T=18 \mathrm{~ms}, h=.36 \mathrm{deg} / \mathrm{ms}
\end{aligned}
$$

25 

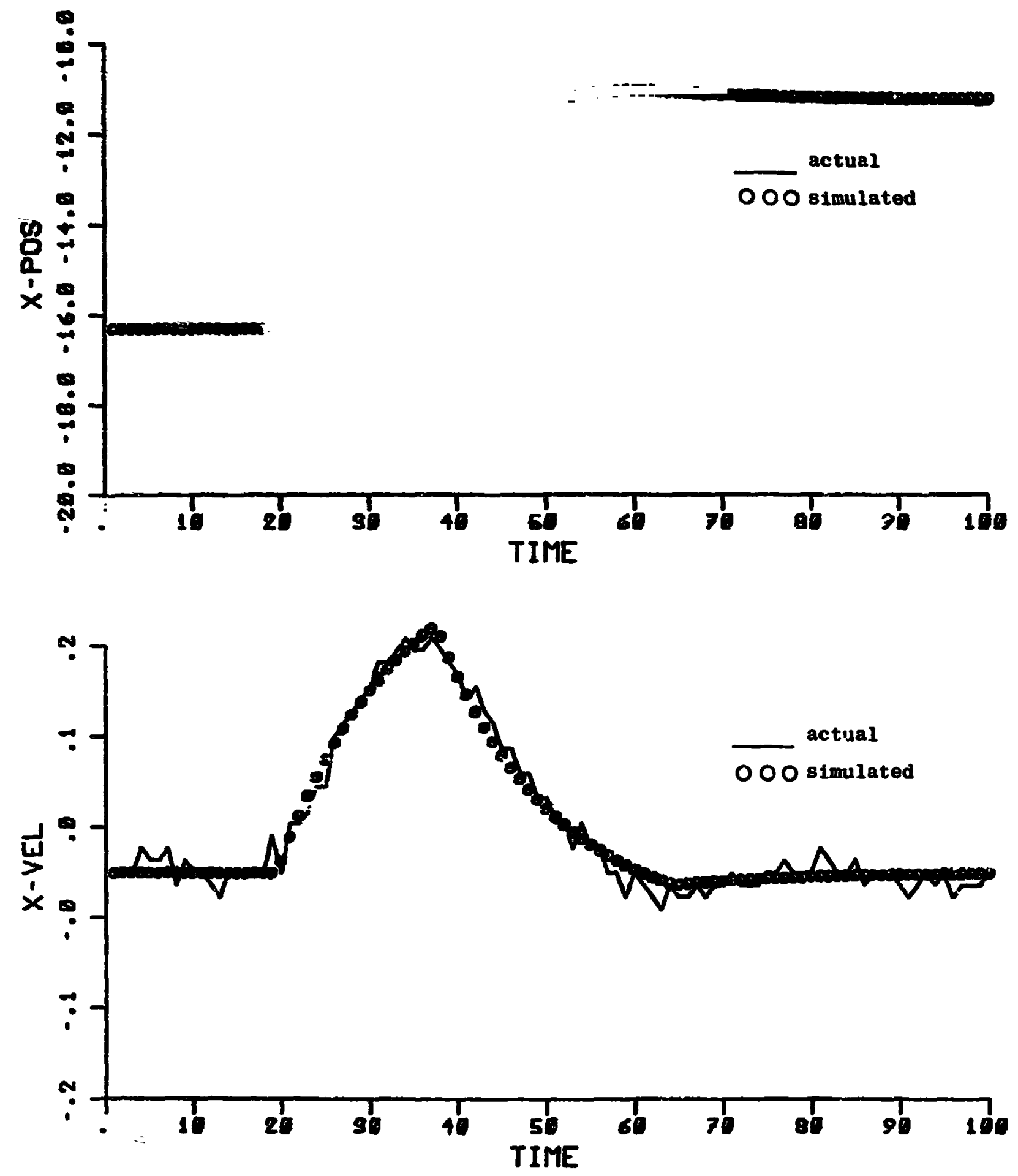

Figure 12 Actual and model simulated saccade position and velocity with two-pulse input

$t_{0}=20 \mathrm{~ms}, T_{1}=150 \mathrm{~ms}, T_{2}=13.1 \mathrm{~ms}$,

$T_{3}=150 \mathrm{~ms}, T_{1}=18 \mathrm{~ms}, h_{1}=.36 \mathrm{deg} / \mathrm{ms}$,

$T_{2}=27 \mathrm{~ms}, h_{2}=-.05 \mathrm{deg} / \mathrm{ms}$ 

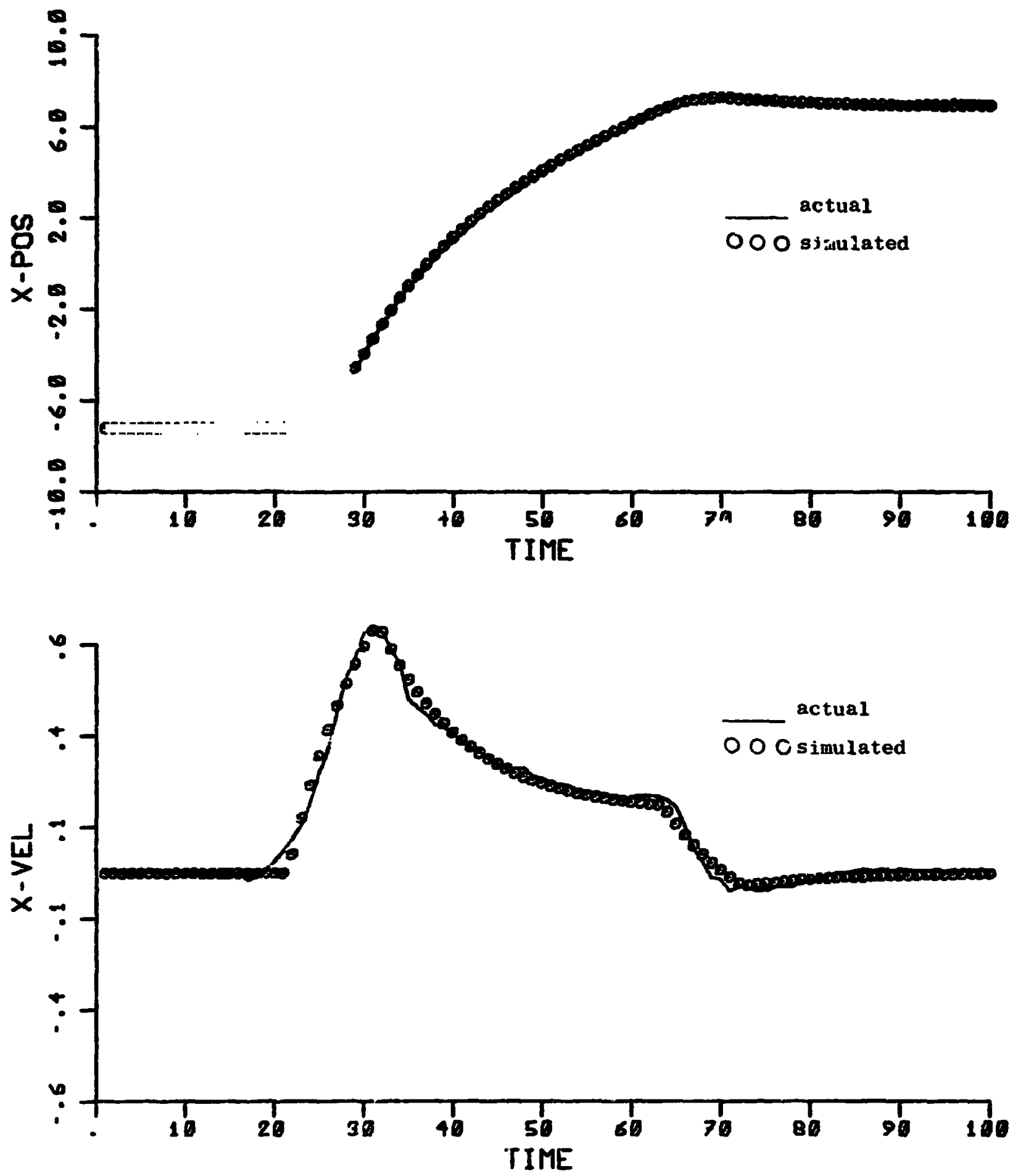

Figure 13 Actual and model simulated saccade position and velocity with three-pulse inpit.

$\mathrm{t}_{0}=20 \mathrm{~ms}, \mathrm{~T}_{1}=150 \mathrm{~ms}, \mathrm{~T}_{2}=9.9 \mathrm{~ms}$,

$T_{3}=150 \mathrm{~ms}, T_{1}=10 \mathrm{~ms}, h_{1}=1.05 \mathrm{deg} / \mathrm{ms}, T_{2}=32 \mathrm{~ms}$,

$h_{2}=.16 \mathrm{deg} / \mathrm{ms},{ }^{\top}{ }_{3}-9 \mathrm{~ms}, h_{3}=-.18 \mathrm{deg} / \mathrm{ms}$ 
value, then approaches a steady positive value, followed by a rapid fall to a negative maximum and decay to zero. This identifies four distinct regions, suggesting four different input levels or three p's $18 \mathrm{~s}$ (one level being sero). In fact, for the fitting, the pulse widths are identified by the instants where the velocity signal changes character. This would le easier to identify on a more noise-free systen where the second derivative or acceleration can be observad. However, it is clear that the input is more complex than a single pulse. At present, me are trying to investigate the relationships between the heights and widths of the various input levels for different saccade lengths for the purpose of prediction. Similar responses are observered for equal iength saccades which indicates that some identifiable relations exist. We are also trying to extend the results to vertical ' iblique saccades. The above approach is useful fcr prediction of the final position of the saccade, given a part of the saccarle; $1 . e$. , we can use it for prediction only $r$ fter a certain time has elapsed since the onset of the saccade. However, we also need to know when a saccadc will occur in resprnse to a stimulus. Normally, there is a delay of between 150 ms to $250 \mathrm{~ms}$ from the presentation of the stimulus to the saccadic response. If we can predict $t^{2} 3$ actual delay, we can predict the course of the Eye novements following the presentation of the stimulus by usin-this delay in conjunction with the above model. We decided to use information in the EEG alpha rhythm to predict the onset of the saccade. Gagrder et al. have shown that fixation saccades are initiated during a particular phase of the alpha. This is in accordance with Wiener's hypothesis that the alpha cycle serves as a clock which 
provides timing for the data gathering and processing portions of the visual sjstem. This result ras obtained from nicrosaccades occurring during fixati $m$. We want to deternine if it applies for the large saccadic wovenents as well. If so, we can use an EDC-alpha-wave predictive sribene to predict the phase of the raveform and then use this information for estinating the onsec of the saccade.

The sane expcriment as described earlier for studying borizontal saccades and in addition to record simultaneousiy the CDG signals coll $\because d$ as described in subsequent sections has been ferformed. The DoG was filtered in the alpha range. Two methods were used to determine the relation betreen the saccade onset and the alpha phase. first, the quadrant of alpha duriug which the ssccade started ras deternined. The $x^{2}$-test ras used to test the distribution of saccades in each of the four quadrants, which wis fuund to be significantly different $(p<.05)$ from a uniform distribution. This test is identical to the one used by Gaarder et al. In addition, the alpha was averaged with the saccade onsets lised up. Results indicate that there is indeed a preferable chase of the alpha rhythm, onset of the saccade. This fact can be exploited for the prediction of the onset of saccades if a scheme can be found for predic:ing the EEG alpha waveforms; espeically, their phasic variaiions. Such a method will be described in the next section. 
III. MODELING OF BEG SIGNALS

DURIKG VISUAT STIMLATION AND PREDICTION OF EDG AIPIA EATEFORIS

In onde: to determine the temporal cues that are important in visual Desory, It is necessary to understand the relation between the temporal structure of visual perception and the EDG alpha cycle. To this end, we have investigated the changes produced in the EBO signal by sinple visual stimli. In particular, we are modeling and investigating the various ExG entraiment phenomena caused by periodic photic stimuli and the ohasic changes in EEG due to photic stimuli. This 111 enhance our knowledge in several areas: it enables us to unify several seemingly different EEG phenomena under one principle, prcides a model for the phase-dependency of stimulus efficiency, and enables us to study the phase-depenfencies of onset times of saccades. A number of researchers have suggested that the alpha cycle is phase locked with a clock signal -hich prorides the time base for a sampled-data system consisting of the eye, its control mechanism, and the visual cortex. The evidence for this has been accumulated slowly; it is known that visual perception times and reaction times are on the order of one alpha cycle and dependent upon the phase of the stimulus. In addition, some recent work has shown that a saccade is most easily iniilated on sertain phases of the alphb rhy $:$ he, which coupled with the fact that vision is blocked during a saccade, suggests that the alpha cycle delineates visual data sampling and processing periods.

The above disclisoion outlines the motivation for modeling the EFG signal during simple visual stimulation; the modeling efforts to date have been based on a simple nonlinear oscillator which is amenable to 
analysis and simulation.

1. A Nonlinear Mathematical Model for Entrainment of EEG Signals by Periodic Photic Stimulation

The model is a van der Pol oscillator representing the behavior of a subject's EEG during periodic visual stimulation by a stroboscope or a set of LED goggles. The stinuli are delivered for 20 seconds at some fixed frequency followed by a 10-second stimulus-off period. This sequence is repeated for each desired stimulus frequency.

The van der Pol oscillator can be represented by

$$
\ddot{x}-\mu\left(1-x^{2}\right) \dot{x}+\underset{0}{2} x=\mu_{0}^{2} E(t)
$$

where $x(t)$ denotes the EEG signal; ${ }_{0}$ is the unstinulated alpha frequency; $E(t)$ is the external excitation (stimulus): and $\mu$ is the nonlinear coupling coefficient.

When $E(t)$ is a sinusoid, a first approximation to the solution $x(t)$ can be made by a classical technique, such as harmonic balancing. The possible sulutions can be classified in the following way when $E(t)=E_{0} \sin \left(\ldots_{1} t+E_{0}\right):$

(1) natural oscillation ( $E_{0}$ is small):

$$
x(t)=A \sin \left({ }_{0} t+\phi\right) ;
$$

(2) harmonic entrainment $\left(._{0} \approx \omega_{1}\right)$ :

$$
x(t)=A(t) \sin \left(\omega_{1} t+\theta(t)\right) ;
$$

(3) mth-order subharmonic entrainment $\left(m \omega_{0}=u_{1}\right)$ :

$$
x(t)=A(t) \sin \left(\frac{1}{t} t+o(t)\right) ;
$$

(4) nth-order superharmonic entrainment $\left(\omega_{0} \approx n \omega_{1}\right)$ :

$$
x(t)=A\left(l: \sin \left(n+\omega_{1} t+D(t)\right) ;\right.
$$


(8) conbined frequency osc1llations (all other casea):

$$
x(t)=A_{0}(t) \sin \left(w_{0} t+\phi_{0}(t)\right)+A_{1}(t) \sin \left(w_{1} t+\bullet_{1}(t)\right)
$$

Sone Initial data have been collected with a set of enecially constructed IED gogBles which provide a sinusoidaliy modulated intensity. and the results agree well with the above solution classes. However, since the experirental stimulus is often a train of liaghes, we have developed an analysis technique for approxinating the solution of the van der Pol equation when $E(t)$ is a pulse train.

We assume that the unperturbed osc111ation $(B(t)=0) 18$ correctly represented by

$$
x(t)=a_{0} \sin \theta(t)
$$

where the angular displacenent can be written in terms of frequency and phase:

$$
\theta(t)=\omega_{0} t+(t)
$$

We wish to examine the result of $E(t)$ being a series of impulses of strength $q$ at a frequency $w_{1}$.

Following a method due to Blacquière, we can assess the perturbation caused by one inpulse. At an angular displacement

$$
\theta_{n}=\omega_{0} t_{n}+
$$

we apply the nth inpulse. Its effect will be seen directly in $\mathbf{E}(t)$, causing a small step change

$$
\Delta \dot{x}=\int_{t_{n}}^{t_{n}+\Delta t} x(\tau) d \tau=q i_{0}^{2}
$$

over time $\Delta t$. However, $x$ will be continuous, so $\Delta x=0$.

To a first approximation, we can expand $\Delta x$ and $\Delta \dot{x}$ as below:

$$
\Delta x=\Delta a \sin \theta_{n}+a_{0} \Delta \oplus \cos \theta_{n}=0
$$




$$
\Delta \dot{x}=\Delta a \omega_{0} \cos \theta_{n}-a_{0} \omega_{0} \Delta \sin \theta_{n}=q \omega_{0}^{2}
$$

were $\Delta^{a}$ repreaents the charge in amplitude and $\Delta^{\circ}$ represents the change in phase of the systen. Solving the above equations sinultaneous1y for $\Delta^{2}$ and $\Delta^{*}$, we obtain

$$
\Delta \mathrm{a}=\mathbf{q} \omega_{0} \cos \theta_{\mathrm{n}}
$$

and

$$
\Delta *=-\frac{q \omega_{0}}{a_{0}} \sin \theta_{n}
$$

In Figure 14, we demonstrate the applitude and phase perturbations as a result of an inpulse falling on angular displacenent $\theta_{n}$.

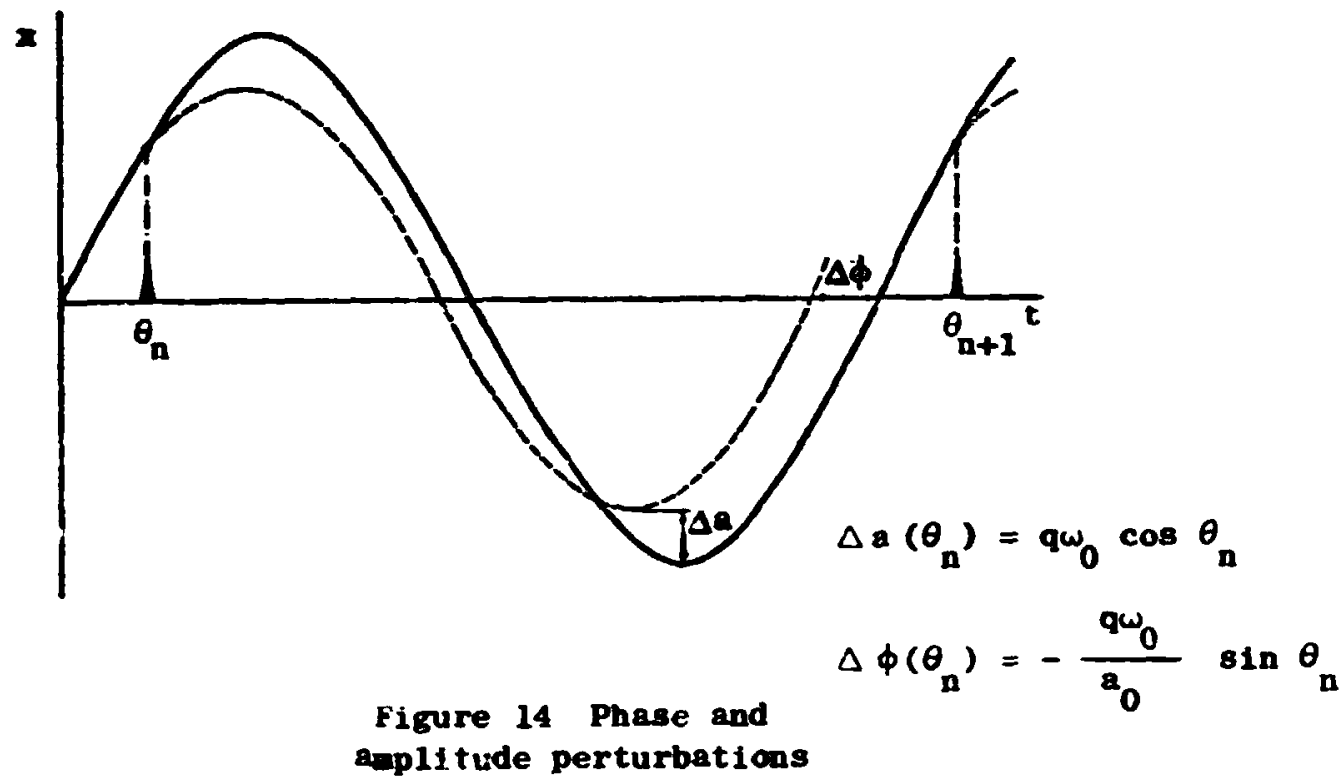

The unperturbed solution would have followed the dashed line, and the perturbed solution follows the solid line.

In order to deal with a series of these impulses, $\Delta a$ will be assumed to be negligible. This is reasonable since a more detailed analysis shows that the amplitude change decays exponentially with time. Let $T_{0}=\frac{2 \pi}{\omega_{0}}$ and $T_{1}=\frac{2 \pi}{\omega_{1}}$ be the alpha and stimulus periods, 
respectively. Then referring again to Figure 14, we see that applyitis the nth pulse a: displacement $\theta_{n}$ results in a ner displacement $\theta_{n}+\Delta \oplus\left(\theta_{n}\right)$. Since the pulses are spaced $T_{1}$ seconds apart, the $(n+1)$ th pulse will arrive at displacenent

$$
\theta_{n+1}=\theta_{n}+\Delta \theta\left(\theta_{n}\right)+T_{1}
$$

Cleerly, for entrainent to occur, we must have the congruence relation

$$
\theta_{n+l} \equiv \epsilon_{n} \quad\left(\operatorname{modulo} \mathrm{T}_{0}\right)
$$

or

$$
\theta_{n}+\Delta \cdot\left(\varepsilon_{n}\right)+T_{1} \equiv \theta_{n}\left(\operatorname{modulo} T_{0}\right)
$$

Hence

$$
\Delta \partial\left(\theta_{n}\right)+T_{1}=k T_{0}, k=0,1,2, \ldots
$$

When $k=0$, we have the unlikely situation of resetting the phase of oscillation; the required phase change $\Delta \theta\left(\theta_{n} ;\right.$ is very large. We will not consider this case here.

for $k=1$, the solution is called harmonic entrainment, and for $k<2$, it is called $k^{t h}$-order superharmonic entrainment, where $k$ represents the number of alpha periods elapsed per stimulus impulse. It is casy to show that this is stable near

$$
\left|\theta_{n}\right|_{\bmod T_{0}}=0 \text {. }
$$

as one would expect from the form of $\Delta^{\star}$.

In a similar fashion, for subharmonic entrainment to occur,

$$
\theta_{n+m} \equiv \theta_{n} \quad\left(\operatorname{modul} 10 T_{0}\right)
$$


$\mathbf{O r}$

$$
\theta_{n}+\sum_{i=n}^{n+n-1} \Delta \bullet\left(\theta_{1}\right)+m r_{1} \equiv \theta_{n}\left(\operatorname{codul} 1 T_{0}\right)
$$

Bence,

$$
\sum_{1=n}^{n+n-1} \Delta \bullet\left(\theta_{1}\right)+m T_{1}=T_{0} .
$$

When $m=1$ we have harmonic entrainment again, and for $22, m^{\text {th }}$ order subharmonic entrainent occurs. The stability of this solution is currently being investigated, but it appears that for $=2$ a gall stable range exists.

In sumary, when the stimulus frequency is near the alpha frequency, harmonic entraiment is possible. When the alpha irequency is near an integer witiple of the stimulus frequency, superharmonic entrainsent is possible. And when the stinulus frequency is near an integer multiple of the alpha frequency, subharmonic entrainent is possible.

When the stimilus frequency is not in one of the above ranges, coabined frequency oscillations exist. Thus, we have the sane five solution classes for both sinusoidal and impulsive stimuli. The major differences lie in the amplitudes required to produce the various effects, and in the fact that the impulsive stimulus will produce integer harmonics of its fundamental frequency due to its luherent harmonic content. Results obtained frot EFG data on the model are described and compared in the next section.

\section{Model Simulation}

It is necessary to simulate the nonlinear oscillator model to 
obtain reasonably accuraie solutions since nonlinear analysis is by nature approximate. We are using a variable o:der differential equation solver (DVDQ) which has an Adams-Faulkner predictor and an AdamsMoulton corrector. It provides for up to twentieth order interpolation of output values positioned independently of the changing stepsize, which greatly facilitates signal processing of the simulated solution by allowing a constant sample deriod.

The sine wave stimulus is handled in a straightforward fashion, but the impulse train is treated specially. Since it is known analytically that the exact change in $\dot{x}(t)$ is $q_{\omega_{0}}^{2}$ (by integration) at the time an impulse is called for, the state vector is perturbed and the integration restarted. The management of impulse arrival and sample output is performed by a discrete event-queuing scheduler on a priority basis; impulse arrival has priority over all events to avoic frequency shifts in the impulse train. Error propagation as a result of restarting the integration is linear with the requested error tolerance and adequately simall.

Figures 15 and 16 show the phase and amplitude pertirbations caused by a single flash landing on phases of $0, \pi / 2, \pi$, and $3 \pi / 2$ radians. The simulations mach the first order aporoximations developed in the previous section very we11. These perturbations produce appropriate entrainment phenomena, as seen in the spectra of Figures 17 and 18; there is one spectrum for each stimulus frequency, representing 5.12 seconds of impulse driven simulation at a lon-Hz sampling rate. The five phenomena predicted in the previous section can be clearly seen; viz., harmonic entrainment, subharmonic entrainment, superharmonic 

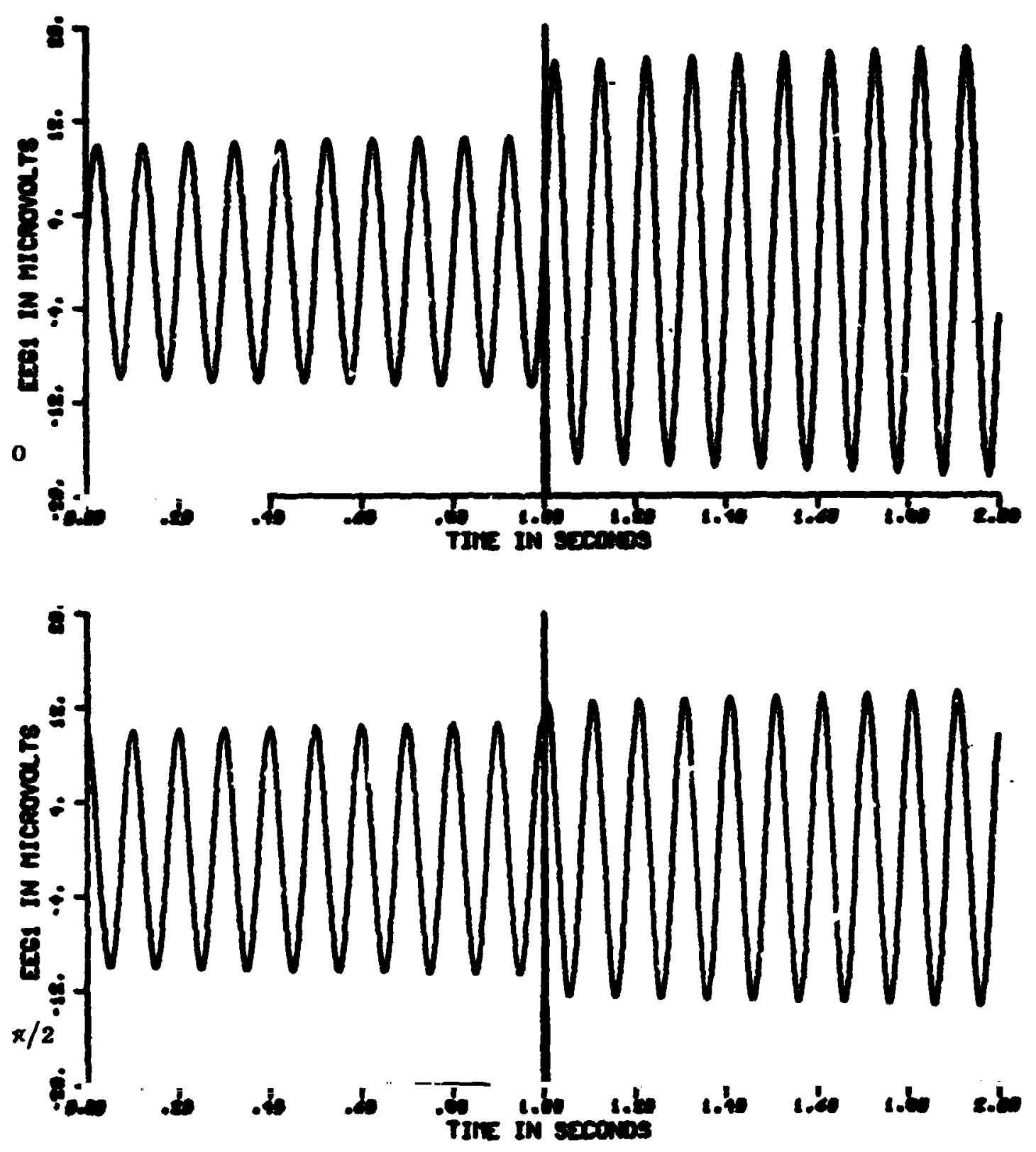

$$
\begin{aligned}
& \text { Figure } 15 \text { Simulated EEG perturbations resulting } \\
& \text { from flash at phases of } 0 \text { and } \pi / 2 \text { radians }
\end{aligned}
$$



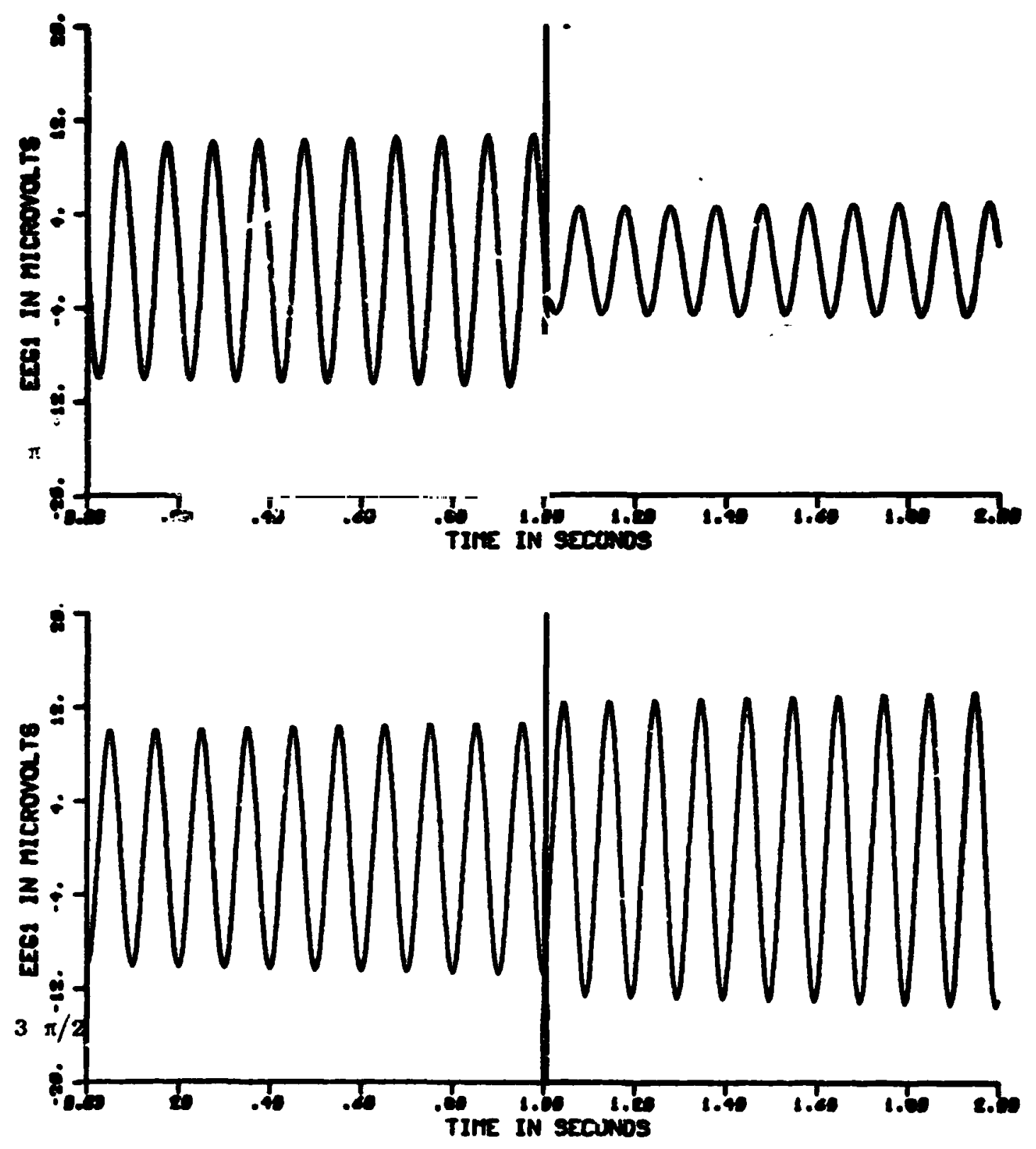

Figure 16 Simulated EEG nerturbations resulting

from fiash at phases of $\pi$ and $3 \pi / 2$ radians 


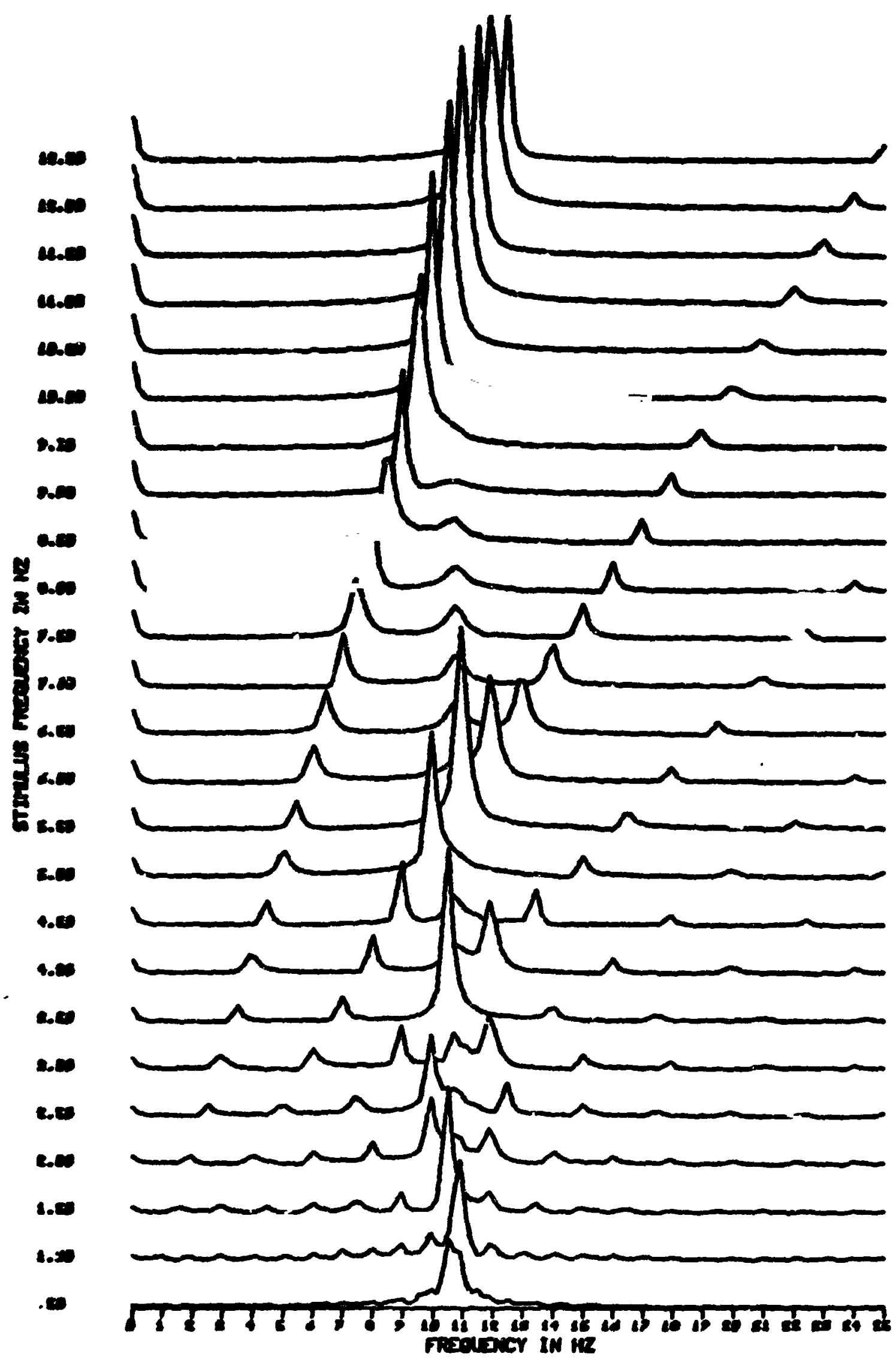

Figure 17 Simulated EEG spectra for flash

frequencies from $.5 \mathrm{~Hz}$ to $12.5 \mathrm{~Hz}$ 


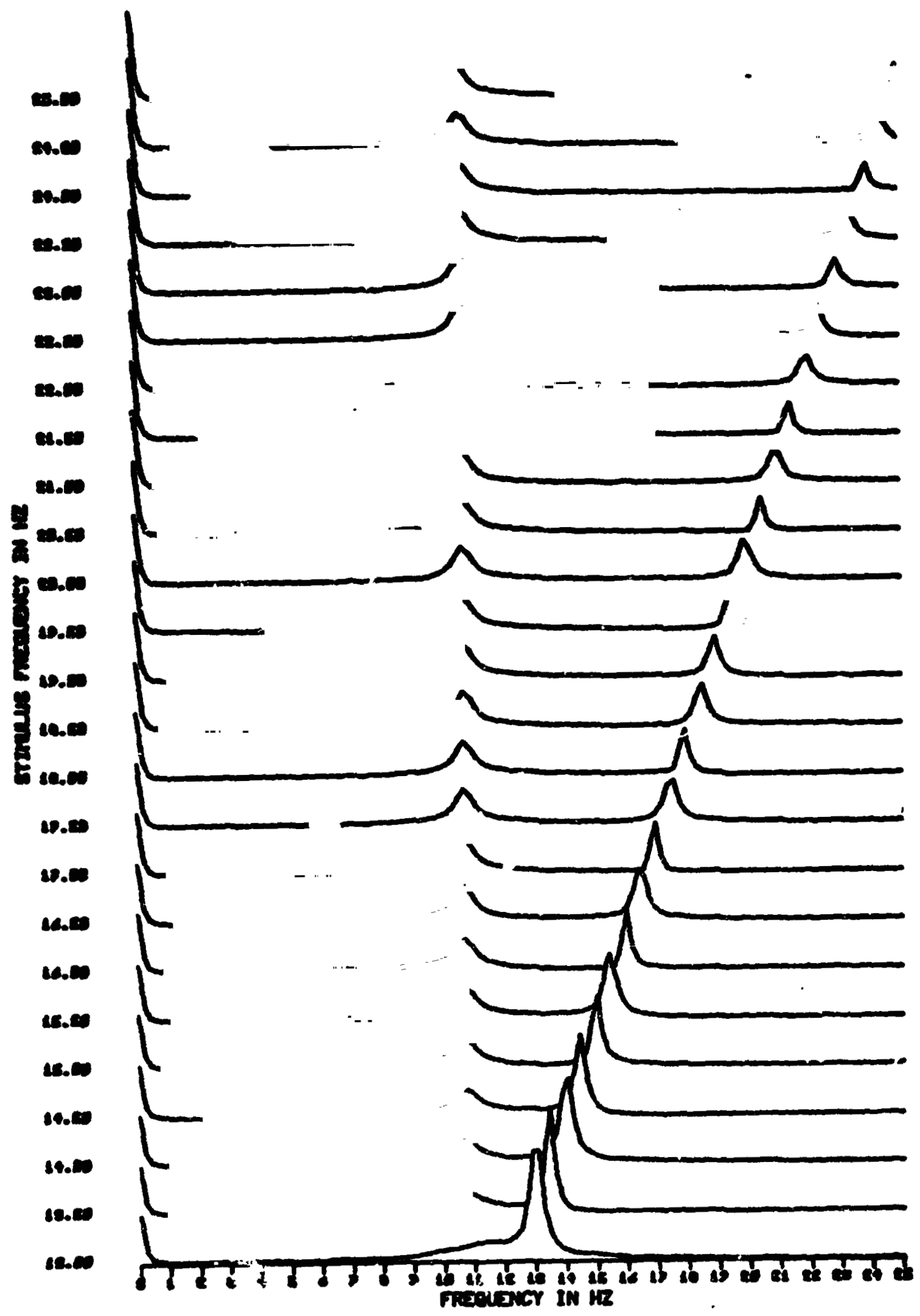

Figrie 18 Simulated EEG spectra for flash frequencies from $23 \mathrm{kz}$ to $25 \mathrm{~Hz}$ 
entrainment, combined frequency oscillations, and stimulus harmonics. These effects can again be seen in Figures 19 and 20 which are spectra from 5.12 seconds of sine wave driven simulations. These spectra will be compared with those obtained from experimental data in a section below; the next sectil 2 discusses data collection and processing.

\section{Data Collection and Processing}

The data collected to test the model have been obtained from a very simple experimental paradigm. Subjects are presented a series of stroboscope flashes or sinusoidally modulated intensities through closed eyelids; the stimulus is delivered for 20 seconds at some fixed frequency, followed by a 10-second rest period. This sequence is repeated for each desired frequency, typically .5 Hz through $25 \mathrm{~Hz}$ in $.5 \mathrm{~Hz}$ steps. The frequency pattern can be selected arbitrarily. The EEG signals are obtained from left and right occipital electrodes referenced to yoked earlobes; the ground electrode is on the mastoid. The Grass preamp bandpasses the signal between $1 \mathrm{~Hz}$ and $300 \mathrm{~Hz}$, and the $\mathrm{A} / \mathrm{D}$ analog prefilter is a 6-pole Bessel with a $100 \mathrm{~Hz}$ lowpass cutoff frequensy. Digitizing is at $1000 \mathrm{~Hz}$, and subsequent filtering is cone by a transversal filter to avold further phase distortion. Power spectra are $\therefore$ vuted by Fast Fourier Transfon? on 5.12 seconds of the data, forming the power spectrum and then averaging three such spectra 4.0 seconds after the start of the stimulus.,,- 1, adure substantially reciuces the nolse, which is furthe: reduced for viewing ans etics by the noncausal recursive filter

$$
H(z)=\frac{z^{2}+2 z+1}{4 z} .
$$




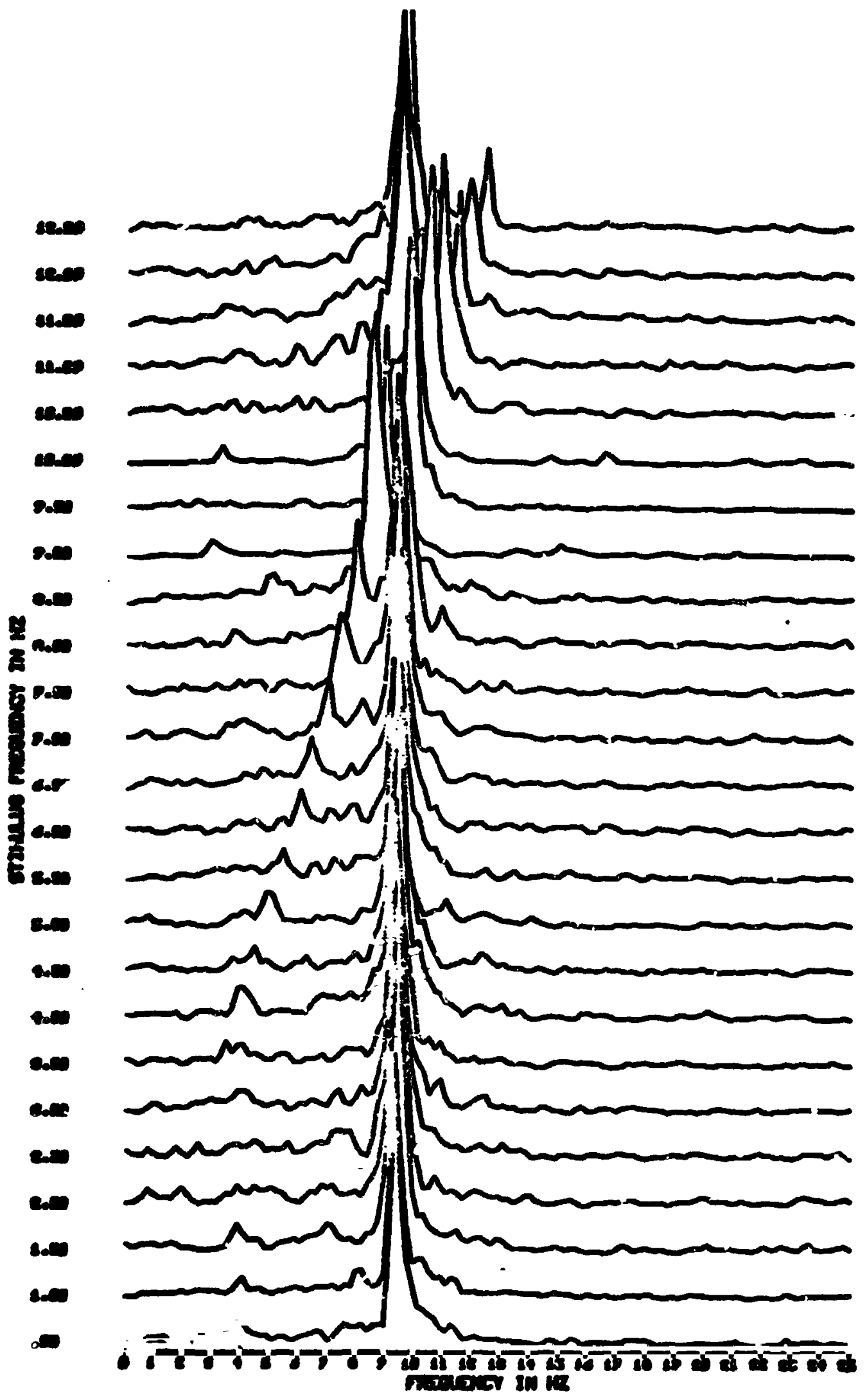

Figure 19 Simulated FEG epectra for sine frequencies from $.5 \mathrm{~Hz}$ to $12.5 \mathrm{~Hz}$ 


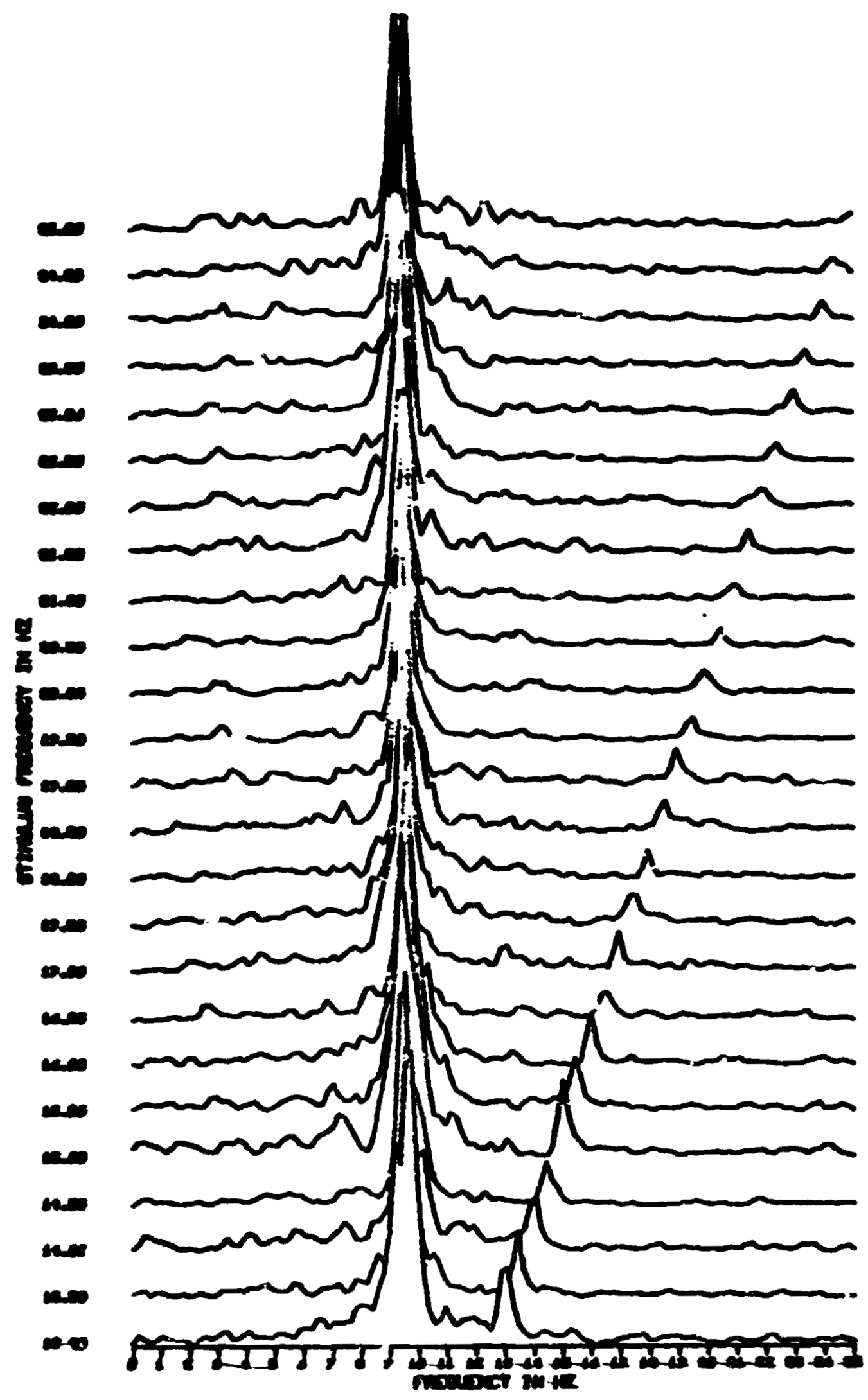

Figure 2') Simulaied EEG spectra for sine frequencies from $13 \mathrm{~Hz}$ to $25 \mathrm{~Hz}$ 
The resulting epectra nay be superimposed with hidden lines renoved by classical graphice techniques; a sall anount of 1 nformation wust be saved after each epectrin is plotted.

The stroboecopic stinuli are produced by a Grass PS-2 strobe labp 1.: a scund-proof enclosure. It is driven by a relay contact. The situsoidal is modulated intensity stimil are produced by a pair of hewispharical goggles, each containing ten LDD, driven by a current source controlled by a D/A converter on the PDP-15. The voltage supplifd 15 proportional to exp $\left(\sin \omega_{1} t\right)$ since the LD anplitude is linear with current and sinusoidal intensity is desired. Both stimuli are delivered through closed ejelids to ensure a uniform visual field.

\section{Comparisun of Hodel Sinulations and Experinental Data}

The compariscn of nodel simulated results with experimental results is subject to difficulties arising from the nolve in the data and the rantom nature of much of the EDG signal. The alpha frequency is not fixed and is in fact nonstationary; it is influenced by the subject's level of alertness and other uncontrollable factors. The response of the EEG to a stimuius is only measurable in the average, since individual responses are nasked or corrupted by noise. Averaging can also mask certain characteristics of the response, dependi.; upon the scheme used.

The best comparison of model-produced results and data 1 jr entrainaent phenomena is a comparison of their power spestra. This allows the deta speccrum to be re'atively free of noise by averaging successive spectra from the same stimulus epoch. Examples of stroboscopically stimulated 
data spectra may be seer, in Figures 21 through 24. Note the excellent match overall with the sinulated spectre discussed prefiously. The last subjezt has virtually no alphe rhythn, but arhibits all of the entrainment phencmena predicted, so the model accounts surprisingly we $\lambda$. for extrene cases. Fi ares 25 and 26 show spectra for a sinusoidally stimulated subject. Note the reduction in harnonic anplitude as predicted by the simulation. Some detailed comparisons of each type of phenomena follow. Figure 27 shows the unstimulated case with the nodel paraneters adjusted to match the subject (records were selected from Figures 21 and 22 ). Figure 28 illustrates harmonic entratment, with subharmonic and superharmonic entrainment treated in Figures 29 and 30 . Figure 31 is an example of combined frequency oscillation. The nodel sinulations agree well with the cata. Additional comparisons ay be found in previous reports.

Furthe $r$ comparisons are in progress, especially the comparison of phase end amplitude changes induced by the stimuli. Preliminary results indicate that the model predictions are reasonable first order approximations to the data, but that revisions in the model will likelv be necessary to fully account for the observed phenomena. The excellence of match in the frequency domain bears out the goodness of the phase shitt predictions for saall phase shifts, but it appears that larger shifts are occurring than predicted for certain cases. In sum, a nonlizear model for the behavior of the EEG during visual stimulation has been analyzed and compared with actual EEG data. The model accounts for several phenomena well in a unified fashion, and suggests other phenomela of interest. The model specifies a trigonometric 


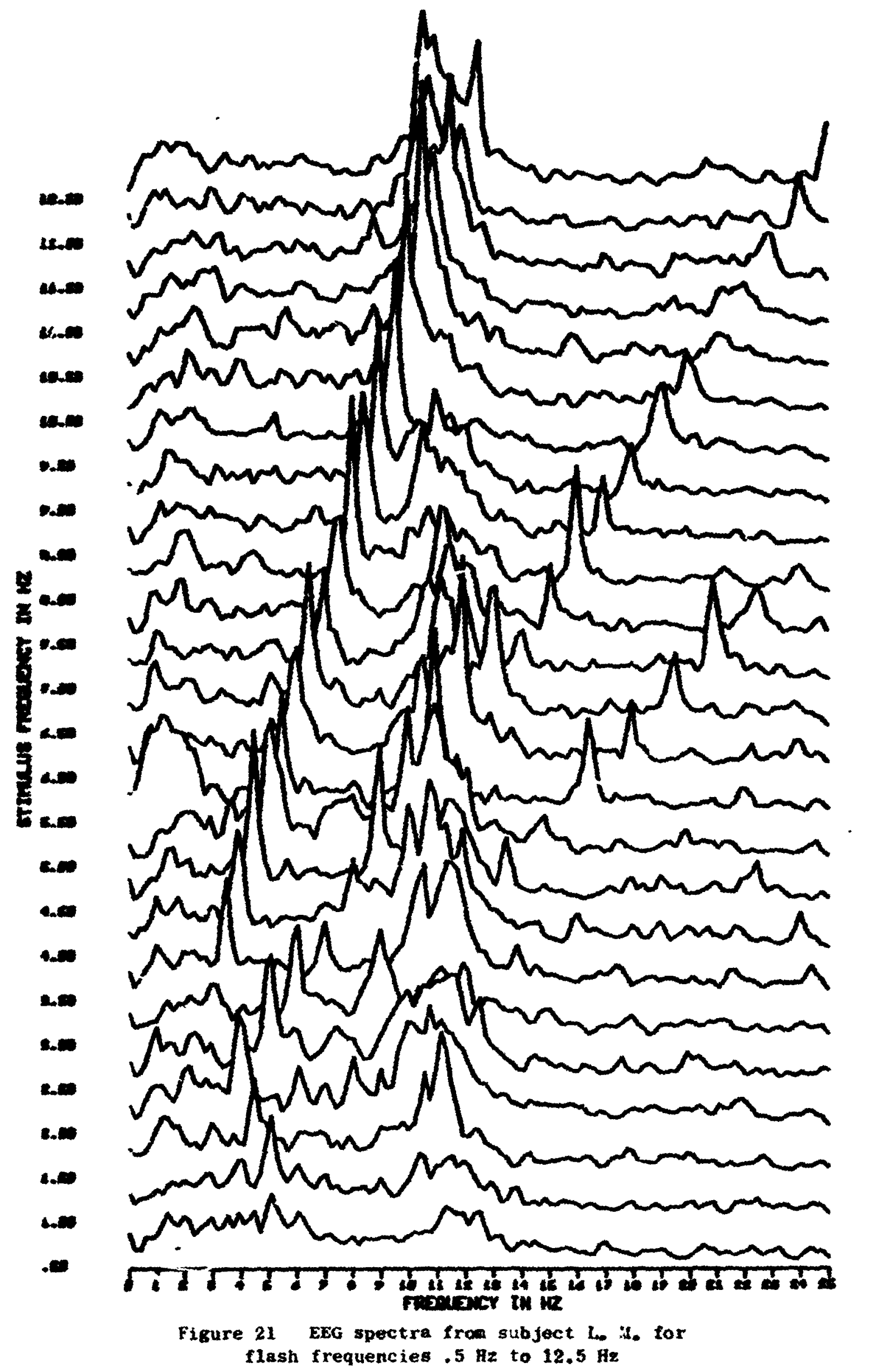




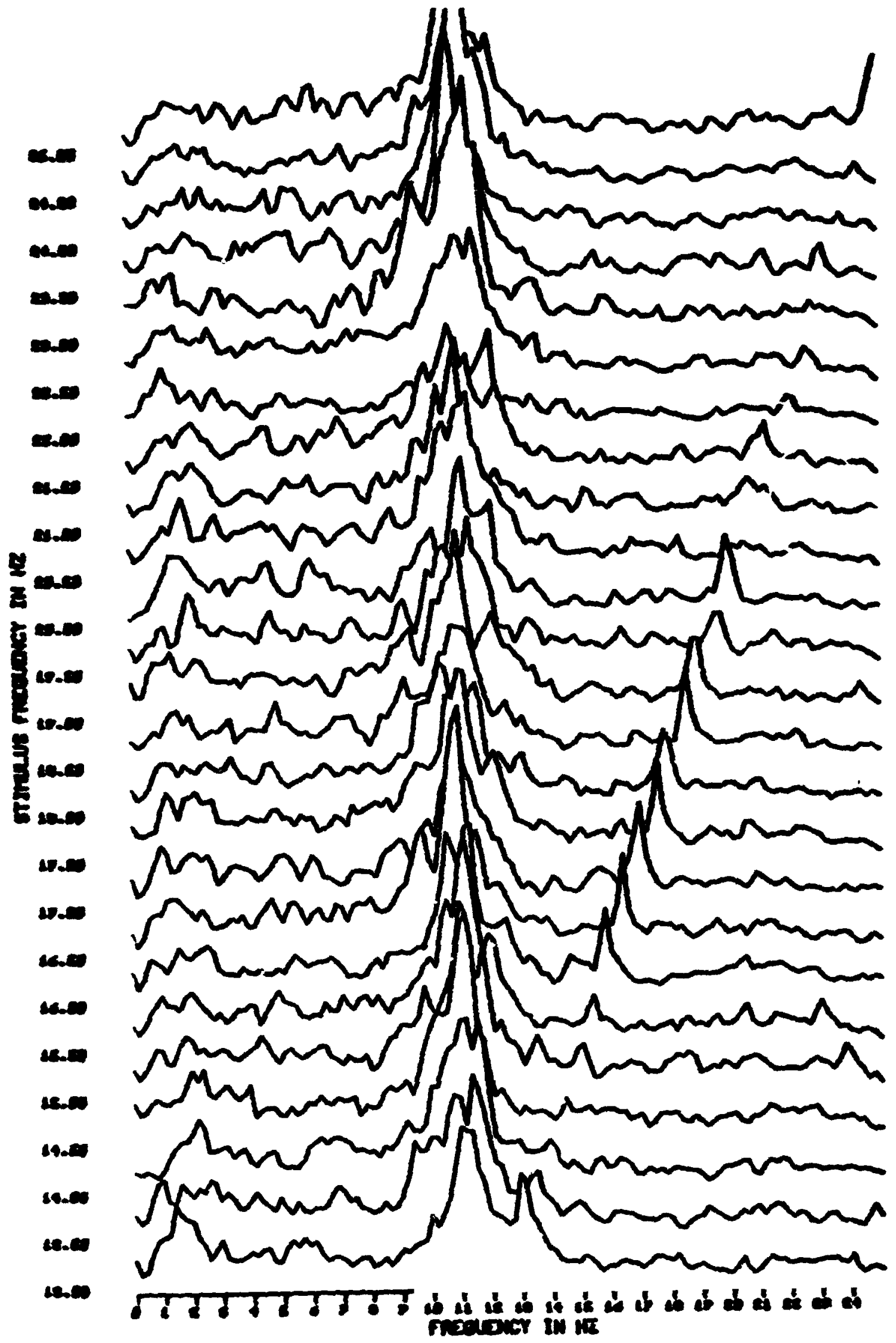

Figure 22 EEG spectra from subject h. M. for flash frequencies $13 \mathrm{~Hz}$ to 2 f $d z$ 


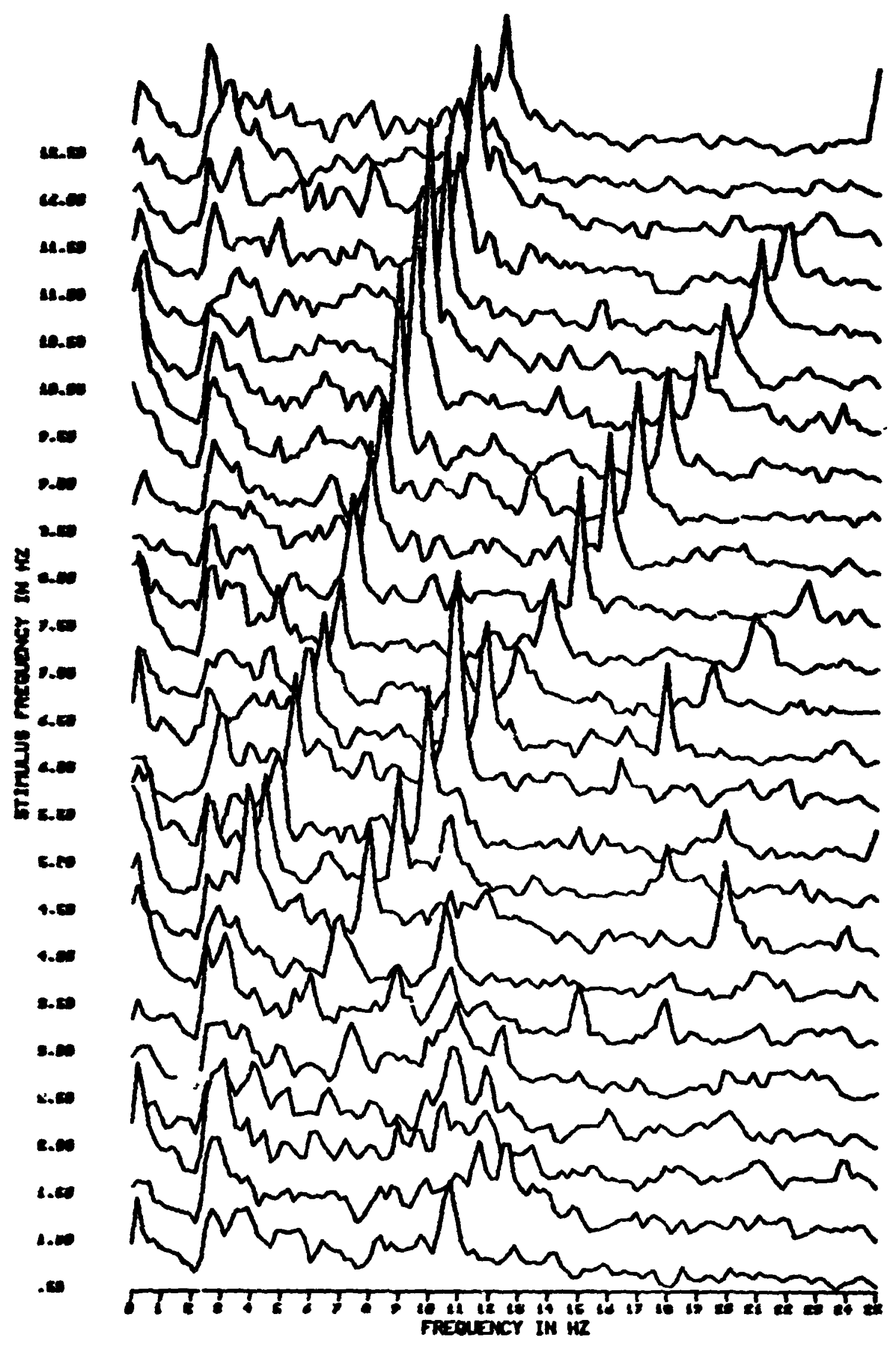

Figure 23 EEG spectra from subject $f$. M. for flash frequenctes .5 $\mathrm{Hz}$ to $12.5 \mathrm{ll}$. 


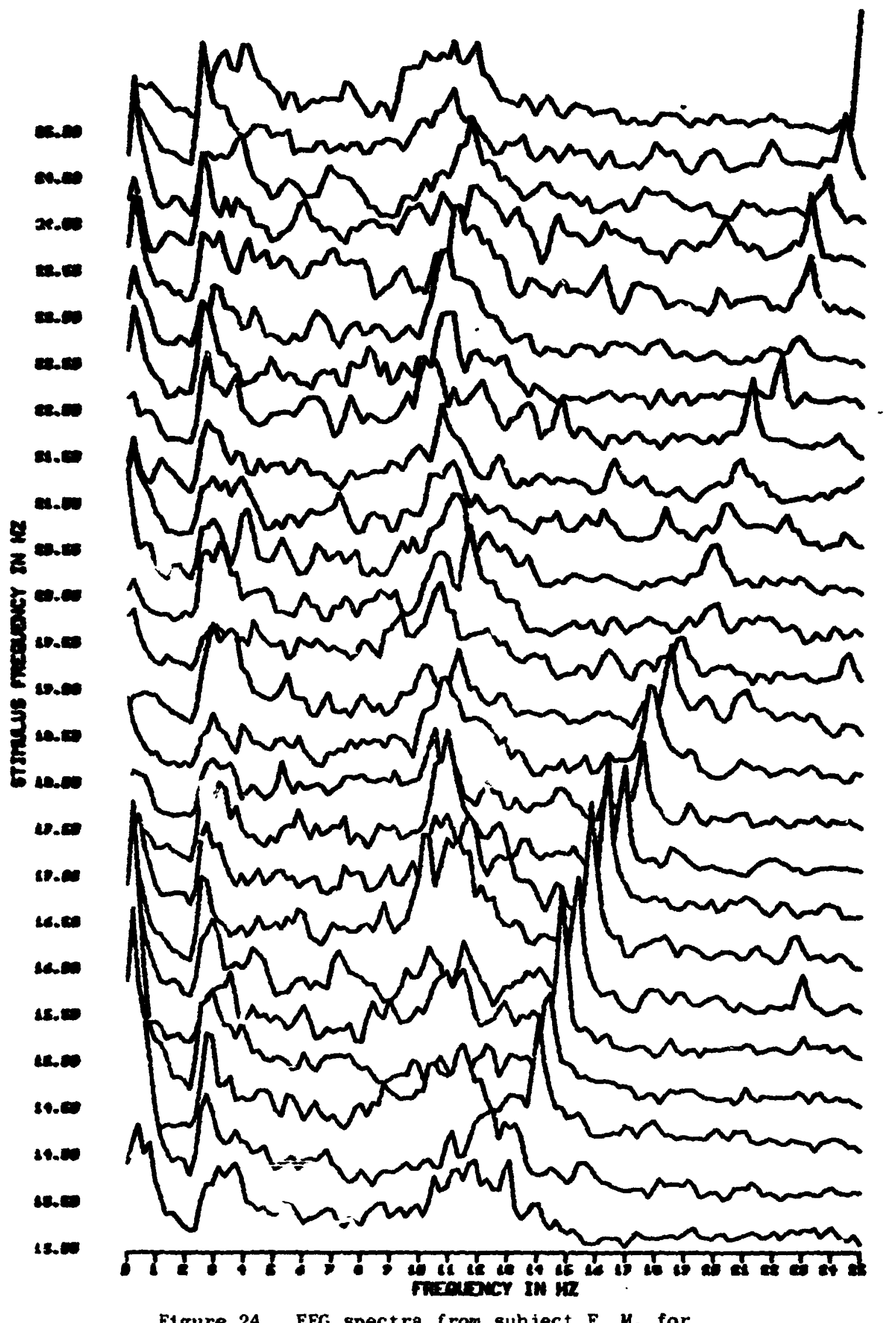

F1gure 24 EEG spectra from subject $F$. $M$. for

flash frequencies $13 \mathrm{~Hz}$ to $25 \mathrm{~Hz}$ 


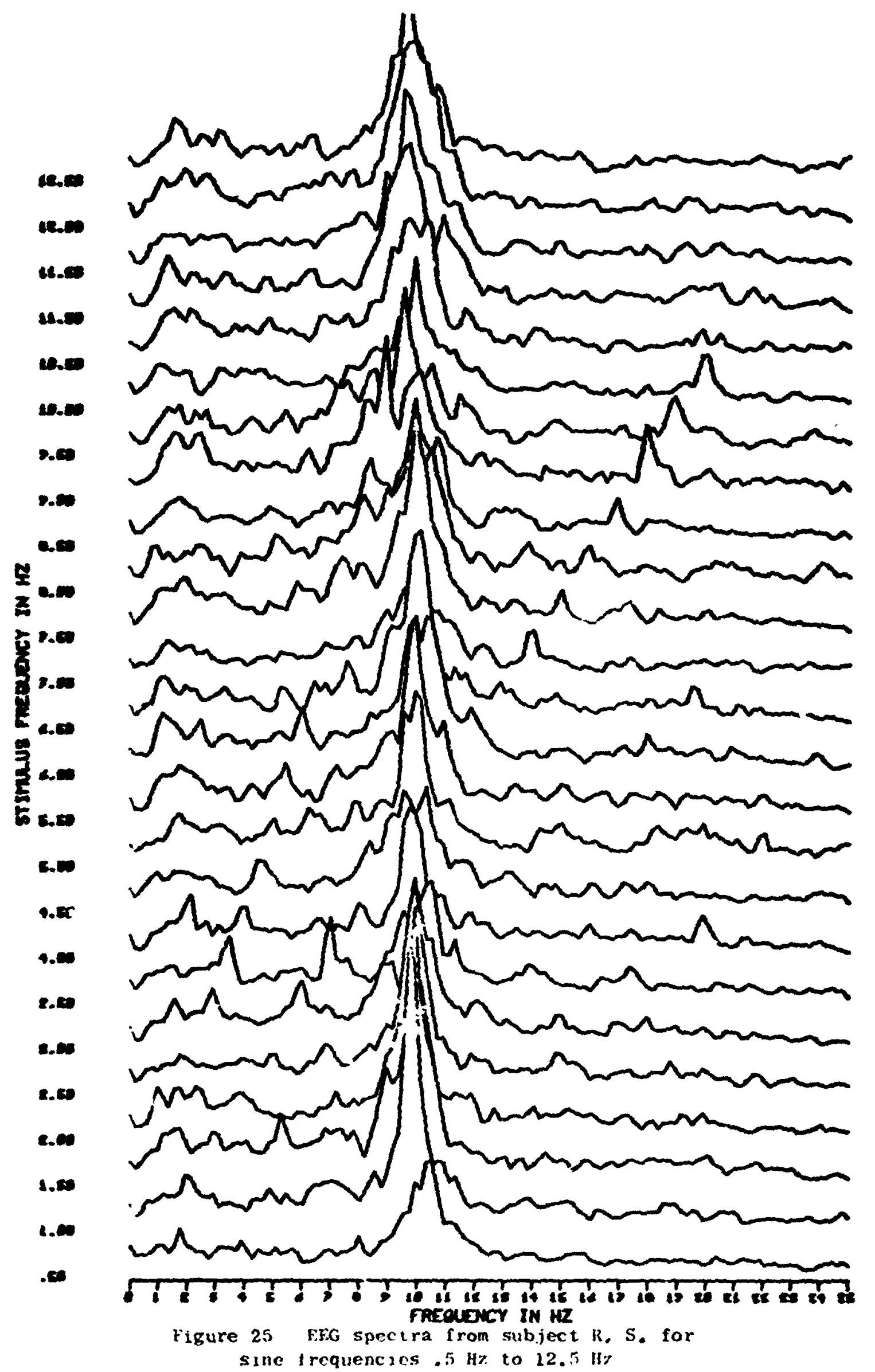




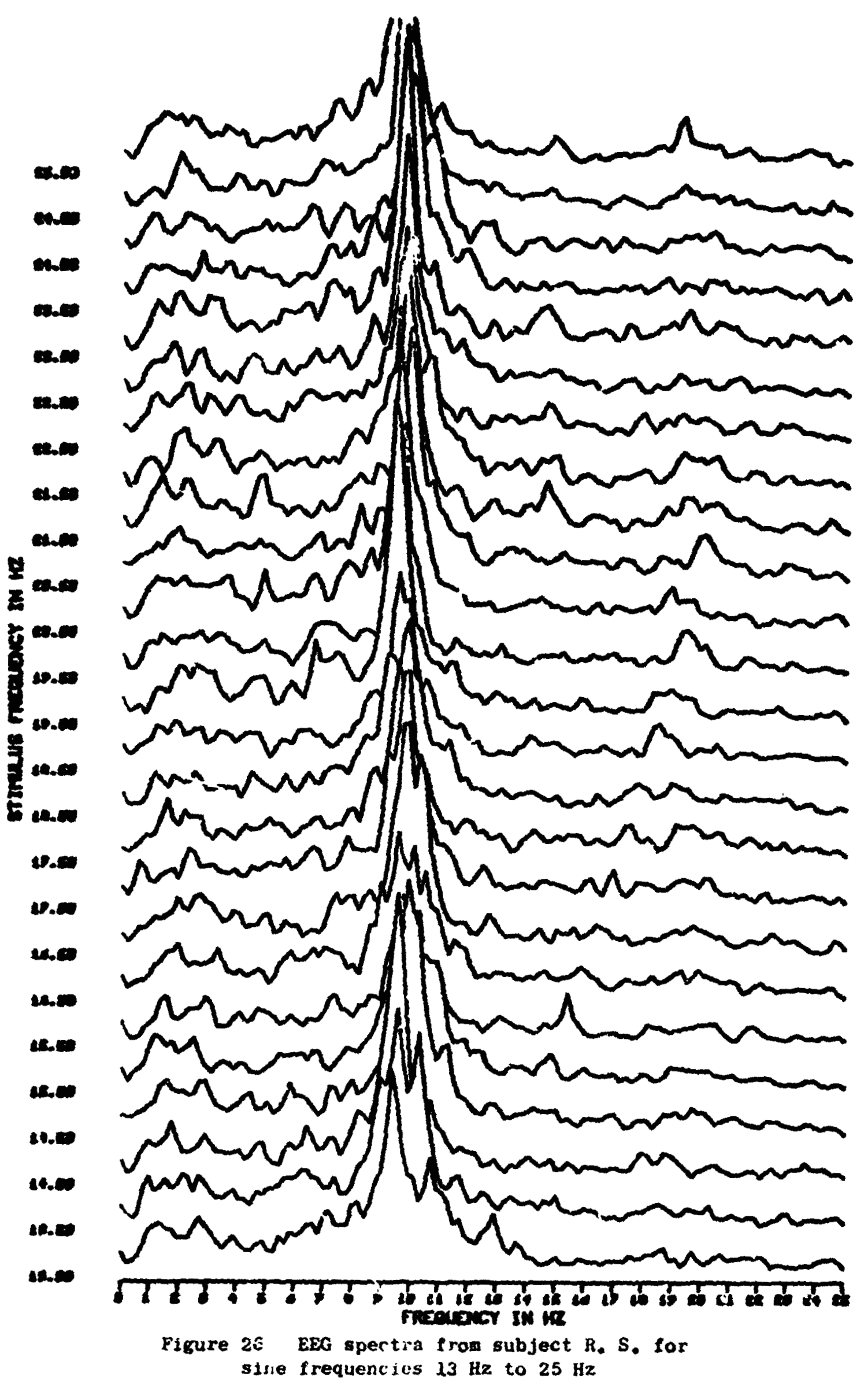




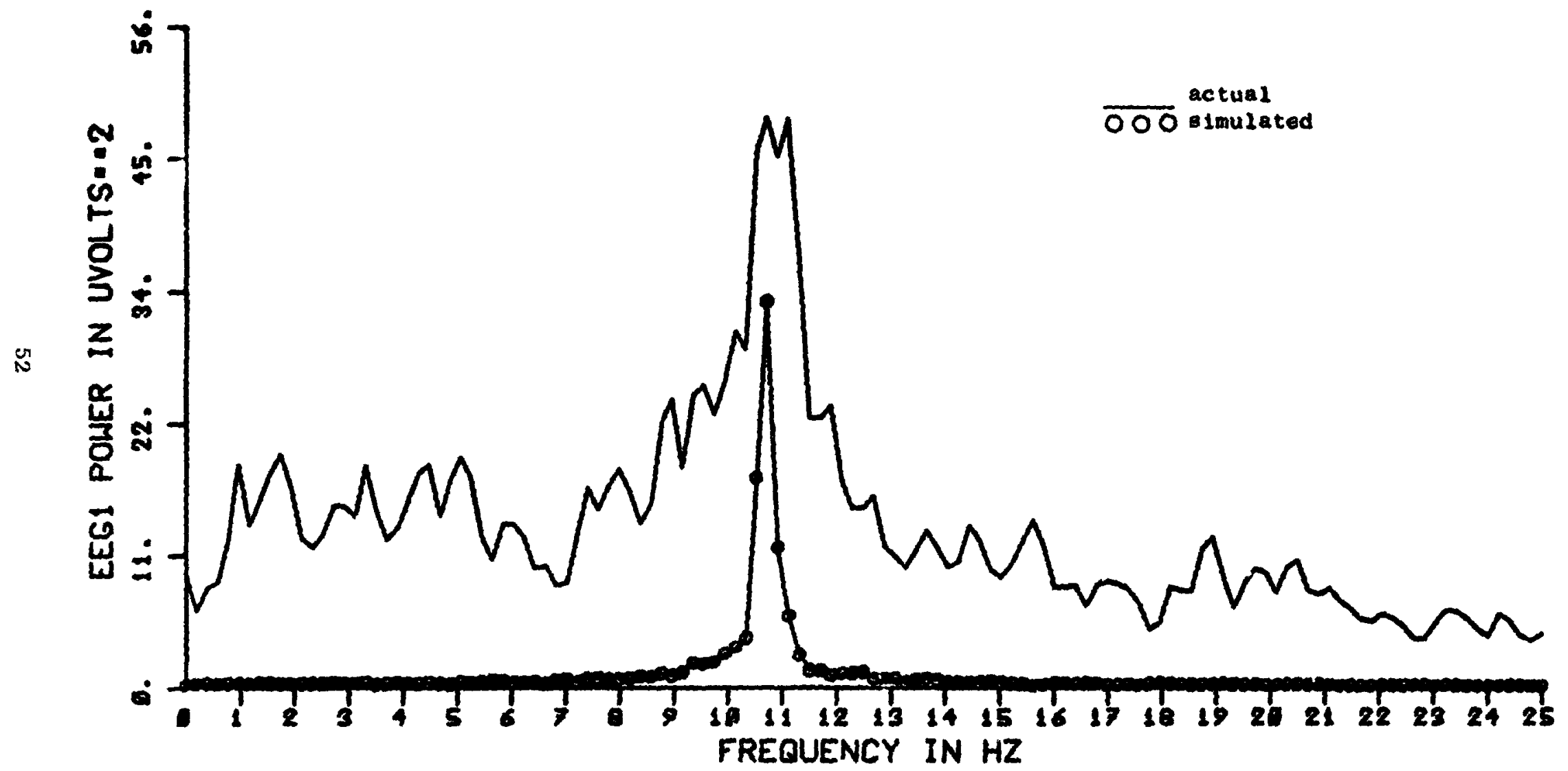

Filure 27 Actual and simulated EEG spectra

in the absence of stimulation 


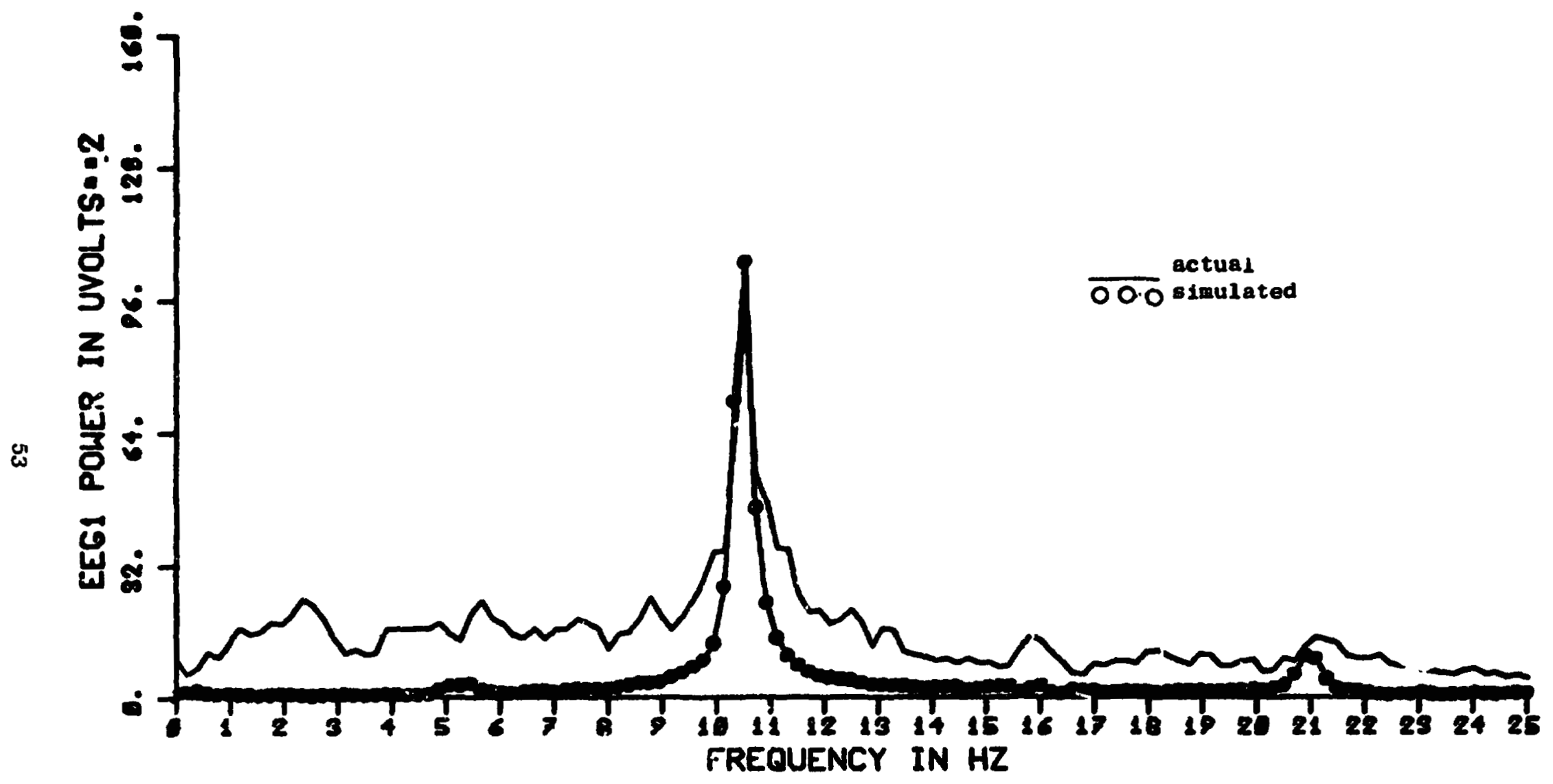

Figure 28 Actual and simulated EEG spectra curing flash stimulation of $10.5 \mathrm{~Hz}$ 


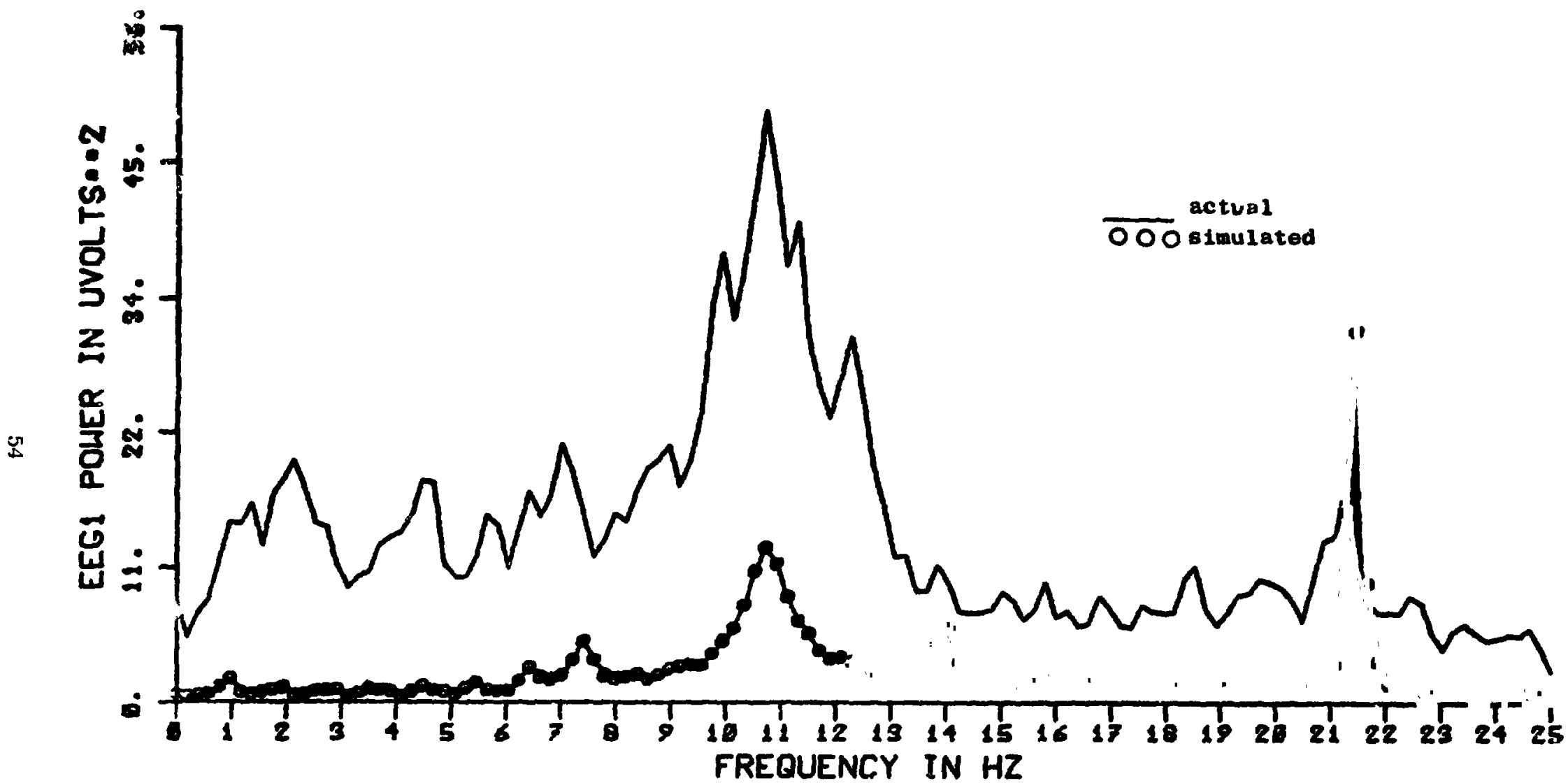

Figure 29 Actual and simulated EEG spectra during flash stimulation of $21.5 \mathrm{~Hz}$ 
Ande- 


$$
\text { Ande- }
$$


form for the excitability of the EBg as a function of phase, which explains rell the various entrainment phenomena seen in EEG datu. Detailed phase analyses are in progress which indicate that the nodel prediction is good to a first degree, but needs some revision. One possibility at this point is the existence of an excicability function at half the alpha frequency. The phase-dependency of the model response has considerable bearing on the phrse-dependency of saccade onset.

\section{Prediction of EEG Alpha Wareforns}

In order to present the visual stiruli to coincide with the sost favorable brain state and to predict the onset of saccadic eye movenent, it is necessary to have the capability to predict the EEG alpha waveforms, in particular, their phasic features. In conjunction with the EbG model, re have developed and implemented an EEG-waveform predictive scheme by using aut egressive processes. The developent and implementation of this scheme will be aescribed in detail. Our discussior. Will be centered around the modeling of EEG data by an autoregressive process and its lise for forecasting.

The itting of time-series models to EEr signals has been treated in the literature. They have been specifically applied to EEC analysis in the following areas: use for EEG spectral analysis; use of the mixed model to define certain parameters for describing the stationary parts of the EEG sigual; and use of the one-step ahead prediction error to compare two differen models. Our interest lies in the pzediction of the alpha activity in the EEG for a longer lead time.

Aithough autcregrestiv? orciesses have been used icr prediction 
of time series in general, they have nat been used for prediction of EEG datu. In those general cases, the signal or time series is assumed to be stationary. EEC signals are, in general, nonstationary. For expedience, they nay be considered piecewise-stationary; 1.e.. stationary over short intervals of time. Hence, in our application, we are restricted to linited sample lengths. This restriction creates certain problens which we shall discuss later.

To model a discrete time series $x_{i}, i=1,2, \ldots$, by an autoregressive process of order $p$, we ma: write

$$
x_{t}=a_{1} x_{t-1}+a_{2} x_{t-2}+\cdots+z_{p} x_{t-p}+c_{t}
$$

where $a_{1}, a_{2}, \ldots, a_{p}$ are the parameters of $:$ he process to be estimated and $\epsilon_{t}$ is a zcromean white Gaussizn noise. It is generally assumed that the process $x_{t}$ has zero sean; otherwise, the mear is subtracted from the entire series. In cereral, the autocorrelation tunction of an autor $z$ gressiye process consists of two conpments; viz., decayıng exponential and damped sinusoidal waveforms. It has been recognized that the real roots of the characteristic equation of the sutoregressive process, 1.e.,

$$
1-a_{1} B-a_{2} p^{2}-\ldots-a_{p} B^{p}=0
$$

give rise to the decaying expoentials and its complex-conjugate-root pairs are respr.isible for the damped siausoids in the autocorrelation function. We show in Figure 32 the autocorrelation function of an EEG sample filtere in the alpha range. It is seen that the EEG autoccrrelation function may be a.: $_{1}$ approximated by a sum of cecaying exponentials and damped sinusoits. In figure 32 , we superimpose the autocorrelation 


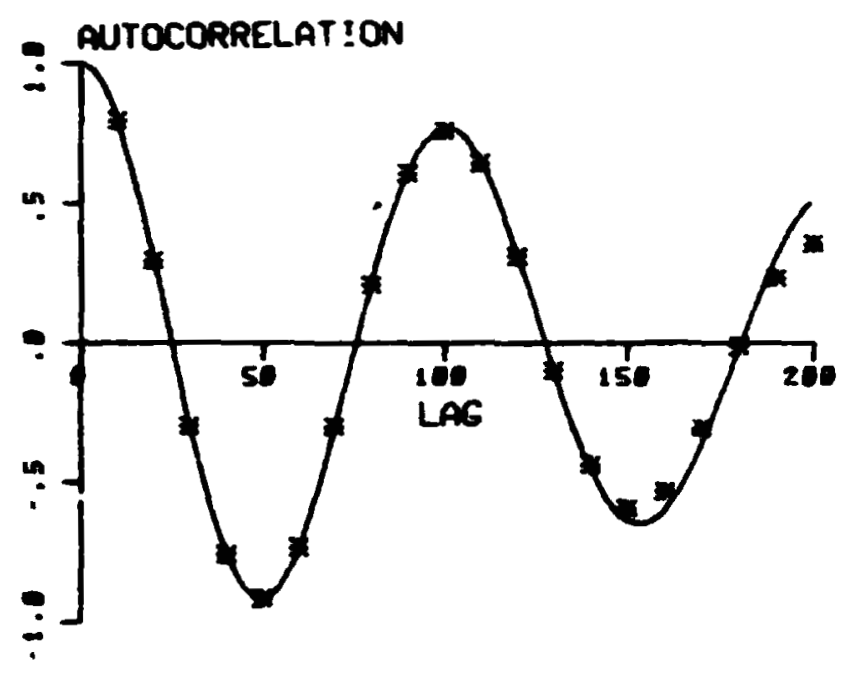

Figure 32 Autocorrelograms: solid curve from a typical EEG alpha waveform and dots from an autoregresuive process fitted to the data 


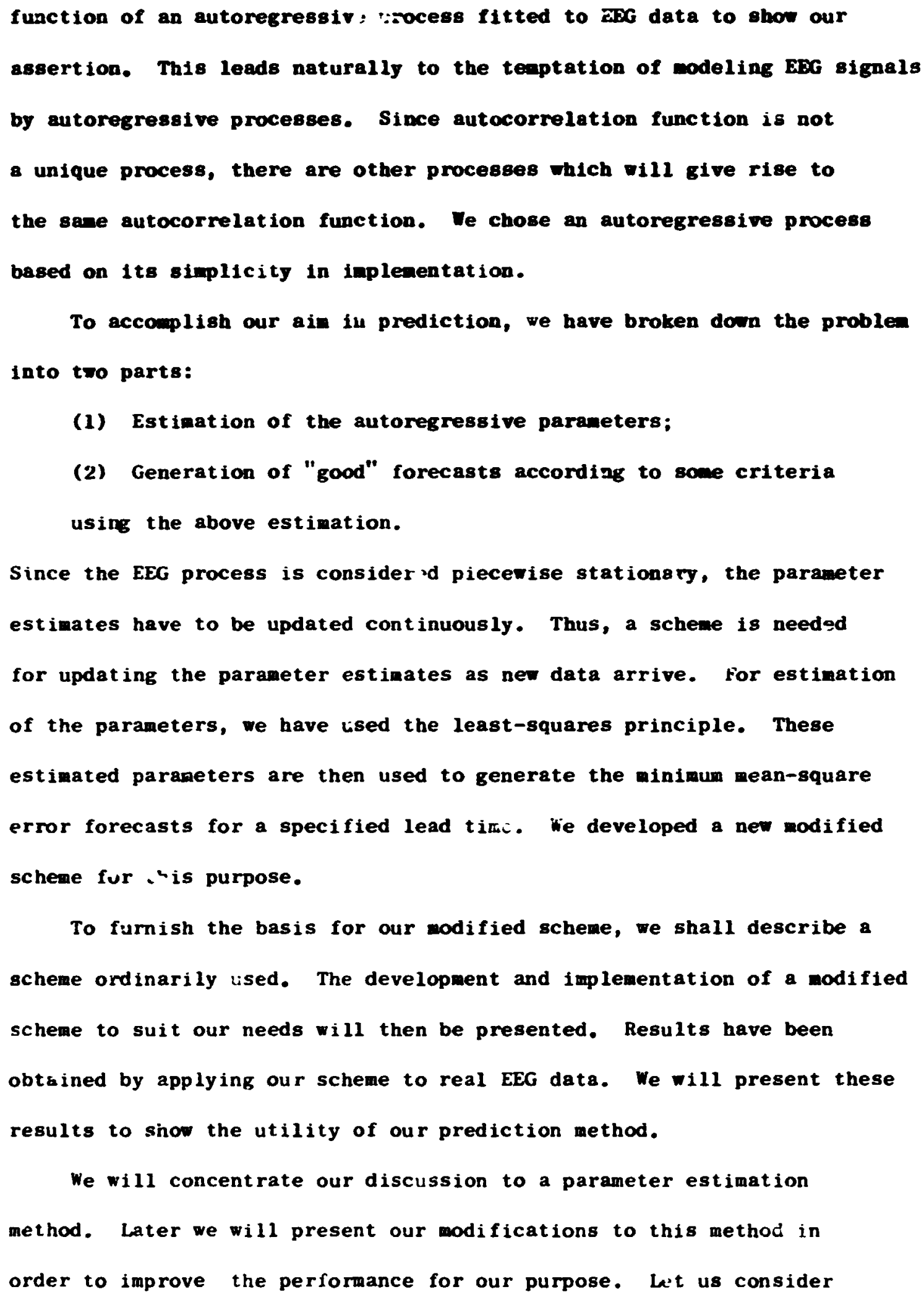


the $p^{\text {th }}$-order process

$$
x_{t}=a_{1} x_{t-1}+a_{2} x_{t-2}+\ldots+a_{p} x_{t-p}+e_{t}
$$

where $e_{t}$ is white Gaussian noise. The order of the autoregressive process $\$ s$ estinated by successively fitting wale with higher order to the data and determining when the last parameter a becomes saall enough.

The least-8quare estimates of the parameters can be shown to satisfy the following set of linear equations

$$
\left\{\begin{array}{l}
a_{1} Q_{22}+a_{2} Q_{23}+\ldots+a_{p} Q_{2, p+1}=-Q_{12} \\
a_{1} Q_{23}+a_{2} Q_{33}+\ldots+a_{p} Q_{3, p+1}=-Q_{13} \\
a_{1} Q_{2, p+1}+a_{2} Q_{3, p+1}+\ldots+q_{p} Q_{p+1, p+1}=-Q_{1, p+1}
\end{array}\right.
$$

where the $Q_{i j}$ 's are given by

$$
\begin{gathered}
Q_{11}=\sum_{i=1}^{n} x_{1}^{2} \\
Q_{1 j}=-\left(x_{1} x_{j}+x_{2} x_{j+1}+\ldots+x_{n-j+1} x_{n}\right)
\end{gathered}
$$

and

$$
\begin{gathered}
Q_{i j}=x_{i} x_{j}+x_{i+1} \ddot{*}_{j+1}+\ldots+x_{n-j+1} x_{n-i+1} \\
1 \neq 1 . j \neq 1
\end{gathered}
$$

Knowing $Q_{i j}$ 's, we solve the set of snlations to obtain the leastsquare estimates of the parameters $a_{1}, a_{2}, \ldots, a_{p}$. The leastsquare estimate of the noise variance is given by

$$
\hat{v}_{\epsilon}^{2}=\frac{1}{n}\left(Q_{11}+\left|Q_{12}, Q_{13}, \ldots, Q_{1, p+1}\right|\left|a_{1}, a_{2}, \ldots, a_{p}\right|^{\prime}\right)
$$

Previcus discusaions furrish us a numerical procedure for estimation of the parameters $a_{1}, a_{2}, \ldots, a_{p}$ and $\sigma_{e}$ in the least-square sense from the data $\left(x_{1}, x_{2}, \ldots, x_{n}\right)$. Based on this procedure, one can model 
a weakly stationary process by a ph $^{\text {th }}$-order autoregrese1ve process. Since DEG date exhibit nonstationarity, this nethod has to be nodified for our problea. Besides, our Interest is in the use of the paraneter for prediction rather than aodeling.

Having obtained the estinates of the paraneters, we turn our attention to the problen of prediction. We need a scheme wheroby the prediction can be uade for a certain lead time and then when a new data point becomes ava11able, the forecast can be updated without repeating the original process all over agzin.

We will consider here animu mean-gquare forecasts only. Denote the estination of $x_{t+l}$ obtained at $t$ ime $t$ by $x_{t+l \mid t}$. At $t i n e$ $t$, the values of the samples up to time $t$ are knom. The minimuin mean-square error forecast is given by (using the projection theorem):

$$
x_{t+\ell \mid t}=a_{1} x_{t+\ell \mid t}+a_{2} x_{t+\ell-2 \mid t}+\ldots+a_{p} x_{t+\ell-p \mid t}
$$

which provides the forecasts in the form of a difference equation. Given the samplo values $x_{t}, x_{t-1}, \ldots . x_{t-p+1}$, we can progressively calculate $x_{t+1 \mid t}, x_{t+2 \mid t}, \ldots$ by using the above equation. Using this procedure, we can generate forecasts for any lead time utilizing the parameters estimated earlier. However, the forecasts at each point have to be updated as soon as the sample $x_{t+1}$ becomes available. It is rather cumbersone to do in the above form. Hence, a different approach is required.

Instead of writing the original equation as

$$
x_{t}=a_{1} x_{t-1}+a_{2} x_{t-2}+\ldots+a_{p} x_{t-p}+e_{t} \text {, }
$$

we will express $x_{t}$ in a weighted infinite sum of $e_{t}, e_{t-1}, \ldots$ as 


$$
x_{t}=\sum_{j=0}^{\infty} b_{j}^{e} t-j
$$

where the $b_{j}$ 's can be expressed as

$$
\begin{aligned}
& b_{0}=1 \\
& b_{1}=a_{1} b_{0} \\
& b_{2}=a_{1} b_{1}+a_{2} b_{0} \\
& \vdots \\
& b_{j}=a_{1} b_{j-1}+a_{2} b_{j-2}+\ldots+a_{p_{j-p}}, j \geq p .
\end{aligned}
$$

The minimum-mean-8quare-error iorecast is

$$
x_{t+\ell \mid t}=\sum_{j=\ell}^{\infty} b_{j} e_{t+\ell-j}
$$

This form lends itself easily to updating. This can be demonstrated by $x_{t+\ell \mid t+1}$ after $x_{t+1}$ arrives. We may write

$$
x_{t+i \mid t+1}=\sum_{j=l-1}^{\infty} b_{j} e_{t+l-j}
$$

and hence

$$
x_{t+\ell \mid t+1}-x_{t+\ell \mid t}=b_{\ell-1} e_{t+1}
$$

Thus, at tine $t+1$, the forecasts for lead lengths up to $l-1$ can be easily obtained from the predicted values at time $t$ for lead lengths up to $l$ by using Eq. (5) and by recognizing

$$
e_{t+1}=x_{t+1}-x_{t+1 \mid t}
$$

This provides a convenient scheme for updating forecasts in mors data become available.

The variance of the forecast error may be easily olta 4 ned from Eq. (4). Since the $\ell$-step ahead forecast error at time $t$ i given by 


$$
e_{t+\ell \mid t}=x_{t+\ell}-x_{t+\ell \mid t}=\sum_{j=0}^{\ell-1} b_{j} e_{t+l-j} .
$$

The vartance $V(l)$ nay then be expressed as

$$
v(l)=\sum_{j=0}^{l-1} b_{j}^{2} \sigma_{e}^{2}
$$

This variance gives us a measure of the goodness of 1 it for the model. Since we heve assumed the $e^{\prime} s$ to be normal, the conditional probability density function $p\left(x_{t+\ell} \mid x_{t}, x_{t-1} \ldots\right)$ is normal with mean $x_{t+\ell \mid t}$ and variance $V(\ell)$. Based on this information, we can obtain confidence intervals for the forecasts. For example, $95 \%$ of the normal distribution mass lies within $\pm 1.96 \sigma$ of the mean where $\sigma$ is the standard deviation. Hence, $x_{t+\ell \mid t} \pm 1.96 \sqrt{v}$ is the $95 \%$ confidence interval for the forecast, i.e., the probability that the actual value will lie in that range is .95

The previous formulation gives the forecasting procedure to predict values \& samples ahead from any time $t$. In order to increasc the lead time for forecasting, one has to increase the value of $l$. It is, however, evident from Eq. (6) that the error variance becomes larger as $\ell$ increases and the confidence interval for a given level of confidence will also increase accordingly. Another way to increase the lead time would be to increase the sampling interval and thus keep the value of $\hat{l}$ as low as possible so that the level of performance of the predictor may be maintained. However, the sampling rate or sampling interval for a signal is determined by the bandwidth of the signal. If the signal is furnished in digital form, then one has little cloice in altering the sampling interval. Cne could, of course, 
increase this interval by dropping every $k^{\text {th }}$ block of data points. In any event, the increase in sampling interval means reduction in the number of data points in a given interval of tine. This reduction in data points leads to a higher variance for the estinates. Besides, the number of data points ay be 80 much reduced, since the EEG aignal is considered stationery only for a short period of tin?, that the esting tes are not statisticeing significant. For these resons, we iffut y.jate the autoregressive model in a more general form as

$$
x_{t}=a_{l} x_{t-k}+a_{2} x_{t-2 k}+\cdots+a_{p} x_{t-p k}+e_{t}
$$

which, when $k=1$, reduces to the case discussed earlier. Th: ,

equivalent to an autoregressive model for the time series

$$
\left(x_{t}, x_{t-k}, x_{t-2 k} \cdots\right)
$$

i: e least-square estimates of the parameters can be obtained by a logical extension of the earlier results; viz.,

$$
\begin{aligned}
& a_{1} Q_{22}+a_{2} Q_{23}+\ldots+a_{p} Q_{2, p+1}=-Q_{12} \\
& a_{1} Q_{23}+a_{2} Q_{33}+\ldots+a_{p} Q_{3, p+1}=-Q_{13} \\
& \vdots \\
& a_{1} Q_{2, p+1}+a_{2} Q_{3, p+1}+\ldots+a_{p} Q_{p+1, p+1}=-Q_{1, p+1}
\end{aligned}
$$

where the $Q_{i j}$ 's are now redefined as

$$
\begin{gathered}
Q_{11}=\sum_{i=1}^{n} x_{i}^{2} \\
Q_{1 j}=-\left(x_{1} x_{(j-1) k+1}+\ldots+x_{n-(j-1) k} x_{n}\right) \\
Q_{i j}=x_{(1-1) k+1} x_{(j-1) k+1}+\ldots+x_{n-(j-1) k} x_{n-(i-1) k}, \\
i \neq 1, j \neq 1 .
\end{gathered}
$$

The least-square estimates are the solutions of this new set of equations. 
The forecast equations are modifield in a similar manner to give

$$
\begin{aligned}
x_{t+k \ell \mid t}= & a_{1} x_{t+k(l-1) \mid t}+a_{2} x_{t+k(l-2) \mid t}+\cdots \\
& +a_{p} x_{t+k(l-p) \mid t}
\end{aligned}
$$

and Eq. (4) becomes

$$
x_{t+k \ell ! t}=\sum_{j=\ell}^{\infty} b_{j} e_{t+k(\ell-j)}
$$

with the $b_{j}$ 's defined in terms of the $a_{j}$ 's as before. In essence, the scheme processes the available data in such a regrouped fashion by resampling the data in $k$ multiples of the origina) sampling interval that the level of performance is not degraded. The performance of this scheme $0 . \quad r$ data will be discussed next. The usefulness of the scheme is demonstrated by our results.

We developed a computer program to implement an algorithm for recursive estimation of parameters and forecast of future values by using the new modified scheme. The program was written in FORTRAN for a PD-15 computer. As an example for illustration, we applied our scheme to real EEG data, which were recorded while the subjects with closed eyes were stimulated by stroboscopic flashes for 50 seconds at the rate of 10 flashes per second, then no stimulation for 50 seconds, then inother 50 seconc's of stimulaticn, etc. The signals were sampled at an interval of $1.2 \mathrm{msec}$. Since we are mainly interested in the alpha component of the EEG, the data were filtered to obtain the components around the alpha range (7-13 Hz) through a transversal filter. The computer program reads .hIs EEG data as its input. Other required information such as the number of sample points $N$ for which the process is considered stationary, the order of the process $p$, the resampling 
value $K$, the prediction lead length $L$ and the window widh NWD for updating the paraneters are also read in as input. (For efficiency, the paraneters are not updated with each new data point, but only after MWN new data pointe have been read in.) A flow chart of the program 18 shom in Figure 33. As soon as the above variabies and the initial N points are entered, the program computes the least-square estimates of the parameters by solving the set of linear equations (7). The error variance $\sigma_{e}^{2}$ is also estimated. These estimates are then used to generate inimum mean-square error forecasta up to $L$ steps anead; i.e., forecast of $t+K L$ is obtained at time $t$. The variance of the forecast errors and the confidence interval for a certain eignificance level are also calculated. At this time, the next data point is read in; the residual is calculated as the difference between the actual value and the forecast; and the forecasts for the remaining points are updated by using Eq. (5). A new forecast for the value $L$ stops ahead is produced. Th1s process is repeated until NWND new points have been exhausted. The procedure will repeat again starting with the recalculation of the parameter estimates. Results of the jrediction for various lead times are shown in Figures 34 through 38. In order to compare the predicted waveforms with the actual EEG, we plotted the predicted waveforms and then superimposed the actual EEG on top of them. The order of the sutoregressive process was chosen as $p=7$ by examining the partial autocorrelation function of EEG data for $k=10$. The effective lead time in seconds $1 \mathrm{~s}$ $k \ell T$ where $T$ is the sampling interval and $\ell$ denotes the lead time in number of samples. In Figures 34 through 38, the waveforms were 


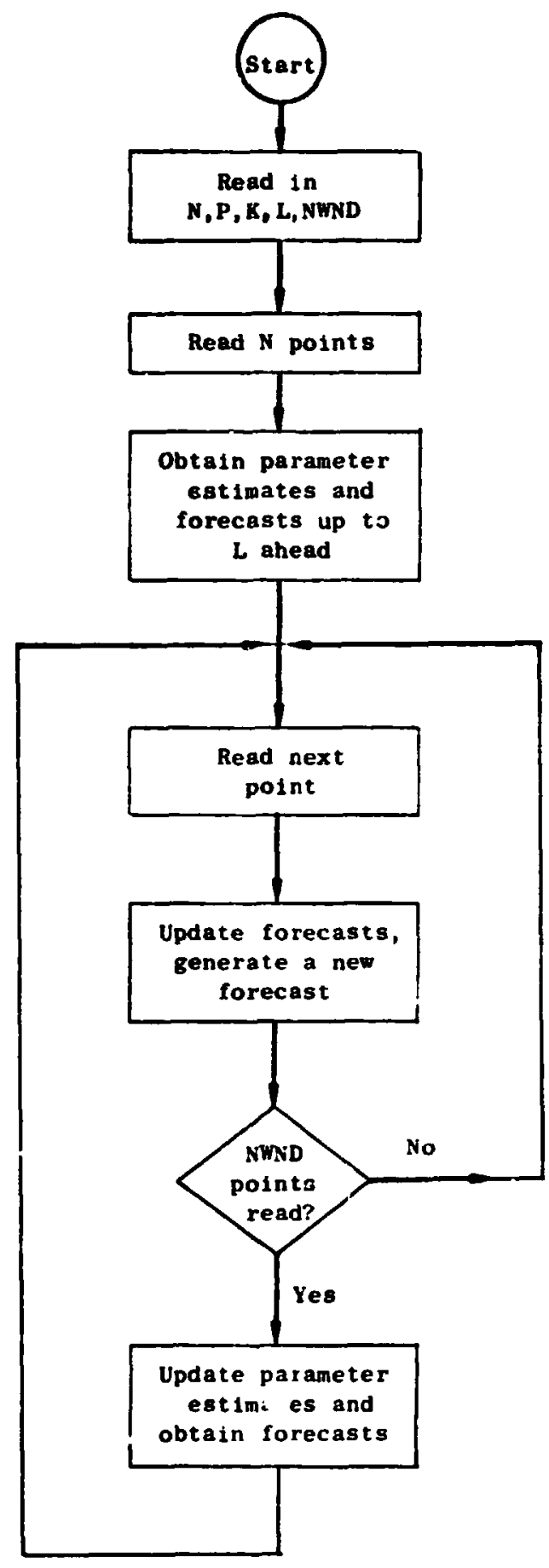

Figure 33 A flowchart for the realization of the prediction scheme 


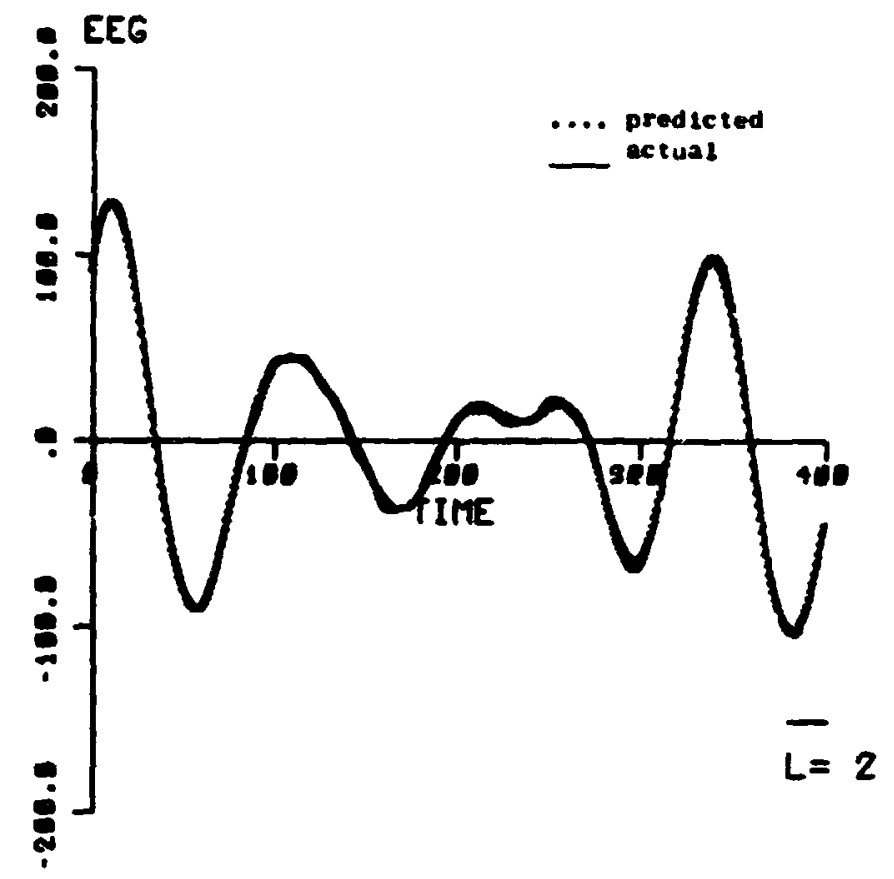

Figure 34 Actual and predictsi waveform for lead $t$ ime of $24 \mathrm{msec}$.

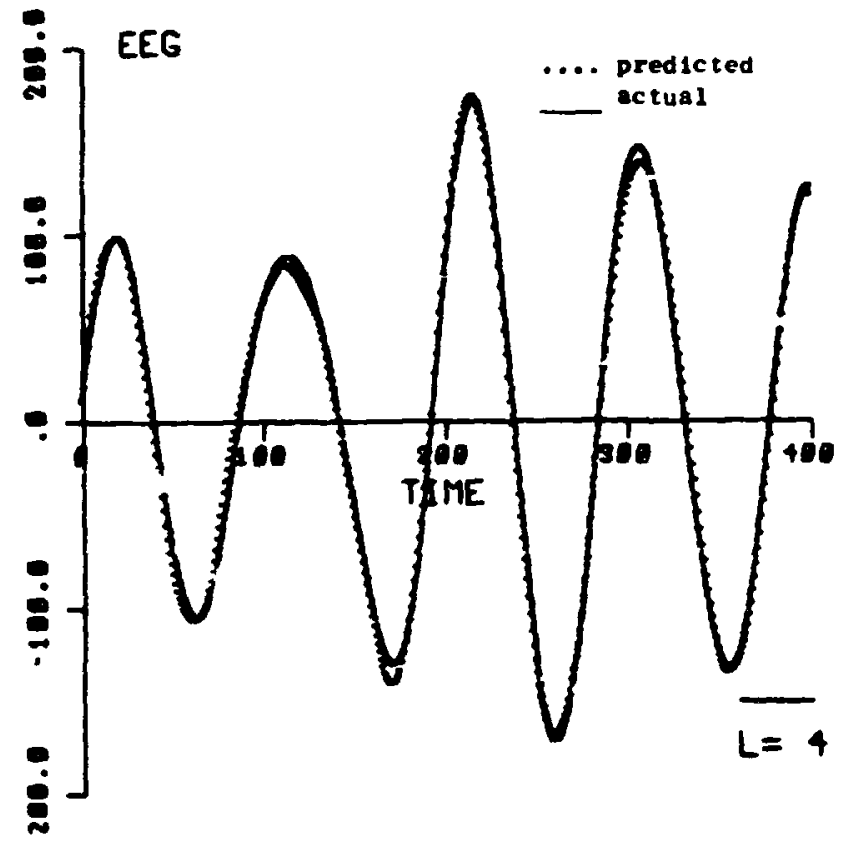

Figure 35 Actual and predicted waveform for lead time of $48 \mathrm{msec}$. 


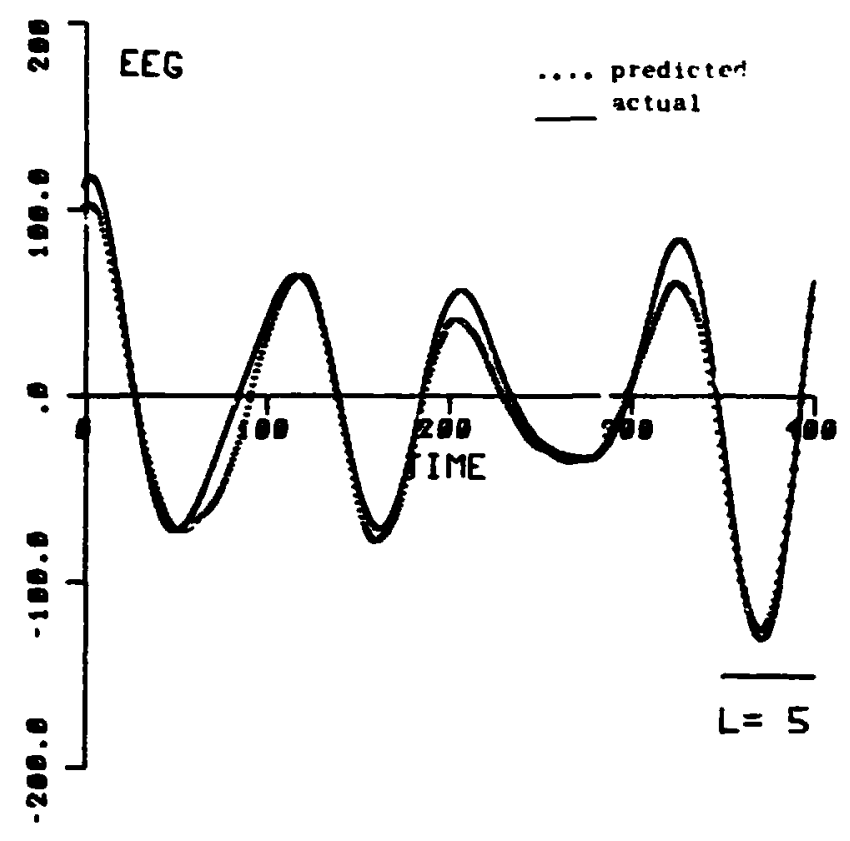

Figure 36 Actual and prodicted wave form for lead time $160 \mathrm{msec}$.

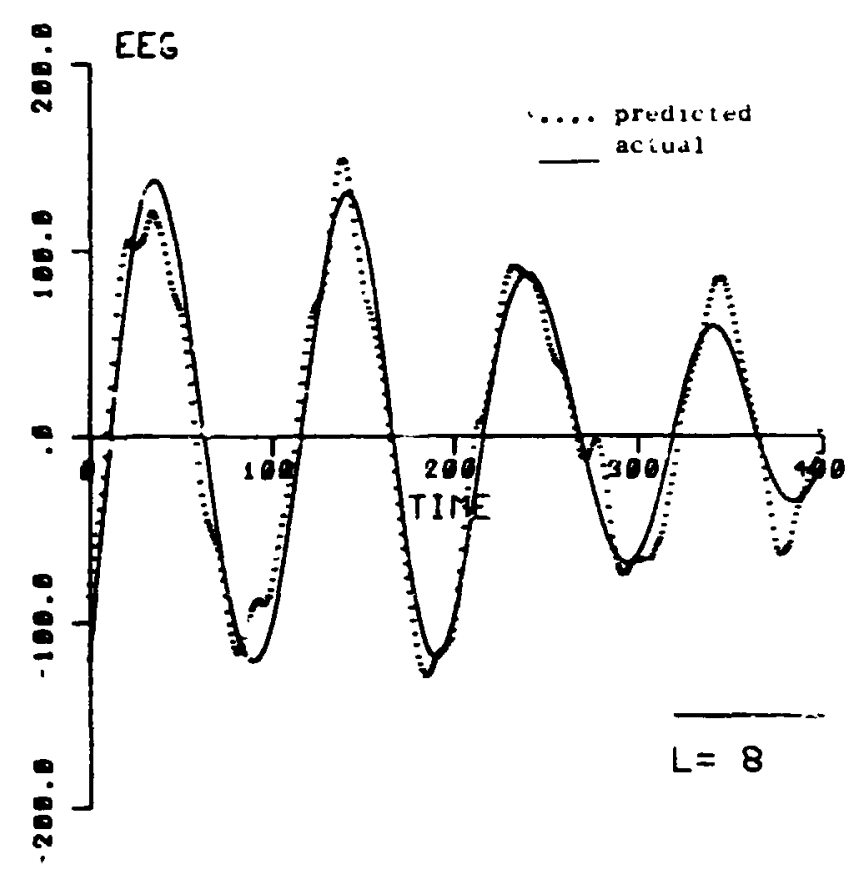

Figure 37 Actual and predicter wave form for lead lime of 96 issec. 


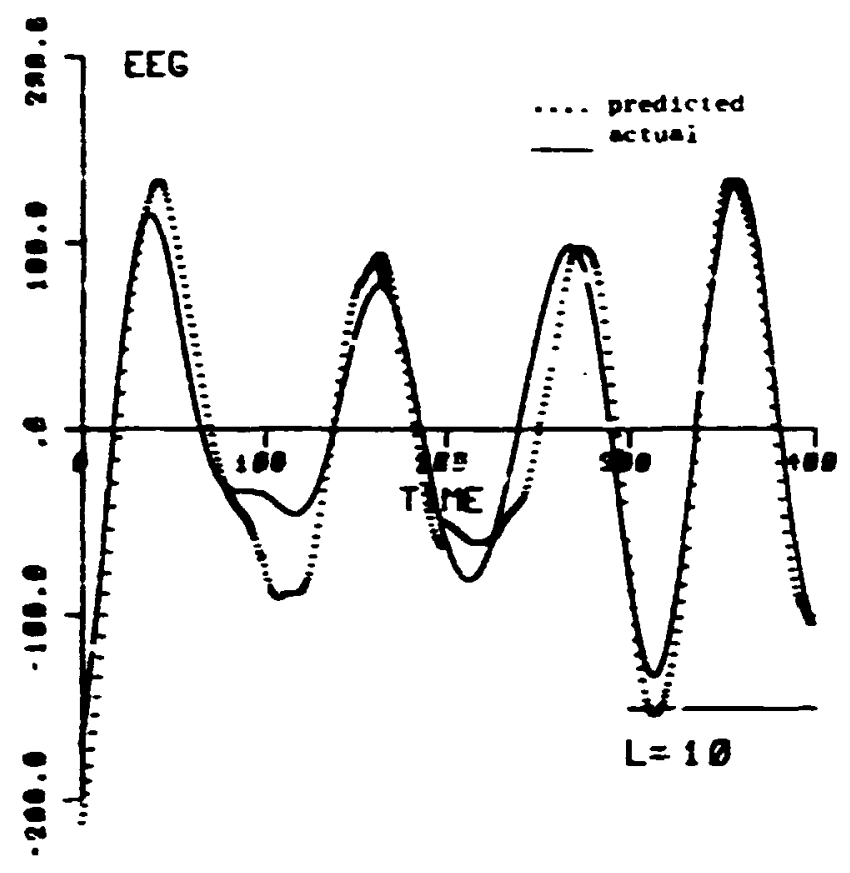

Figure 36 Actual and predicted waviform for lea: $t$ ime of $120 \mathrm{msec}$.

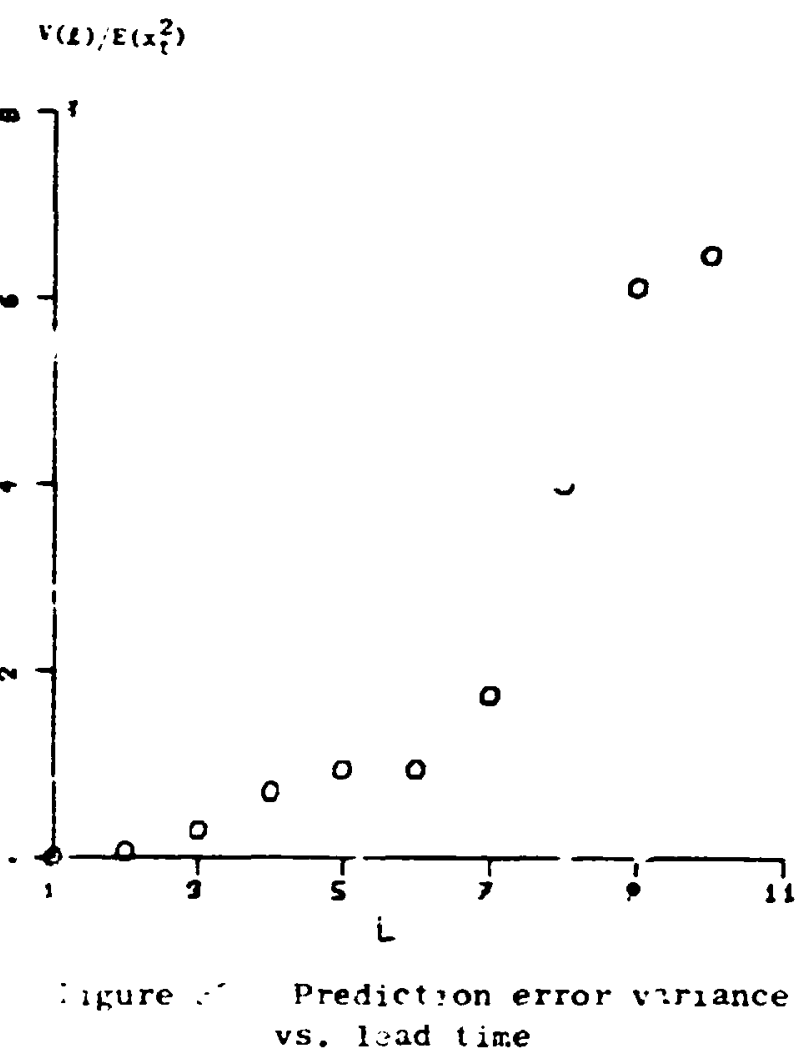




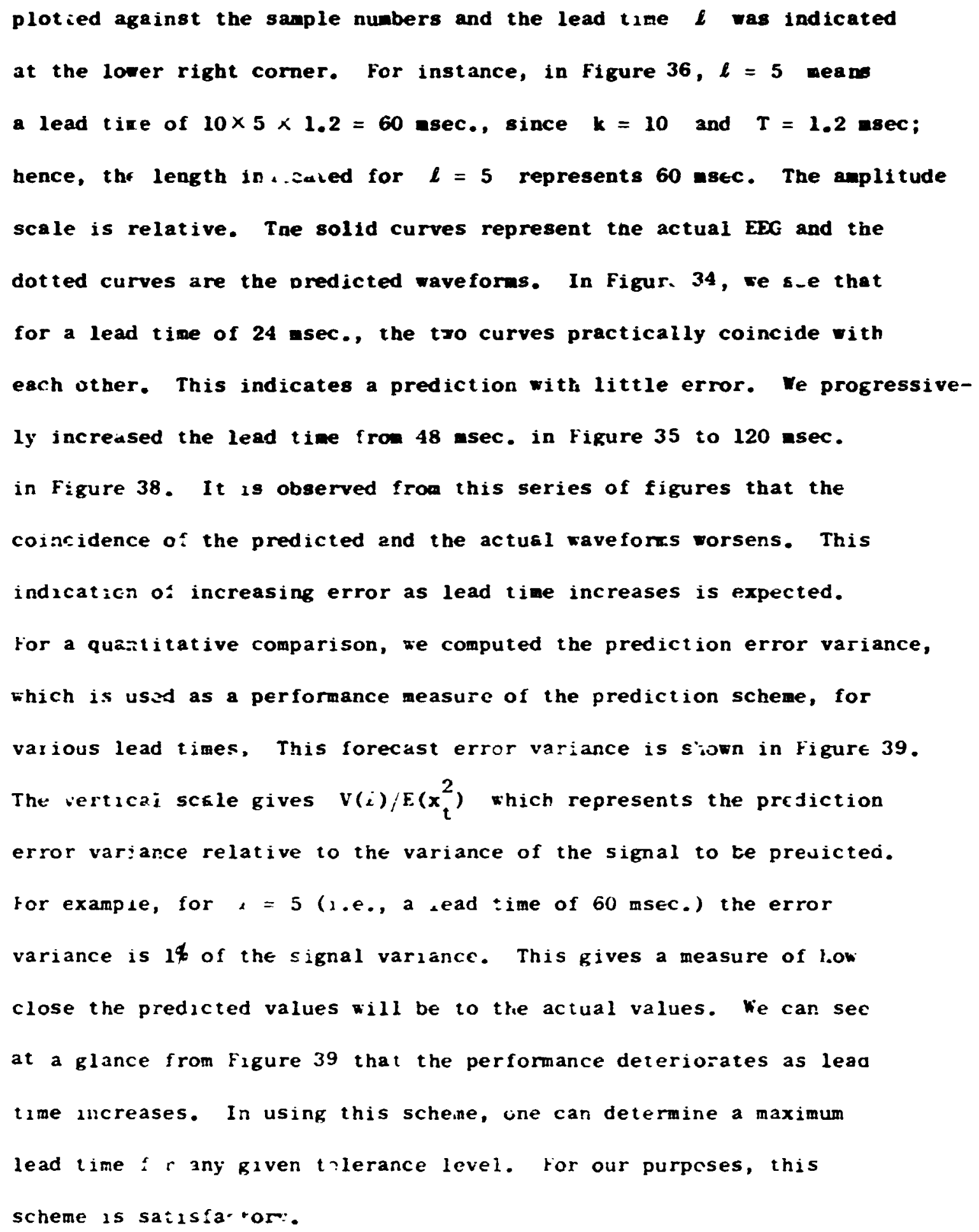




\section{CHARACTERIZATION OF SCAN PATTEKNS}

One of the important aspects of the research done in this project has been the development of techniques and tools for the automatic analysis, characterization and display of scan patterns. In visual tasks, the sequence of fixations used in scanning the visual carget is called the "scanpath", and we will refer to a "scan pattern" as a collection of information abmut the properties of one or more scanpaths recorded by one or several different obsezvers. Naturally, to be able to differenti..te a superior scan pattern which results in superior visual memory from an inferior one, we must first be able to characterize a scanpath in some terms other than just a list of $(X, Y)$ fixation coordinates.

A gramical i:'ustration of a sequence of the foveal fixations is shown in Fugures 40 and 41 . Figure 40 shows the outline drawing of a still life scene whych was laspected by a subject with his scanpath superimposed. In figure $t 1$ we have plotted aketch 0 : the visual stimulus impressed on the fovea for cach fixation point shown in Figure 10 . The sketches show a visual field of $6^{\circ}$ in diameter, $a$ region which includes all of the tovea under practically any definitisn. These drawing, then, represent i tike sequence of snapshots which are the v:sual input to the ooserver who must create a inified picture of the scene being viewed Irom the sequence of picture fragments shown in the sketches.

One observation which ias eften been made is that the fixatian poin's tend to be urouped around certain leatures or areas of the visual imakc, and are relatively sparse elsewhere. Trus, we can measure 


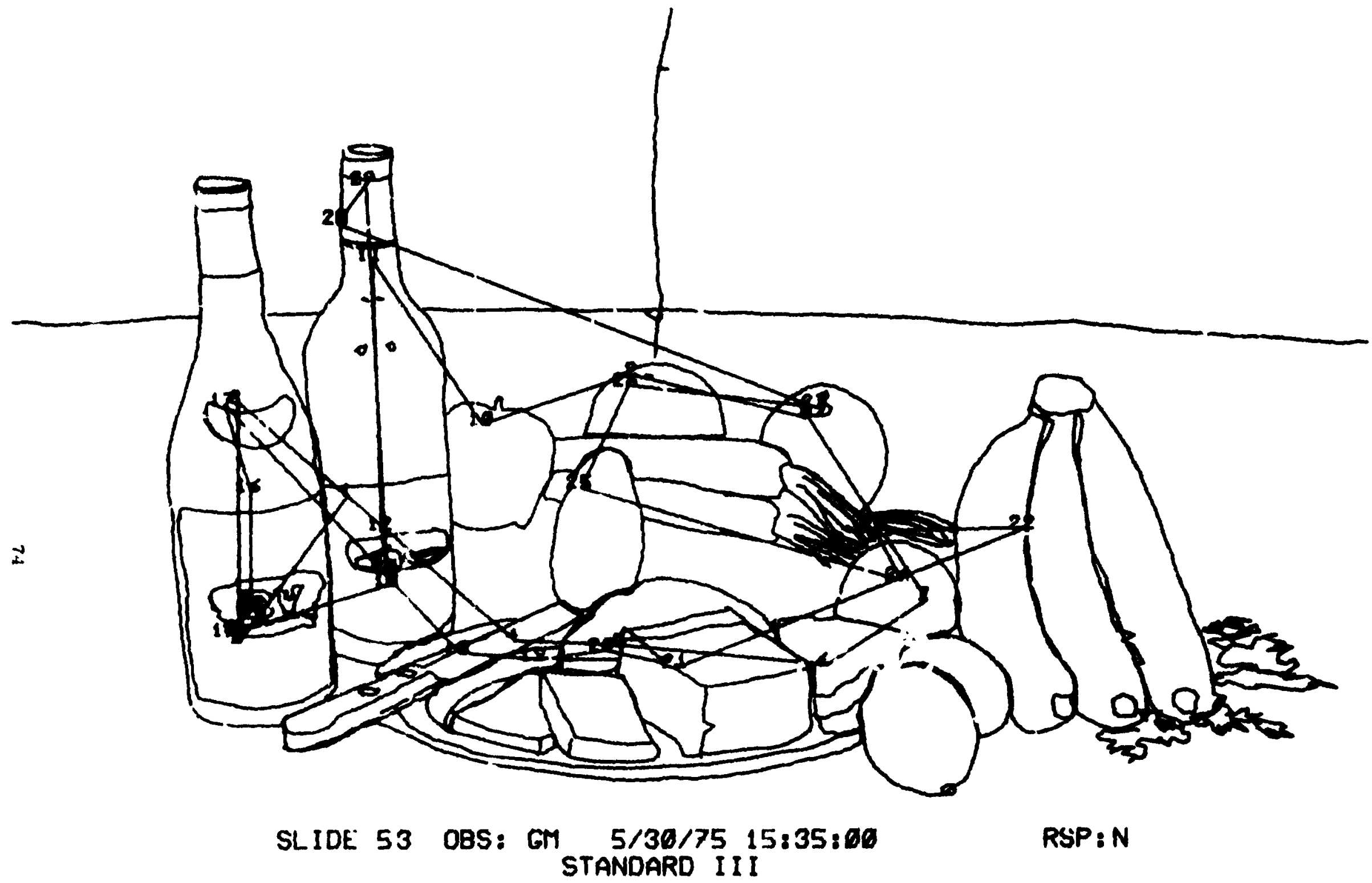

Figure 40 Computer derived scanpath superimposed
on sketch of original scene 
RET INAL. PLOT - 3.0 DEG. DIAMETER FIELD

1

to

6<smiles>CC12CC3CC4CC5C(C1)CC(C4)(C3)C5C2</smiles>

11

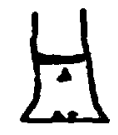

16

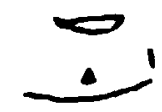

21

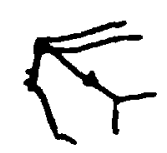

26

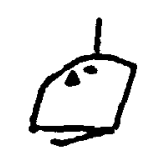

2

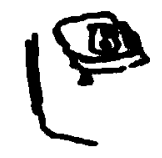

7

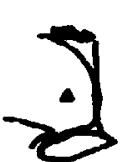

3

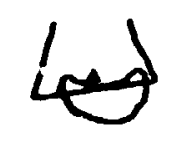

8<smiles>CC1C2CC3CC(C2)CC1C3</smiles>

13

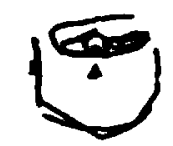

18

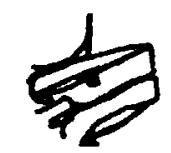

23

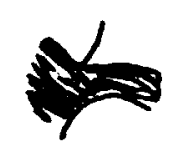

28

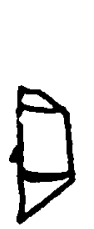

4

5

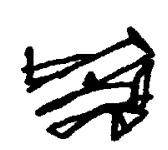

9<smiles>[131IH]</smiles>

14<smiles>C1CC2CC1C2</smiles>

19

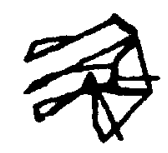

24

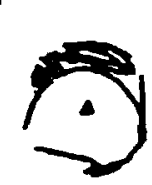

29

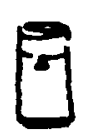

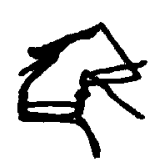

19<smiles>CCCCCC</smiles>

15

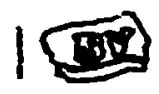

20<smiles>C1=Cc2cccc(c2)C=C1</smiles>

2.5<smiles>Cc1ccccc1</smiles>

30 


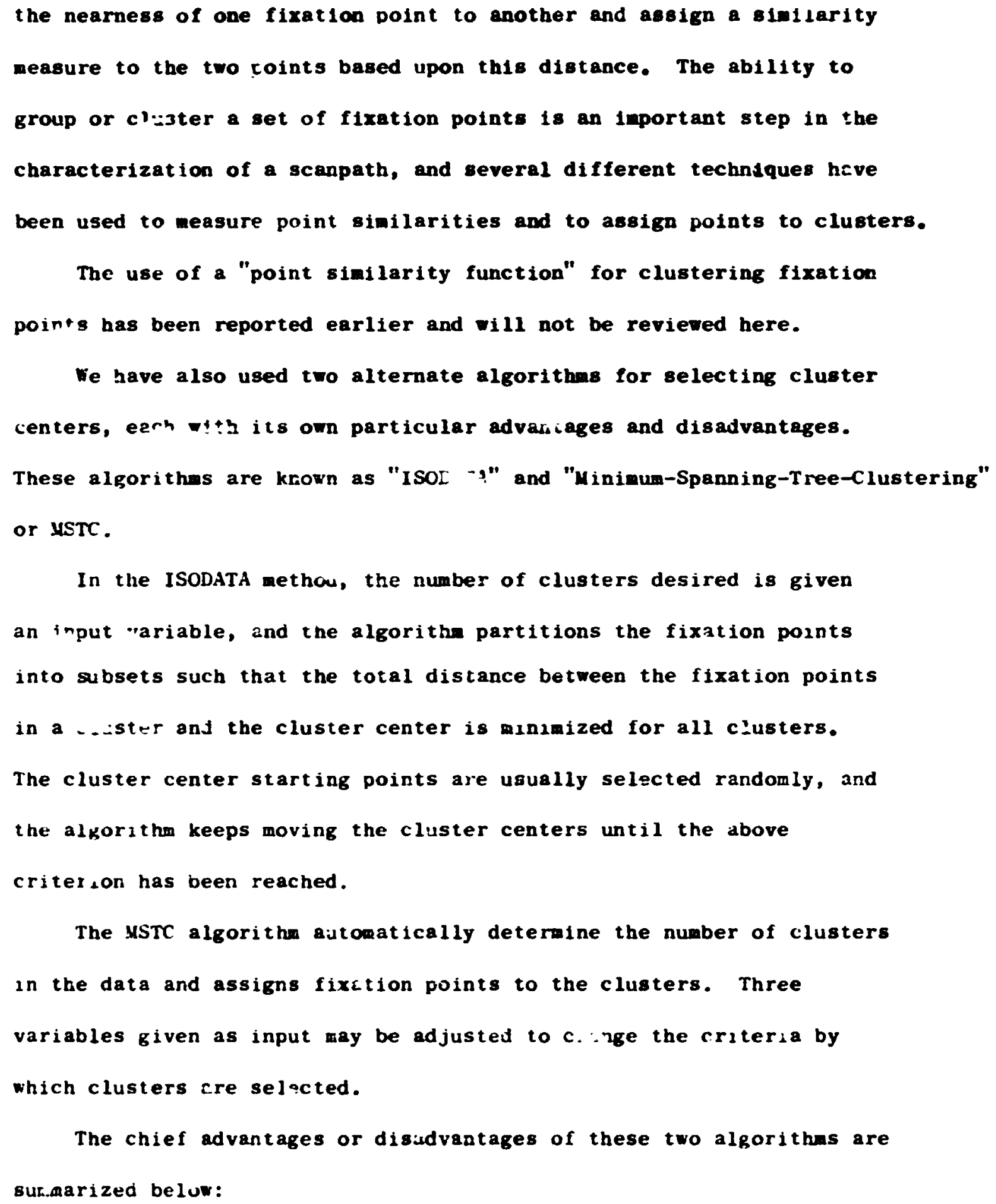


ISODATA

(1) Requirod the desired number of clusters, which usually is not known.

(2) Solutions often are not unique, but vary with starting conditions.

(3) The iterations can require a substantial amount of computing.

(4) Many points can be easily accomodated.

MSTC

(1) The solution is unique, and the number of clusters is automaically determined.

(2) The computation is quite fas:.

(3) Nany points requires a large amount of storage.

Our approach to characterizing scan patterns is based on

the following two assumptions:

(a) There are a discrete number of "fixation ceniers" in the scene being viewed and each fixation point in the scan can be assigned to one of the fixation centers. This process of assignment or clustering is done using the MSTC algorithr. described above. The center of the clusters should be in close agreement with tine centars of the fixation. Due to the random nature of the fixation points, in any repetition (cycle) of the eanpath, the fixation po:its do not always coincide.

(b) A scanpatin then becomes a sequence of transitions from one cluster center to another. Any saccade with starting anc ending points in the same cluster is discardei. 
From the set of all saccades leaving a given cluster center, we can find the transition or transitions wich have the highest probability. These transtions are termed the "most-probable-saccades". The "mostprobable-scanpatn" is then defined to be the set of all most-proublesaccades. The most-probable-scanpath depends on how the clusters are chosen, and is not necessarily a closed path through the cluster centers. Its usefulness is that it concisely sumarizes the most important aspects of the scanpath ueed by the observer in viewing the given visual target. A scan pattern is some set of sost-probable-scanpaths for a given observer viewing the same ur different targets, or for several observers viewing the same target, etc.

Figures 42 and 43 illustrate how these methods may be employed to reduce scanpath data to a more concise form. Figure 42 is a graph of a scanpath superimposed upon a line drawing representing the still life scene which the observer was viewing. The first recorded fixation (1) is in the center of tre avocado. The last fixation (45) is in the $m$ Idle of the carrot. The viewing time required to create this scan totaled 20 seconds. Figure 43 represents the same data after processing by the MSTC program. The program partitioned the fixation points irito 11 subsets or cluster:i (using certain criteria supplied by the programer) and then comou ed the most likely transitions from cluster to cluster. Clusters contain.ng only one fixation point were ignored. The resulting plot shows the most likely saccades between areas containing large numbers ol flxations, and pres ta the orlicial data 2n a highly condensed format.

In ordur to compare one set of fixdt $*$; or one scanpattern 


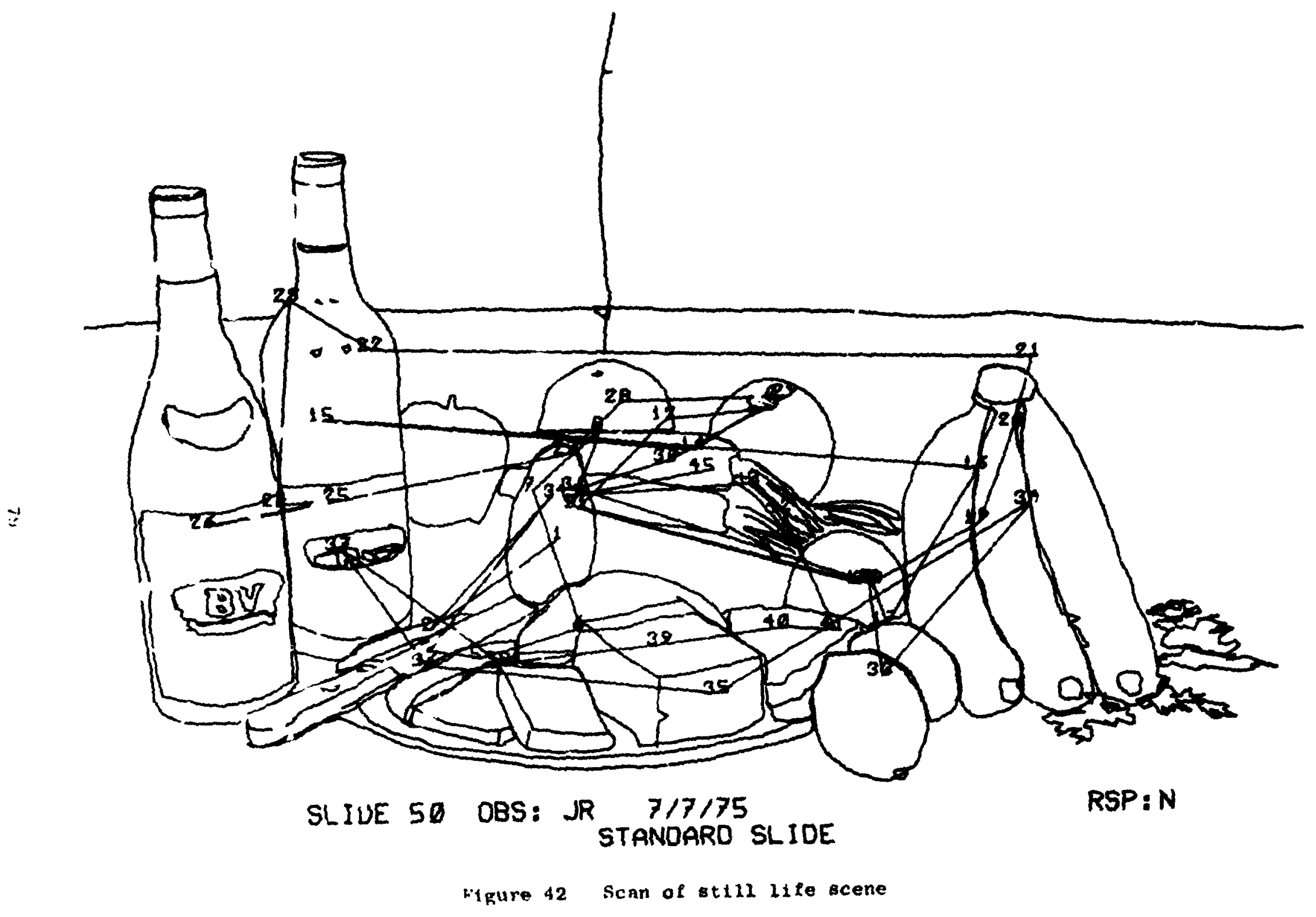




$$
\text { to }
$$


against another, criteria must be established which can be used to evaluate subtle differences in the following characteristics:

(1) Total number of clusters - The MSTC algorithm partitions

all the fixation points into some number of clusters, very rarely will the number of clusters in two different scans be the same. Rules must be established for eliminating or merging clusters which complicate the analysis. For example, clusters containing a single point can usually be removed.

(2) Similarity between clusiers - The geometrical center of two clusters will usually be different, and yet it may seem obviuus that both clusters are associated with or centered on some feature of the picture.

(3) The most probable saccades between clusters will often be different in two scans, even if the cluster centers are nearly alike. The similarity of two scans is judged by their transition probabilities.

The above criteria are dependent upon the type of ensariment being run and no fixed set of rules will te suggested here. Based on the above criteria and using statistiral methods, we are able to show from our preliminary results that the scan patterns of the same visual material by the same subject who scored very high on Marks' Visual-Menory Task are consistent. 


\section{TECHNIQUES FOR THE PRESENTATION OF VISUAL CUES}

The measurement and prediction of eye movements and ralated EEG potentials are necessary prerequisites for the control of visually displayed material which can enhance an ouserver's perception or memory of a scene or visial environment. This section describes some means to couple the measurement of eye movements with the control of a computer-driven graphical assplay.

The task undertaken was to provide a facility for dynamically controlling the toveal or peripheral field of view of an observer. Such a tacility rould provide a llexible method for studying interaction between eye position and ghanges in the visual field. Some of the objectives of this research are:

(a) to wevelop techniques for dynamically controlling the visual field in humans $u_{1}$ thout any restrictive mechanical attachment to the eye;

(b) to obtain a subjective feeling for perception without use of the normal visual field; and

(c) In quantitatively measure changes in the observer's performince (and scanpath characteristics) as a functior of field size and type. The system works as lollows: At the start of each refrest. of the display (30 times per serond), the position of the eye is measured and the corresponding point on the display is computed. Parameters within the frogram determine what portion of the visual lield will be displayed-lovea only, periphery only, and the size the field in eltiver case. Then, each point in the display list is checked, and if it is wittin the 
required fleld, it is displayed. Figures 44 and 45 depict the stimulus for the two modes of display. The box (which was used instead of a circle to simplify computatinns) remains centered oi the fovea, no watter where on the screen the observer 100ks.

The visual scenes used in these experiments were outline drawings of simple, still scenes. No text or highly detalled pictures were involved. A new scene could be entered lito the computer through use of a graf/pen digitizer. Once entered, the points in the picture were stored by $X, Y$ positirn, and a display list was created for iater use by the real-tine inte;active program.

Af: $=$ - adjusting the eye tracker and calibrating the instrument, the observer would be presented with a field of view which could be either a fovea-only presentation or a periphery-orly presentation. The size of the field (width of box boundary) was also adjustable, from less than one degree to the maximum width of the displas. Use of this program has produced, so far, these results:

Impaired perception for fovea-only vision - If only a two or three degrec wide foveal field is displayed (when the display \pm tself spans twenty or more degrees), the observer finds it difficult, if not impossible, to perceive the display. What the cbserver seed are short line segments, and somelimes junctions letween line segment: rhe only way to perceive an object is to consciously follow the contours and mentally reconstruct the path followed. Simple objects take several minutes to dztect, lew observers get a complete idc of tha entire scele. Far more use of peripheral visual inform.:ion, made than was anticipated. Large 


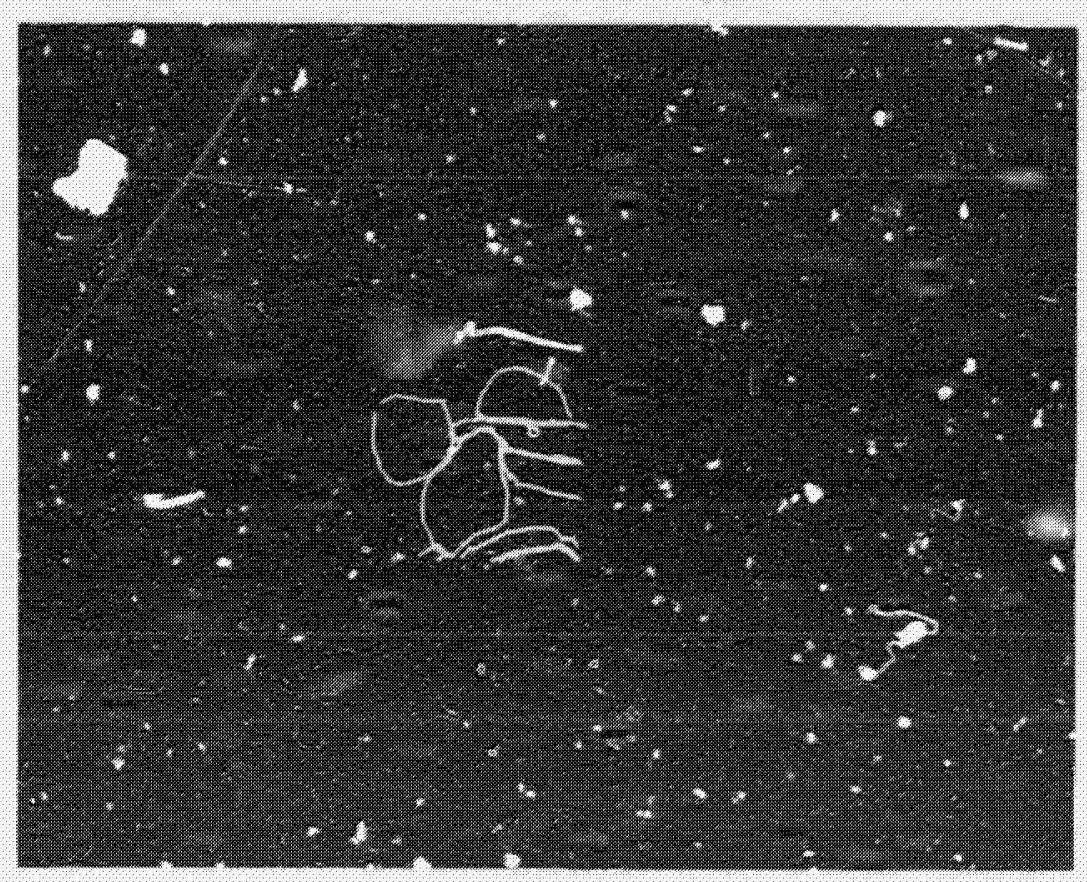

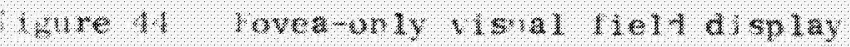

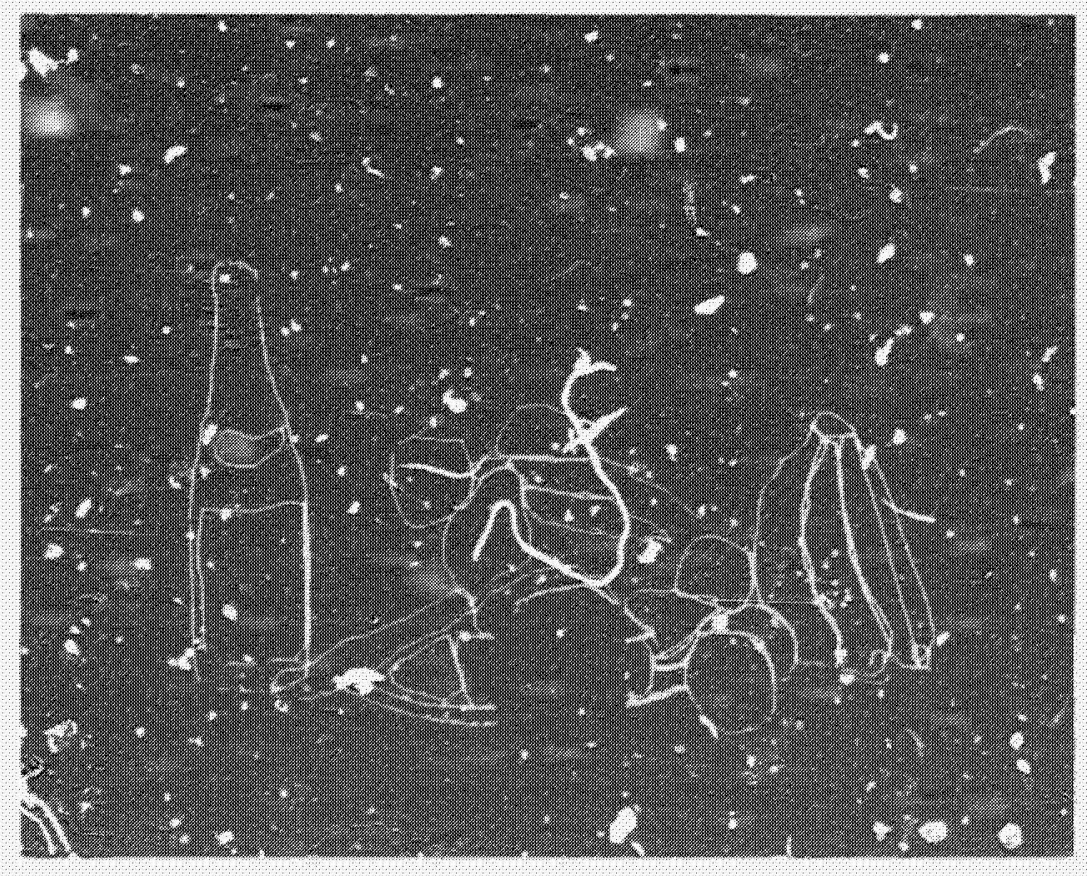

Thure th lertpherat vasual lield alspluy 
saccades must be forced, and the observer becomes very conscious of having to manipulate his own eye movements.

Perception with peripheral vision - If the foveal region is blanked, litie perceptual loss occurs until the windor size approaches roughly 10", that is, the scenc is still nerceived even when the windor is gi:ite large. Our stimuli did not include text or other naterial where high visual acuity was essential. This result is sonewhat surprising in view of the general assunption of the ipportance of foveal-high acuity field. The peripheral field apparently makes an important cor. ribution to the orerall percedtion of a scene, even the visual acuity ay be quite low in the outer regions.

I-portance of closed contours - If the fovea-only visua: field is being displayed, little improvement in perception of objects within the field occurs uncil the windor size is large enough to include the complete, closed contour of an object. The absolute size of the fovezl region seems to be less important than the fact that complete objects are visible, at least, $r$ the line drawings we used. This result supports another observation we have made, which is that fixations tend to be centered on the main surfaces of a simple object, and are not as often t-iund on the edges or corners of the object.

Appearance of a phaniom window - After about ten seconds of viewing, and especially for the fovea-only condition, a phantom window with pronounced frey-black edges appears. The subject sees a grey background ith a black window clit in the center, through which the white lines may be viewed. The window, of course, is fixated on his eye lik. an alierimage. 
Two causes for the rindor are evident. Only the foveal region receives stimulation, and the rods and cones adapt to a higher ambient light level than in the periphery, which adapts to "visual grey". Also, the sharp truncation of many contours along a straight line reinforces the perception of an edge. Similar effects have been noted before by Yarbus.

These preliminary experiments with an eye-movement controlled visual display have proved quite interesting and useful. The next step is to incorporate the predictive algorithms discussed in other previous sections of this report to present the visual zues at the desired locat:ons of the visual field at the desired moments. 


\section{vi. coscunsioss}

Our aim has been to develop and use bioc-bernetic techniques for tre enhancement of visual memory. To this end, re have designed a closelycoupled man-machine system for implementation. We have developed and completed the models for saccadic eye movements and EEG signals in this man-machine systen. The models are used for monitoring and prediction of eye positions and urain states. $w_{1}$ th the continuously up-dated information concerning the eye position and brain state for adjusting the stimulus parameters and the monitoring and prediction schemes, re can guide the eyes to fixate at the specified locations of the visual field at the specified instants oí time through a technique we developed. If these specified locations and instants are the optimally required for superior visual memory, then the vividness and persistence of the desired after-image $x$ ill be enhanced. He have approached the problem of determination of these optimal locations and time instants by monitoring e: movcments and HEG signals through the models ahich we have developed. Through the FEG model, we nave obtained a better assessment of EEG's role as the ining mechans sm for visual information acquisition and processing. Fic have also shown that the scan pattern is more consistent for Individuals with good visual memory (as scored by arks' visual-lyemory Task) than those $\mathrm{x}$ ith poor visual memory. This comparison is made possible by our method of characterization of scan patterrs. With these results, It is possible to determine the optamil locations in the visual field and the optial time instants for presen: int visual stimuli. He conclude 
that the approach for visunl memory enhancenent as proposed is a feasible one. At the termination of this project, ve have inplemented all of the parts shown in the closely-coupled man-machine system but the feedback path.

Significant accomplishments made during this research have been published or presented in international or national scientific conferences and tro Ph.D. dissertations are sear completion. 
APPEXDIX A

:s:a) 
APPENDIX A

ELDTRONIC INTERFACE SYSTEM

We shall describe here the interface system for eye-movement data acquisition only. We are presently using a double Purkinje image eye tracker developed at Stanford Research Institute (SRI) for measuring eyc movements. It relies on measuring the motion of the reflections from the froct surface of the cornea and from the back surface of the lens of the eye (the first and fourth Purkinje images). The instrument is discussed in an article: "Accurate two-dimensional eye tracker using firs: ind fourth Purkinje images", by T. X. Cornsweet ard H. D. Crane in the Joumal of the Optical Society of America, yol. 63, no. 8, pp. 921-928, August, 1973. Figures $A .1$ and $A .2$ show the set up of this eye tracker.

The first ard fourth Purkinje images are generated by positioning a narrow beam of infrared light on the subject's pupil. The image of the eye and its attendant Purkinje image reflect of the infrared mirror in front of the subject, through two large collimating lenses and on to a movable mirror. A four-quadrant photodetector senses the position of the first Purkinje image. Signals from these four quadrants are used to drive two nigh-speed servo motors to detect the movable mirror in altitude and azimuth. The function of this servo system is to position the image of corneal reflection when the eye moves so that the reflection is always in the same position; thus, a stable reference of the eye is provided. As the eye moves, the image reflected by the movable mirror will remain stationary. A second optical system in tandem consisting of ar.other movahle mirror and quadrant photodetector tracks the fourth 


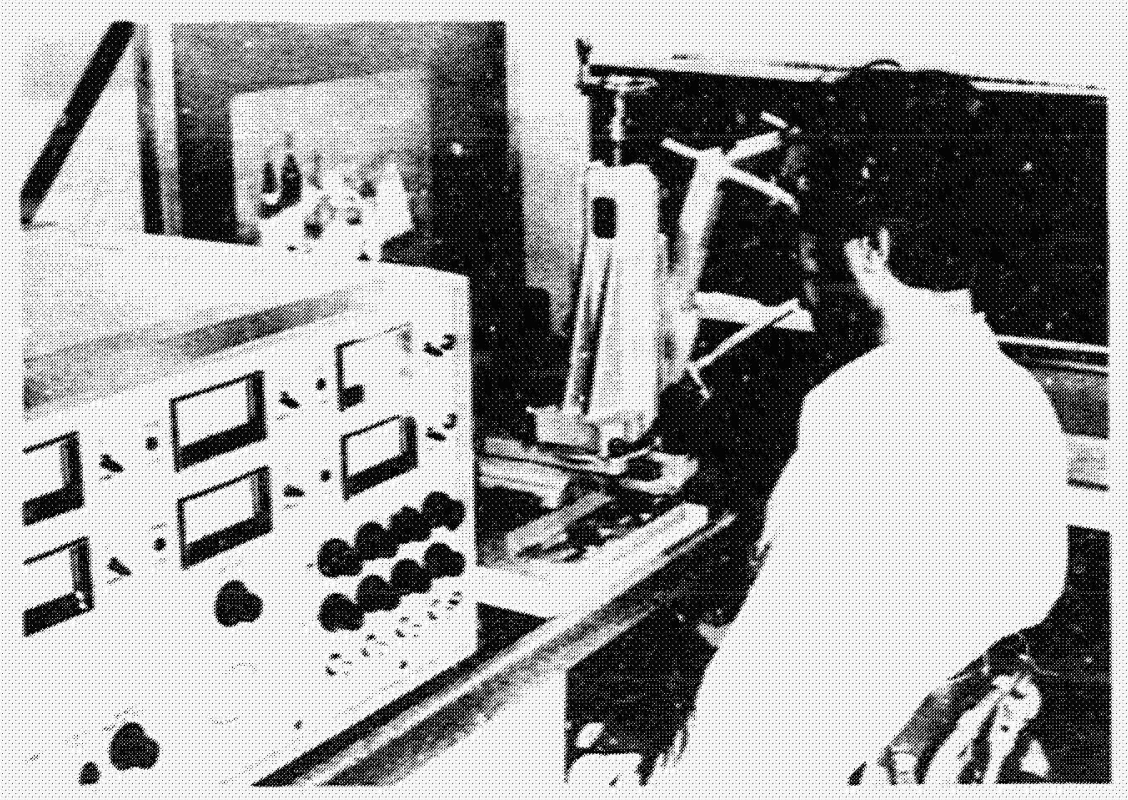

Whare 4.1 ther of sublect in the head positioner with ere-tracker electronics

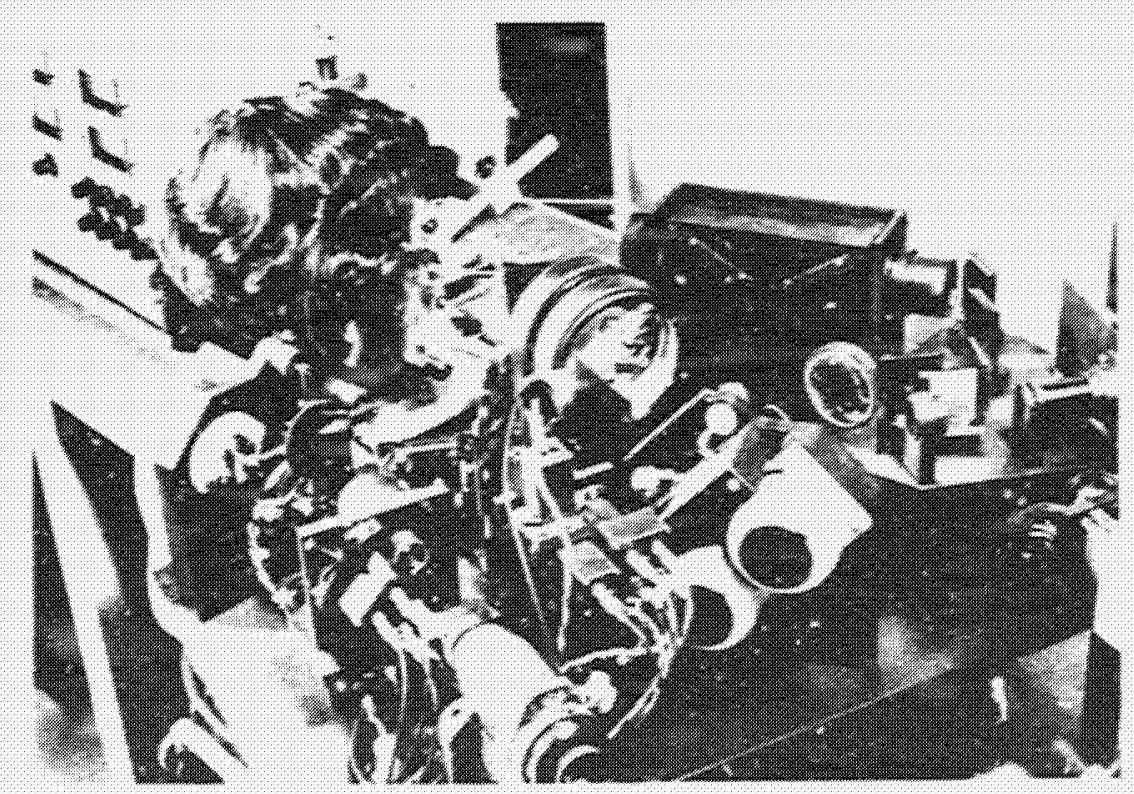

Herare 4.2 Vhet of eye-tracker oplics and sub tect 
Purkinje image and measures its movement relative to the first image.

The two-dimensional motion of this image derived from the position of this mirror system is used as the output signal of the subject's eye movements. The system is designed to measure eye movements with an accuracy of up to two minutes of arc. The overall system has a flat f requency response of up to $100 \mathrm{~Hz}$.

To assure the proper use of the eye tracker requires elaborate procedures for alignment of subjects and calibration of the eye tracker. The calibration is done through a computer program (MAP) we developed. This calibration prugram serves tc:

(1) provice a way of relating the output voltages of the instrument to the stimulus positions;

(2) give an estimate of the size of the visur? field over which the instrument is able to trac: the eye movements; and

(3) indicate whether the eye tracker is correctly adjusted.

It has been a major problem to relate the measured eye positions to the actual locations on the scene. This difficulty arises mainly from the distortion introduced in measuring eye movements. To alleviate this difficulty, ie have developed and implemented a scheme which maps automatically the eye fixations onto the scene without distortion. This is achieved by expressing both the fixations and the line drawing of the inspected scene in terms of visual degrees relative to a calibration slide. Since both are on the same coordinate system, they can be easily superimposed without any fear of distortion.

Our scheme consists of the following computer programs: MAP, FIXFIL, OVLAY, and PFIX. IIAP produces a calibration file relating 
eye tracker voltage with the visual angle subtended by the eye. FIXFIL analyzes the data collected by the DIGIT program. It reduces the data into fixations and, ith the aid of the calibration file produced by S:AP, it translates the location of these fixations into units of visur: angle. The origin of this visual coordinate system is assumed to be the center point of the calibration slide. OVLAY is a variaticn of the DRAW program which uses the graf/pen to digitize pictures. OVLAY is used to digitize an outline of the inspected scene on a slide. Some additional data are adied to the file to enable it to be eventually translated into units of visual angle with the exact coordinate system used by FIXFIL. PFIX plots the fixations and superimpose the outline of the scene. This can easily be done since the fixation locations and the outline are expressed in the same visual angle coordinate system.

To illustrate the effectiveness of this scheme, we show an example in Figures $A_{.3}$ and A.4. The observer was asked to fixate at those circled points of a scene as shown in Figure A.3. The eye-movement data taker. were then processed by the mapping scheme. The result was plotted as shown in Figure A.4. It is seen that the measured eye fixations correspond very closely to those circled points in figure A.2 in the right sequence.

It should be emphasized that the process described is fully automatic and will compensate for different subjects and any of the permissible variations in the experimental set up such as size of stimulus, distance between the screen and the observer, etc. With this system, ne are capable of processing inassive amounts of eye-moverent data with re ative ease. 


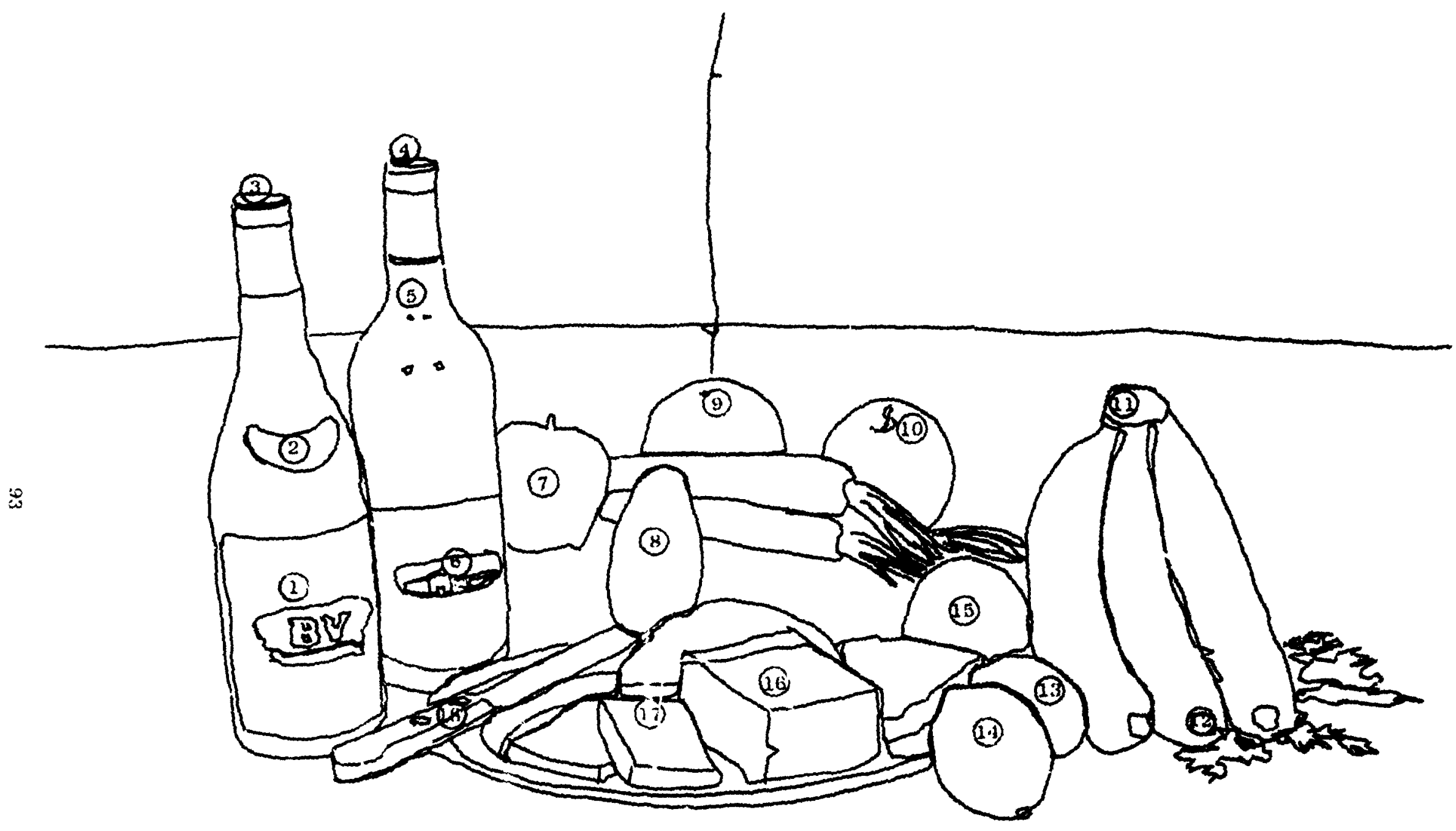

Figure A.3 Requested fixation points 


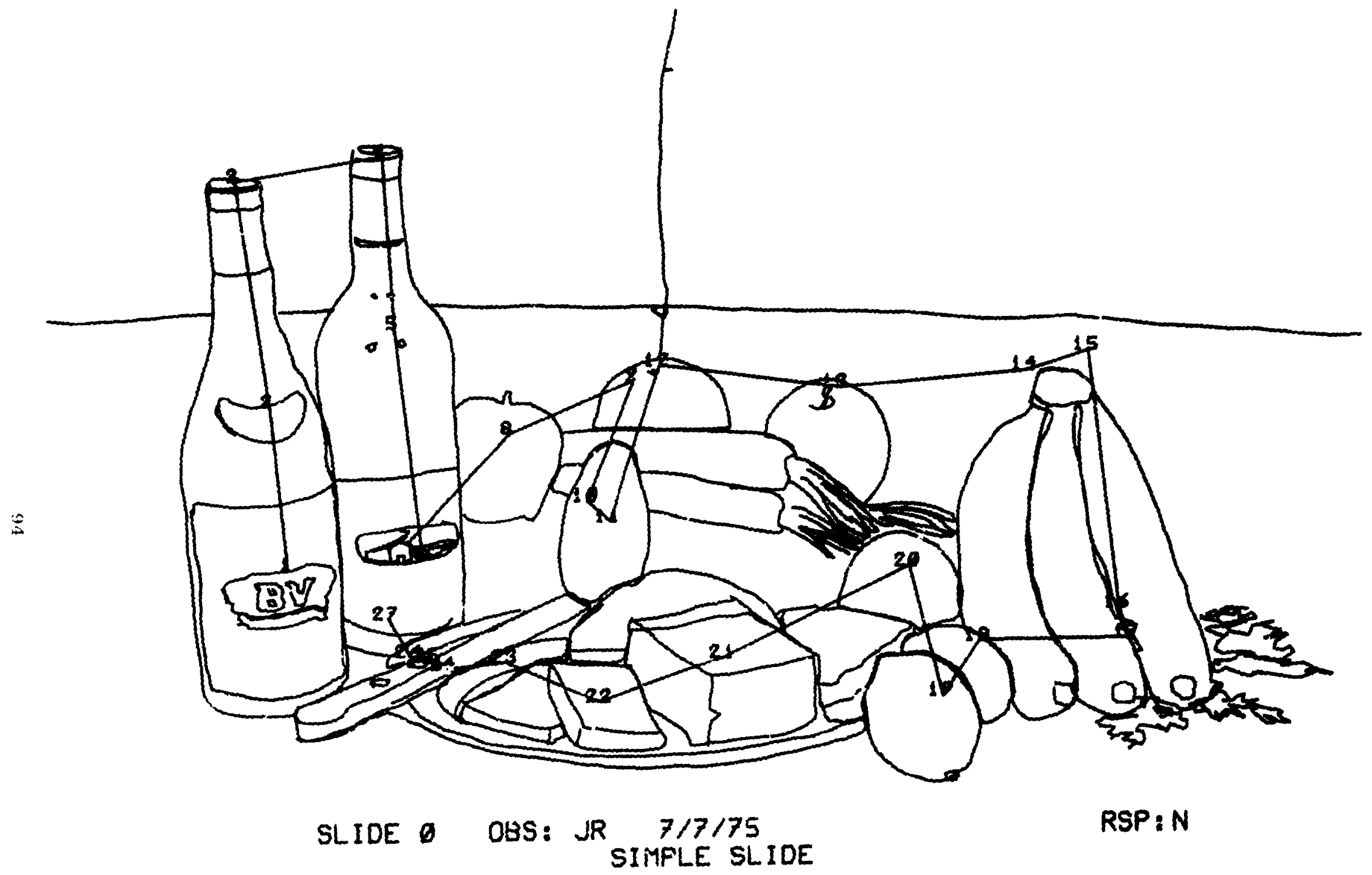

Figure A.4 Responses to requested fixation points 
APPF.YDIX B

5... 
APPENDIX B

\section{(1) LIST OF PERSONS WHO HAVE CONTRIBUTED TO THIS PROJEC:}

Since the $i$ ception of his project in 1972, the following persons have paricipated in this research project. Their present addresses are indicated.

Dr. J. E. Anliker, Research Scientist, MSA/Anes Research Center, Moifett Field, California

Mr. T. E. At cwood, Scientific Programer, Cux, Sunnyvale, California

Ns. K. Dilley, project Secretary, Stanford University, Stanford, Colifornia

Dr. M. Ein-Gal, fuesearch Associate, Information Systens Laboratory, Stanford tiniversity, Stanford, California

Mr. R. Floyd, Graduate Student Research Assistant, Neuroscience Progran, Stanford iniversity, Stanford, California

Xr. A. Huanz, Scientific Prograner, Stanford University, Stanford, California

Mr. K. H. Jacker, Computer S:ience Consultant, Environmental Protection Agency, Chapel .Iill, North Caroisna

Dr. H. S. Lagnuski, Engin zering Yanager, Gamma Technology, Palo Alto, California

* Wr. J. R. Nickolls, Graduate Student Research Assistant, Electrical Engineering Department, Stanford University, Stanford, Califorria

- Nr. A. Shah, Graduate Student Research Assistant, electrical Engineering Department, Stanford University, Stanford, California

Mr. M. Stauffer, Engineer, Time-Data, Inc., Palo Alto, California

X:- L. D. Stricklan, Scientific Programer, Stanford University, Stanford, California

Mr. A. Yang, Student Technician, Stanford University, Stanford, Califcinia

- Dh.D. dissertations on topics relevant to the project are near rompletion. 
APPENDIX $b$

(2) LIST OF RELEVATT PAPEKS PËbLISHED DIIIITG THE PPOJECT

[1] "Application of Frequency Uiscrimination Technique to the Aral sis of Elect roencephalographic Siznals", D. C. lai amil H. L. Lux, Proc. National Electronics Conterence, vol. 27, 1pp. so-85, O-tuber, 1972.

12] "A llode! for the Photically si 1 mulated Elect roncephlograph :-

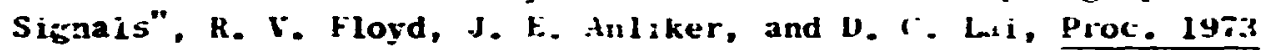
San Diego Biomedical Symposium, rebruary. 1973.

[3] "The Graphics Software DEC forgot to Include", K. H. Jacker, Proc. of the DECLS Spring Syzposiun, Hay 2, 1973.

[4] "Estimating Signal and Joise in Ccherent Time Averages of EFG Data", J. E. Anliker, D. C. Lai, T. Himer, and H. Finker, Pre.. 1973 Anrual Confezence on Enginecrinit in Vedicine and Hology, October, 1973.

[5] "Geal-i ime EEG Analysis and Lonitoring lsing In-phase and Quadrature

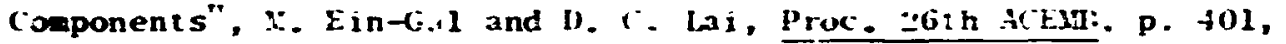
Octcber, 1973.

[6] "Error-free EEG Signal Representation", y. Ein-lial and V. C. Lad, Proc. IEEE International (onterence on Systens, Nir., and Cyberneti:s, pp. 242-.13, Norember, 1973.

[7] "Phase Contingent Expansion of the Visual Evoked Pesponse (IEk)", R. F. Floyd anci J. E. Anliker, Proc. 1974 San Diefo fiomedical Symposium, february, 1974 .

[8] "Computer Determination of fyc ilxations and Saccades", A. Shah and D. C. Lai, Froc. 27th ACFid, p. 103, Uctober, 1974.

[9] "A Sonlinear Model of EtG Entrainment by perrodic Photic Stimulation", J. R. Nickolls, D. C. Lal, and J. H. Anliker, Proc. ith Annual Meeting of the leuroelectric jociety, pp. 13-14, lovember, 1974.

[10] "Remark on Algor: thm 179[7]", 11. 5. Varnusk1, Communica: ions of the ACM, vol. 18 , no. 2, p. 119 , tebruary, 1975 .

[11] "Prediction of EFG Alpha Naveform by Ising an dutoregressive siodel", A. Shah, D. C. Lai, and .J. F. Anllker. Proc. 1975 Siar Diego Biomed:cal Symposium, February, 1975.

[12] "Computer Control of the toveal and Peripheral visual field", H. S. Hagnuski and D. C. Lal, Proc. $28 \mathrm{th}$ AlKal, September, 1975.

[13] "Modeling the EFG Fintranment Process", J. R. Nickolls, D. C. Lai, and J. E. Anliker, Proc. 28th ACHuB, September, 1975. 
[14] "Monitoring and Prediction of Saccadic Eys Novement". A. Shah and D. C. Lai, Proc. 1975 IEEE International Conference on Systens, Man, and Cybernetics, September, 1975.

[15] "A System for Monitoring and Prediction of Eye Movements During Perception of a Tro-dimensional Stationary Scene", Ph.D. Thesis to be submitted, A. Shah.

[16] "A Sonlinear Model for Human EEG During Photic Stinulation". Ph.D. Thesis to be subaitted, J. R. Nickolls. 
APFEXDIX B

(3) LECTURES AND TALKS

The following list gives chronologically the lectures and talks

relevant to the rork peifored under this research project.

1. D. C. Lai, "easurezent of the Entrainment of Fsc Alpia Rhythw in the Huak: Brain by Frequency Discrimination Tecinique", at the 1972 IEEE International Syzposiun on Information Theory, February, 1972 .

2. D. C. Lai, "The Elfect of Photic Stinulation in Human EEG Signals". SEL-TSL Affiliates Yeeting, Scanford iniversity. February. 1973.

3. D. C. Lai, "The Phase-uncertainty yodel for the Photically Stimulated EEG Signals". EE Seminar, Stanford Eniversity, April, i973.

4. H. S. Magnuski, "Sumary of kecent Vork on the kelationship Between Eye Hovenent and "isual Imagery". EE Graduate Semina:, Stanford Iniversity, Hay, 1974.

5. Arun Shah, "An Autoregressive Scheme for Prediction of the EEG Alpha Rhythm". SEL-ISL Affiliates Heeting, Stanford Iniversity, February, 1975 .

6. J. R. Nicliolls, "A Sonlinear lodel of Fuman EEG Entrainmert b: Periodic Photic Stimulation", SEL-ISL Industrial Afiliates Veeting, Stanfors lniversity, February, 1975.

7. H. S. Yagnuski, "Scanpaths and Theory of Vision", EE Graduate Seminar, Stanford Iniversity, May, 1975.

8. J. R. Nickolls, "Nonlinear Models of the EEG Signal During Visual Stimulation", Ph.D. Seminar, Stanford Cniversity, July, 1975.

9. Arur. Shah, "Analysis and Modeling of Eye Novemenis During Perception of Scenes". Ph.D. Seminar, Stanford Iniversity, August, 1975 